Florida International University FIU Digital Commons

4-23-2012

\title{
Effects of Architectural Features of Air-Permeable Roof Cladding Materials on Wind-Induced Uplift Loading
}

Ruilong Li

Florida International University, rli001@fiu.edu

DOI: $10.25148 /$ etd.FI12071110

Follow this and additional works at: https://digitalcommons.fiu.edu/etd

\section{Recommended Citation}

Li, Ruilong, "Effects of Architectural Features of Air-Permeable Roof Cladding Materials on Wind-Induced Uplift Loading" (2012). FIU Electronic Theses and Dissertations. 659.

https://digitalcommons.fiu.edu/etd/659 


\section{FLORIDA INTERNATIONAL UNIVERSITY}

Miami, Florida

\section{EFFECTS OF ARCHITECTURAL FEATURES OF AIR-PERMEABLE ROOF CLADDING MATERIALS ON WIND-INDUCED UPLIFT LOADING}

A dissertation submitted in partial fulfillment of

the requirements for the degree of

DOCTOR OF PHILOSOPHY

in

CIVIL ENGINEERING

by

Ruilong Li

2012 
To: Dean Amir Mirmiran

College of Engineering and Computing

This dissertation, written by Ruilong Li, and entitled Effects of Architectural Features of Air-Permeable Roof Cladding Materials on Wind-Induced Uplift Loading, having been approved in respect to style and intellectual content, is referred to you for judgment.

We have read this dissertation and recommend that it be approved.

Amir Mirmiran

Irtishad Ahmad

Girma Bitsuamlak

Ping Zhu

Arindam Gan Chowdhury, Major Professor

Date of Defense: April 23, 2012

The dissertation of Ruilong Li is approved.

Dean Amir Mirmiran

College of Engineering and Computing

Dean Lakshmi N. Reddi

University Graduate School

Florida International University, 2012 
(C) Copyright 2012 by Ruilong Li

All rights reserved. 


\section{DEDICATION}

This dissertation is dedicated to my parents and wife for their love and support, and the families and individuals who suffered loss during hurricane. 


\section{ACKNOWLEDGMENTS}

I would like to thank my adviser, Dr. Arindam Chowdhury, for his continuous support, guidance and encouragement throughout my entire $\mathrm{PhD}$ research period. I would also extent my appreciation to my committee members: Dr. Amir Mirmiran, Dr. Irtishad Ahmad, Dr. Girma Bitsuamlak and Dr. Ping Zhu for their committee responsibilities.

I sincerely appreciate Dr. Emil Simiu and Dr. Jason Lin for their helpful suggestions and recommendations in this research and throughout the completion of this dissertation. I also would like to thank the entire Wall of Wind team, especially Jimmy Erwin, Roy Liu, Walter Conklin, Jomo Bain, Thomas Baheru, Jimmy Fu, Sheikh Saad Ahmed for their help, advice and support.

I especially wish to thank my parents and my wife for their continuous understanding and love. Without their great support, I would never have been able to complete this dissertation.

Finally, I would send my special thanks to Florida Sea Grant, National Science Foundation, and Center of Excellence in Hurricane Damage Mitigation and Product Development (through FIU's International Hurricane Research Center) for their financial support of this research. 
ABSTRACT OF THE DISSERTATION

EFFECTS OF ARCHITECTURAL FEATURES OF AIR-PERMEABLE ROOF

CLADDING MATERIALS ON WIND-INDUCED UPLIFT LOADING

\author{
by \\ Ruilong Li \\ Florida International University, 2012 \\ Miami, Florida

\section{Professor Arindam Gan Chowdhury, Major Professor}

Widespread damage to roofing materials (such as tiles and shingles) for low-rise buildings, even for weaker hurricanes, has raised concerns regarding design load provisions and construction practices. Currently the building codes used for designing low-rise building roofs are mainly based on testing results from building models which generally do not simulate the architectural features of roofing materials that may significantly influence the wind-induced pressures. Full-scale experimentation was conducted under high winds to investigate the effects of architectural details of high profile roof tiles and asphalt shingles on net pressures that are often responsible for damage to these roofing materials. Effects on the vulnerability of roofing materials were also studied. Different roof models with bare, tiled, and shingled roof decks were tested. Pressures acting on both top and bottom surfaces of the roofing materials were measured to understand their effects on the net uplift loading. The area-averaged peak pressure coefficients obtained from bare, tiled, and shingled roof decks were compared. In addition, a set of wind tunnel tests on a tiled roof deck model were conducted to verify the effects of tiles' cavity internal pressure. Both the full-scale and the wind tunnel test 
results showed that underside pressure of a roof tile could either aggravate or alleviate wind uplift on the tile based on its orientation on the roof with respect to the wind angle of attack. For shingles, the underside pressure could aggravate wind uplift if the shingle is located near the center of the roof deck. Bare deck modeling to estimate design wind uplift on shingled decks may be acceptable for most locations but not for field locations; it could underestimate the uplift on shingles by $30-60 \%$. In addition, some initial quantification of the effects of roofing materials on wind uplift was performed by studying the wind uplift load ratio for tiled versus bare deck and shingled versus bare deck. Vulnerability curves, with and without considering the effects of tiles' cavity internal pressure, showed significant differences. Aerodynamic load provisions for lowrise buildings' roofs and their vulnerability can thus be more accurately evaluated by considering the effects of the roofing materials. 


\section{TABLE OF CONTENTS}

CHAPTER

PAGE

1 Introduction 1

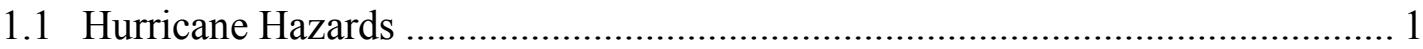

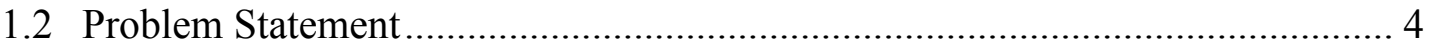

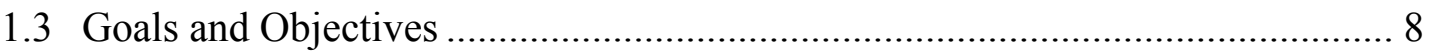

2 Literature Review 10

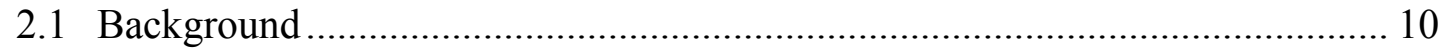

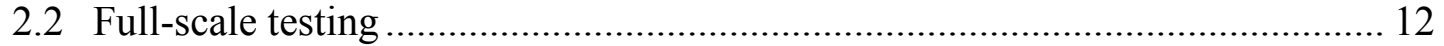

2.2.1 Aylesbury Experimental Building 13

2.2.2 Silsoe Structure Building 15

2.2.3 Texas Tech University Wind Engineering Research Field Laboratory 17

2.2.4 Jan Smuts Experiment 18

$\begin{array}{lll}2.2 .5 & \text { C-130 Aircraft } & 19\end{array}$

2.2.6 "Three Little Pig” Testing Facility 20

2.2.7 Wall of Wind at Florida International University 22

2.3 Effects of Roofing Materials on Roof Wind Loading ...................................... 22

2.3.1 Roof Tiles 23

2.3.2 Pavers and Asphalt Shingles Roofing 25

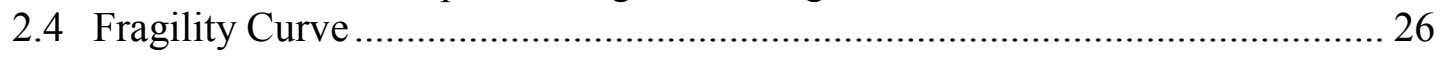

3 Experiment Testing Apparatus and Setup $\quad 29$

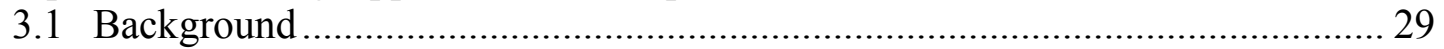

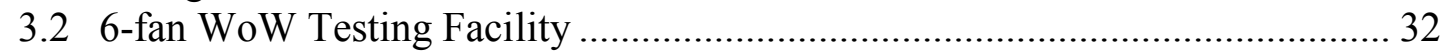

3.3 6-Fan WoW Pressure Field Validation ................................................................ 35

3.4 WoW instrumentations and data acquisition system ......................................... 37

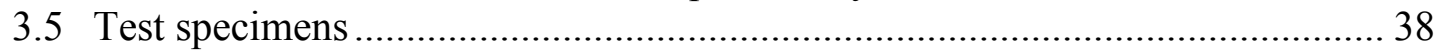

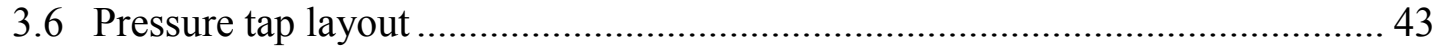

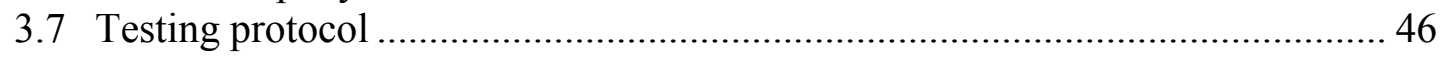

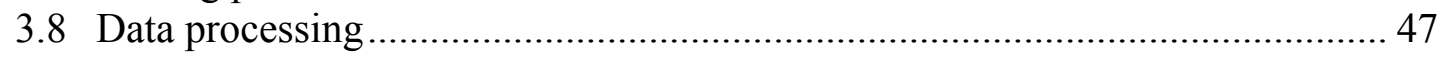

4 An Experimental Study on Wind Effects on Tiled Roof 50

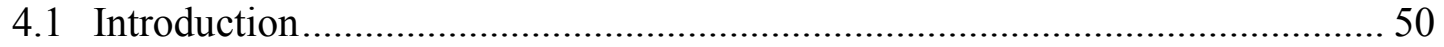

4.2 Effects of Tile Cavity Internal Pressure on Tiled Roof Net Peak Pressure ....... 51

4.3 Effects of Tile Geometry on Tiled Roof Peak Pressures .................................... 56

4.4 Cavity Internal Pressure versus Building Internal Pressure............................... 58

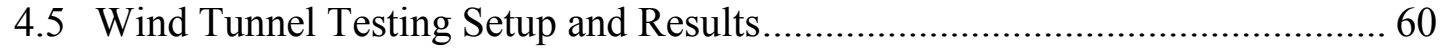

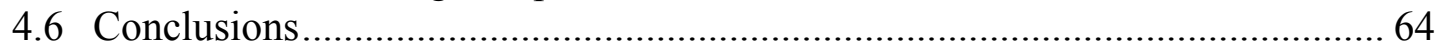

5 An Experimental Study on Wind Effects on Shingled Roofs 67

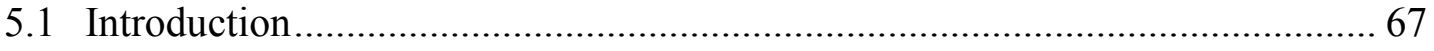

5.2 Effects of Shingle Bottom Surface Pressure ...................................................... 67 
5.3 Effects of Geometry of Roofing Materials on Roof Peak Pressures ................ 69

5.4 Bottom Surface Pressure versus Building Internal Pressure............................. 72

5.5 Effects of Overhang Dimensions on Roof Peak Pressures .............................. 74

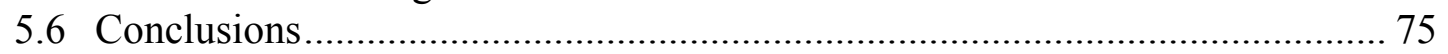

6 Effects of Modeling Roofing Materials for Estimation of Wind uplift 77

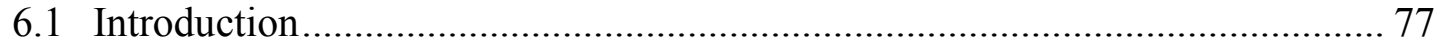

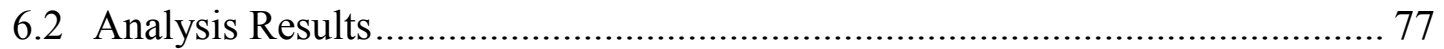

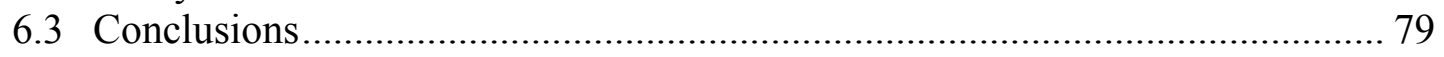

7 Effects of Tile Cavity Internal Pressure on Vulnerability of Roof Tiles 81

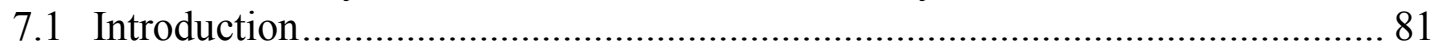

7.2 Fundamental Concepts of Vulnerability Curve and Fragility Curve ................ 82

7.3 Wind Load on Roof Tiles .......................................................................... 83

$\begin{array}{lll}\text { 7.3.1 Tile External Pressure } & 84\end{array}$

7.3.2 Tile Cavity Internal Pressure $\quad 87$

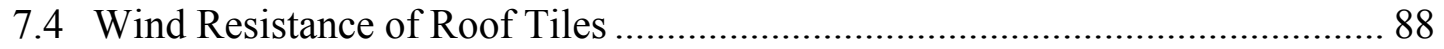

7.4.1 Tile Uplift Testing $\quad 89$

7.4.1.1 The Location of Tile Loading Point........................................... 89

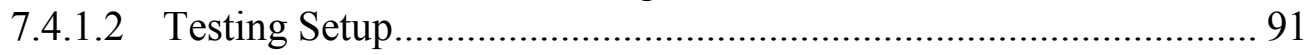

7.4.1.3 Testing Results and Discussion............................................... 93

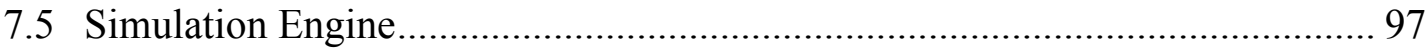

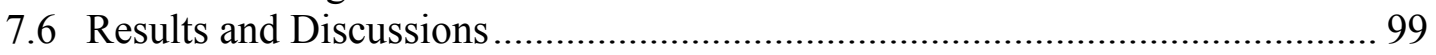

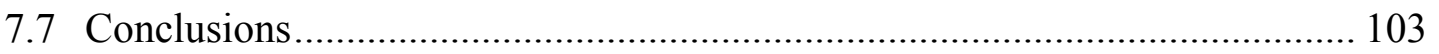

8 Conclusions and Future Work 104

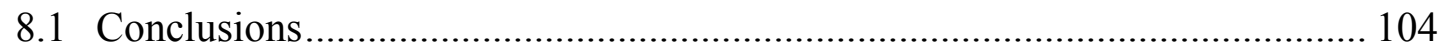

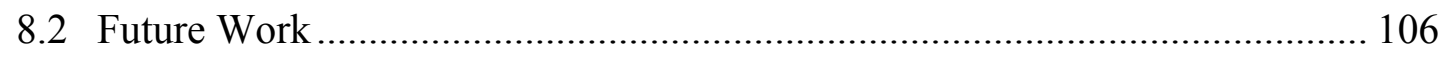

$\begin{array}{ll}\text { REFERENCES } & 108\end{array}$

$\begin{array}{ll}\text { VITA } & 115\end{array}$ 


\section{LIST OF TABLES}

TABLE

PAGE

Table 3.1: Wind Characteristics Comparison between Preliminary Wow at $4000 \mathrm{rpm}$ and FCMP (Huang et al., 2009)................................................................... 33

Table 3.2: Comparison of Wind Characteristics of Modified 6-Fan Wow (Huang et al., 2009) 34

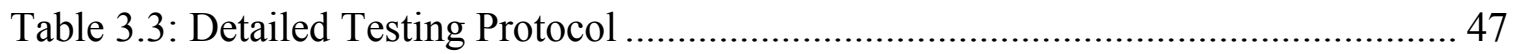

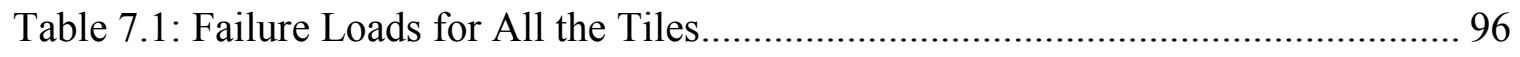

Table 7.2: Wind Resistance comparison of Tile Uplift Testing to Notice of Acceptance 97 


\section{LIST OF FIGURES}

FIGURE

PAGE

Figure 1.1: Breakdown of Damage Costs (EERI report, 2003) ..................................... 2

Figure 1.2: 2011 Atlantic Hurricane Season Track Map (Source: National Hurricane Center) 3

Figure 1.3: Hurricane-induced Damage to Building Envelopes....................................... 4

Figure 1.4: Graph Comparing Pressure Coefficients (Min. Cp) between Average Model Scale (Continuous Line) and Full Scale (Dotted Values) for Tap 10013; XAxis: Angle of Attack, Y-Axis: Min. Cp (Long et al., 2006)........................ 6

Figure 1.5: Roof Tap 6 Mean and Peak Minimum Pressures. The Peak Minimum Pressures are Shown Normalized by Either (a) The Mean Dynamic Pressure at Cube Height for Each Run or (a) The Maximum Dynamic Pressure at Cube Height that Occurred During the Run..................................................... 6

Figure 1.6: 6-fan Wall of Wind Testing Facility ......................................................... 9

Figure 2.1: Wind Flow Streamline Patterns around a Simple Low-Rise Building (Woo et al. 1977, Hunt et al. 1978). 12

Figure 2.2: Aylesbury Experimental Building and Pressure Transducer Locations......... 14

Figure 2.3: Silsoe Structure Buildings 17

Figure 2.4: TTU Wind Engineering Research Field Laboratory Building 18

Figure 2.5: Jan Smuts Airport View and Geometry of Hangar: a. Jan Smuts Airport Hanger Front View; a. Geometry and Instrumented Area View Of Hanger (Milford et al., 1992a)...... 19

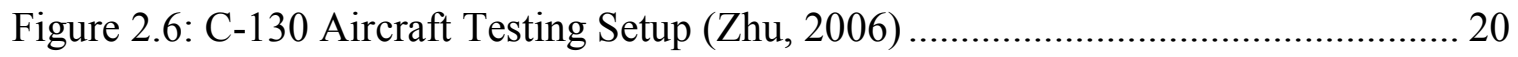

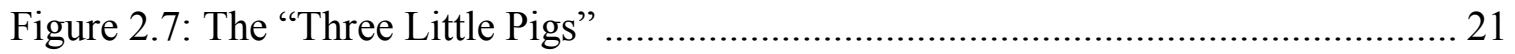

Figure 2.8: 6-fan Wall of Wind with a Testing Specimen ......................................... 22

Figure 2.9: Local Wind Flow over Shingles Showing Uplift Mechanism (Peterka et al. 1997) 26

Figure 2.10: Structural Damage Simulation Engine Flowchart .................................. 28

Figure 3.1: Full- or Large- Scale Testing Facility - Wall of Wind ............................. 30 
Figure 3.2: Preliminary and Modified 6-fan WoW

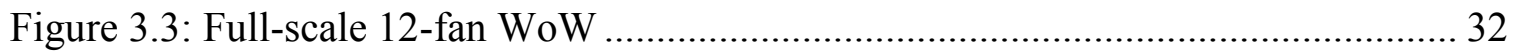

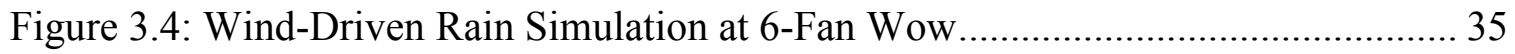

Figure 3.5: Selected Locations to Facilitate the Area-Averaged Pressure Comparison ... 36

Figure 3.6: Comparison of Area-Averaged Pressure Coefficients from Wind Tunnel and Wow for $45^{\circ}$ : (a) Gable Roof with 1:12 Slope; (b) Gable Roof with 5:12 Slope 36

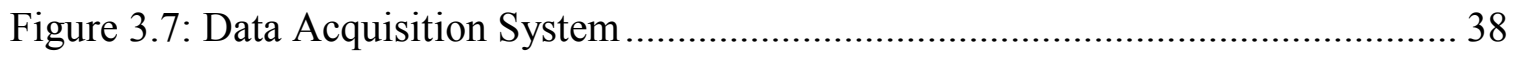

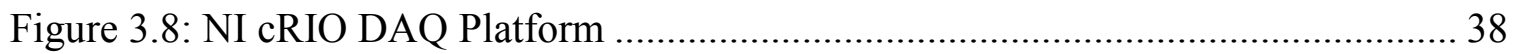

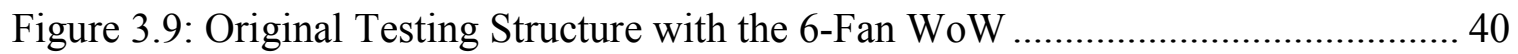

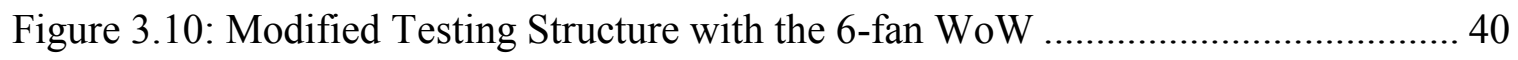

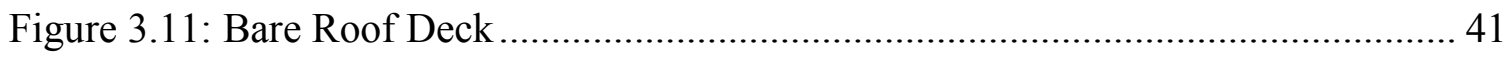

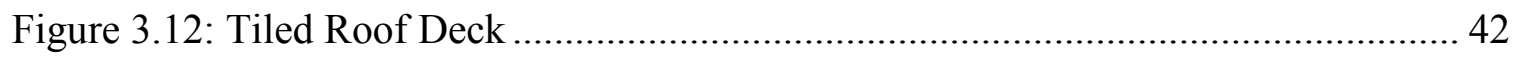

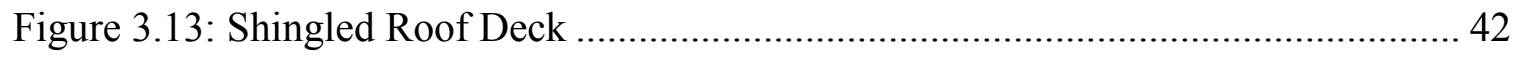

Figure 3.14: 4:12 Monoslope Roof Pressure Tap Layout ............................................. 43

Figure 3.15: 5:12 Gable Roof Pressure Tap Layout .................................................. 44

Figure 3.16: 3:12 and 5:12 Hip Roofs Pressure Tap Layout ..................................... 44

Figure 3.17: Internal Pressure Tap Located at the Birdstep....................................... 45

Figure 3.18: An Example of the External and Internal Tap Locations for Shingled Roof Deck 45

Figure 4.1: Comparison of Estimated Area-Averaged External and Net Peak Pressure Coefficients for 4:12 Monoslope Roof: (a) $\mathrm{AOA}=30^{\circ}$, (b) $\mathrm{AOA}=135^{\circ}$........ 52

Figure 4.2: Comparison of Estimated Area-Averaged External and Net Peak Pressure Coefficients for 4:12 Monoslope Roof: (a) $\mathrm{AOA}=15^{\circ}$, (b) $\mathrm{AOA}=180^{\circ} \ldots \ldots . .53$

Figure 4.3: Top View of Wind Tunnel Testing Model for 3:12 Hip Tiled Roof Deck .... 62

Figure 4.4: Mean Wind Speed and Turbulence Intensity Profiles for RWDI Wind Tunnel 
Figure 4.5: Comparison of Estimated External and Net Peak Pressure Coefficients for 3:12 Hip Tiled Roof Model (Wind Tunnel Testing) for: (a) $\mathrm{AOA}=0^{\circ}$, (b) $\mathrm{AOA}=10^{\circ}$

Figure 5.1: Comparison of Estimated Area-Averaged Net Peak Pressure Coefficients for Shingled roof decks: (a) 3:12 Hip Roof, $\mathrm{AOA}=75^{\circ}$, (b) 3:12 Hip Roof, $\mathrm{AOA}=90^{\circ}$, (c) 4:12 Monoslope Roof, $\mathrm{AOA}=0^{\circ}$, (d) 4:12 Monoslope Roof, $\mathrm{AOA}=15^{\circ}$ 69

Figure 5.2: Comparison of Estimated Area-Averaged Net Peak Pressure Coefficients for 4:12 Monoslope Roof: (a) $\mathrm{AOA}=0^{\circ}$, (b) $\mathrm{AOA}=15^{\circ}$, (c) $\mathrm{AOA}=30^{\circ}$, (d) $\mathrm{AOA}=45^{\circ}$ 71

Figure 5.3: Comparison of Estimated Area-Averaged Net Peak Pressure Coefficients for 3:12 Hip Roof: (a) $\mathrm{AOA}=45^{\circ}$, (b) $\mathrm{AOA}=60^{\circ}$, (c) $\mathrm{AOA}=75^{\circ}$, (d) $\mathrm{AOA}=90^{\circ} 72$

Figure 5.4: Comparison of Building Internal Pressure and Tiles' Cavity Internal Pressure Coefficients for 4:12 Monoslope Roof Model for $\mathrm{AOA}=0^{\circ}$ : (a) Enclosed Building Condition, (b) Partially Enclosed Building Condition 73

Figure 5.5: External and Net Area-Averaged Peak Pressure Coefficients Comparison for Two Different Overhang Dimensions from 3:12 Hip Roof with Shingle: (a) 30 degree, (b) 45 degree, (c) 75 degree, (d) 90 degree. 75

Figure 6.1: Ratio of Area-Averaged Net Peak Pressure Coefficients Obtained from Tiled Versus Bare Roof Decks for Locations 1 And 2: (a) 4:12 Monoslope Roof, (b) 3:12 Hip Roof. 78

Figure 6.2: Ratio of Area-Averaged Net Peak Pressure Coefficients Obtained from Tiled Versus Bare Roof Decks: (a) 3:12 Hip Roof for Locations 3 and 7, (b) 5:12 Gable Roof for Locations 6 and 7. 78

Figure 6.3: Ratio of Area-Averaged Net Peak Pressure Coefficients Obtained from Shingled Versus Bare Roof Decks for 4:12 Monoslope Roof Location 5 and 3:12 Hip Roof for Location 6 79

Figure 7.1: Vulnerability Curve Generation (FPHLM, Volume II, 2005)...................... 83

Figure 7.2: Fragility Curve for the Damage State of 60\% Overall Structural Damage.... 83

Figure 7.3: Mean Wind Speed Profile Comparison 85

Figure 7.4: Longitudinal Turbulence Intensity Profile Comparison 85

Figure 7.5: Normalized Longitudinal Spectral Density at $\mathrm{H}=0.15 \mathrm{~m}$. 85 
Figure 7.6: Wind Tunnel Testing Model for Each Type of Roof: (A) Monoslope Roof with 4:12 Slope, (B) Gable Roof with 5:12 Slope, (C) Hip Roof with 3:12 Slope, (D) Hip Roof with 5:12 Slope 86

Figure 7.7: Pressure Tap Layouts with Tile Location Superposition Sketch for Each Type of Roof: (a) Monoslope roof, (b) Gable roof, (c) Hip Roof ..... 87

Figure 7.8: Converting Loading Point off the Centerline of Tile into The Centerline ..... 89

Figure 7.9: Spanish ' $\mathrm{S}$ ' Tile Loading Point in Y-Direction Distance from the Head Of Tile for Each Type of Roof: (a) 4:12 Monoslope Roof; (b) 5:12 Gable Roof; (c) 3:12 Hip Roof; (d) 5:12 Hip Roof..... 90

Figure 7.10: Barrel Tile Loading Point in Y-Direction Distance from the Head of Tile For Different Type of Roof: (a) 5:12 Gable Roof; (b) 3:12 Hip Roof; (c) 5:12 Hip Roof. 91

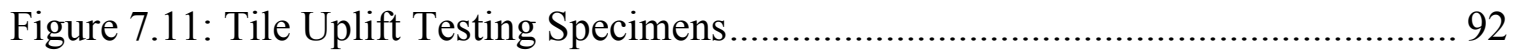

Figure 7.12: Tile Uplift Testing Device............................................................... 93

Figure 7.13: Bonding Failure at the Interface between Tile and Foam (Spanish 'S' tile) 94

Figure 7.14: Failure within the Foam Paddy (Spanish 'S' tile) ..................................... 94

Figure 7.15: Underlayment Detachment from the Deck (Spanish 'S' tile) ..................... 95

Figure 7.16: Bonding Failure at the Interface between Tile and Foam (Barrel tile) ........ 95

Figure 7.17: Structural Damage Simulation Engine Flowchart................................... 99

Figure 7.18: Comparison of Vulnerability Curve of Roof Tile with and without Considering the Effects of Tiles' Cavity Internal Pressure for Monoslope Roof with 4:12 Slope 100

Figure 7.19: Comparison of Vulnerability Curve of Roof Tile with and without Considering the Effects of Tiles' Cavity Internal Pressure for Gable Roof with 5:12 Slope 101

Figure 7.20: Comparison of Vulnerability Curve of Roof Tile with and without Considering the Effects of Tiles' Cavity Internal Pressure for Hip Roofs: (a) 3:12 Slope, (b) 5:12 Slopes. 102

Figure 7.21: Roof Cover Vulnerability of South / Key CGB Homes (FPHLM, Volume II, 2005) 103 


\section{Introduction}

\subsection{Hurricane Hazards}

Wind hazards, especially those caused by hurricane or typhoon, are increasingly imposing a large amount of property losses and human suffering. Residential buildings are particularly vulnerable to damages caused by wind and wind-driven rain action. In addition, damages can also occur from the subsequent storm surge, flooding, and wave effects. Hurricane-induced economic losses have increased steadily in the U.S. during the past 50 years, with estimated annual total losses averaging $\$ 1.3$ billion from 1949-1989, $\$ 10.1$ billion from $1990-1995$, and $\$ 35.8$ billion per year during the last 5 years. In particular, during the 2005 season, estimated total economic losses from Hurricane Katrina are in excess of $\$ 125$ billion and insured losses are $\$ 40.6$ billion (FEMA549, 2005). In addition, the intolerable and unnecessary loss of life was associated with hurricanes - 196 individuals perished from 1986-1995 and approximately 1,450 were lost in the past 2 years alone (NSF, 2007). Figure 1.1 shows the breakdown of costs due to damage by tornadoes and hurricanes compared with costs inflicted by floods and earthquakes (AAWE, 2004). It has been noted that the amount of loss due to hurricane is a large percentage of the total loss due to natural disasters. With such large amount of losses and social impacts, hurricane loss mitigation is still a big challenge that needs immediate attention. 


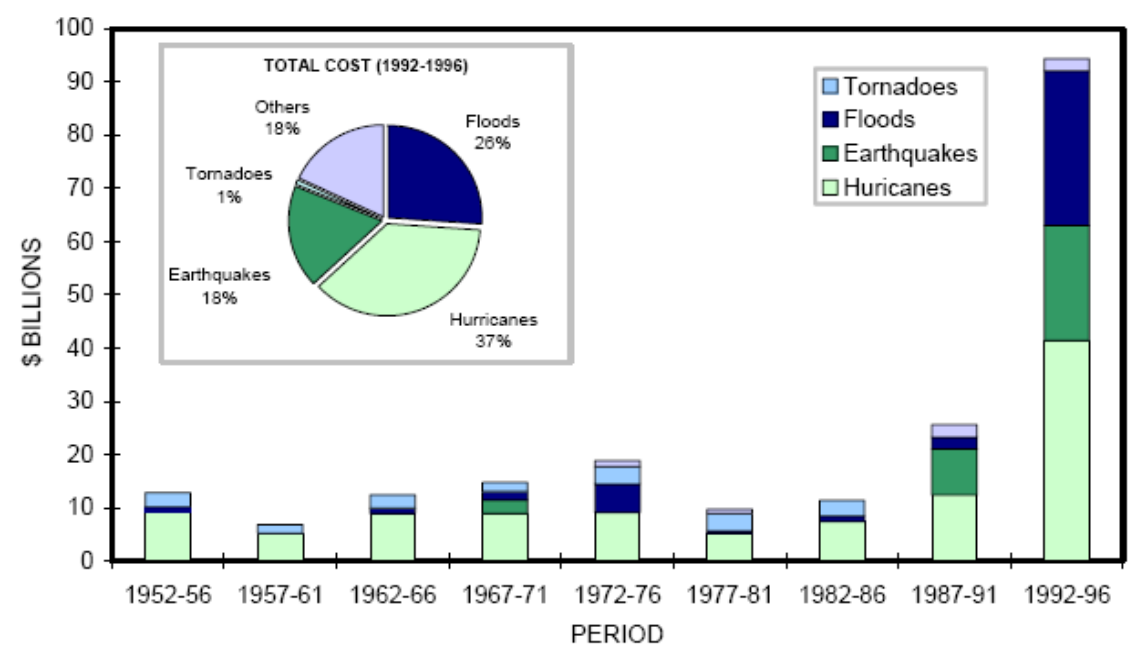

Figure 1.1: Breakdown of Damage Costs (EERI report, 2003)

US East Coast and Gulf Coast region are two of the most hurricane-prone areas in the world. Figure 1.2 provides 2011 Atlantic Hurricane Season tracks map which shows five hurricanes that that made landfall in this region. However, according to the United States Census Bureau, coastal county population has increased rapidly since 1930, especially from the east coast of Florida through the Gulf Coast. For example, the population of Harris County, Texas, has grown by nearly three times since 1960 (Pielke et.al, 2008). Due to the exceedingly large population growth in this region, the potential hurricane-induced loss and social impacts are also highly increased. 


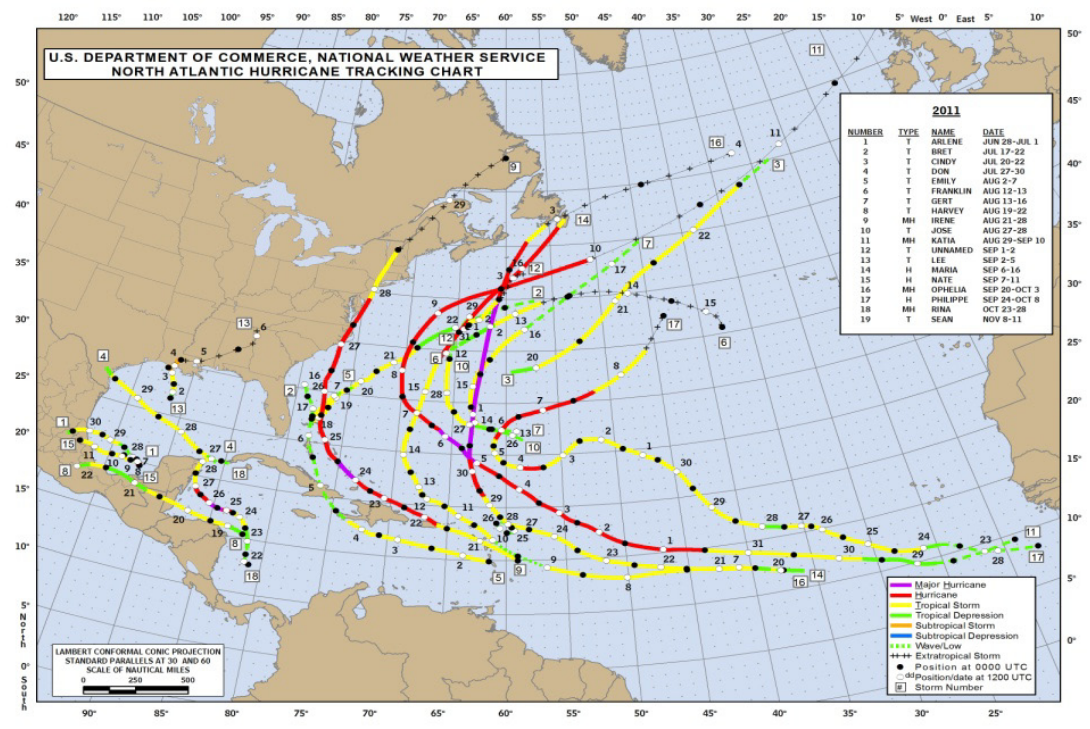

Figure 1.2: 2011 Atlantic Hurricane Season Track Map (Source: National Hurricane Center)

Recent reports in reconnaissance of hurricane damage to physical structures indicate that hurricane-induced losses include a large number of damaged and destroyed residential buildings (FEMA, 2005; NIST, 2006). In most cases, the building envelope systems, including roof coverings, wall coverings, soffits, non-load bearing walls, exterior doors, windows, shutters, and skylights, are damaged by hurricane winds which allow wind-driven rain to enter building interiors and cause damages to building content due to water and subsequent mold growth. In order to identify failure mechanism of the building envelope, it is very important to conduct full-scale experiments that can advance our understanding of wind effects on building components. Experiments could also help in closely investigating the impacts of wind and wind-driven rain on the components of building envelopes. Significant coordinated efforts need to be undertaken to reduce property losses and human suffering caused by hurricanes. 


\subsection{Problem Statement}

Low-rise buildings and structures are located within the lower part of atmospheric boundary layer $(\mathrm{ABL})$ where there is increased wind turbulence that can cause damages to structures. From the post-investigation of wind-induced damages, it is revealed that the roof and roofing system of low-rise buildings are the most vulnerable to high winds. Figure 1.3 shows different hurricane-induced damages to building envelopes. Exterior damage often leads to water intrusion and subsequent mold growth responsible for interior and content damages.
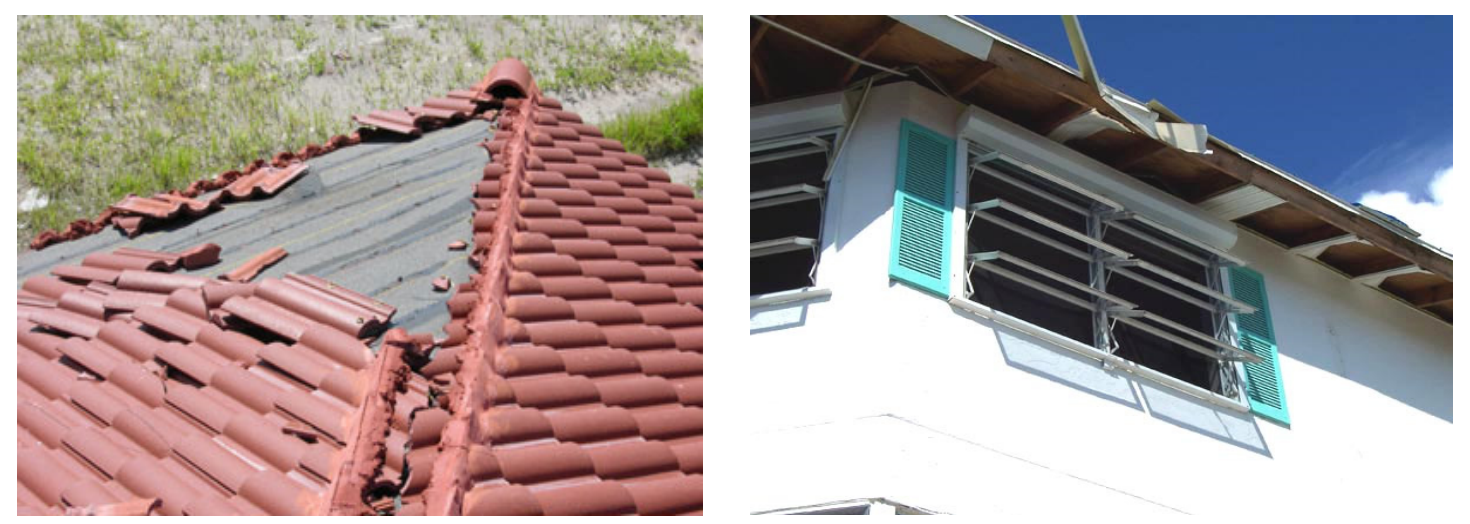

Figure 1.3: Hurricane-induced Damage to Building Envelopes.

However, with the progress of wind engineering, boundary layer wind tunnel testing technique has provided valuable information on the effects of wind on buildings. In addition, as a result of ongoing public and private efforts, a number of wind hazards mitigation measures have also been developed and put in practice in coastal areas. Enhanced building codes have resulted in design of buildings that are structurally resilient to severe windstorms. However, the poor performance of building envelope systems (roofs, wall claddings, etc.) still poses a significant concern during hurricanes. 
Design guidance and additional code enhancements are needed (NIST, 2006) to improve the performance of building envelopes.

Provisions on aerodynamic pressures are derived primarily from wind tunnel measurement on small-scale models. For low-rise buildings wind tunnel test results can significantly deviate from full-scale data because of: (1) the differences in the relative pressure-tap hole size between model and full-scale, (2) model Reynolds number effects, (3) differences in angular standard deviation of wind direction, (4) stability effects in the atmosphere, and (5) viscous dissipation in the smallest eddies of the modeled flow (Peterka et al., 1998). Recently, some comparisons between wind tunnel results and fullscale measurements in natural wind show that the pressure predicted by wind tunnel tests can be lower by as much as half of their full-scale counterparts (Long et al., 2006; Richards et al., 2007). A graph from the paper by Long et al. (2006) is given as Figure 1.4 which shows the pressure coefficient differences between wind tunnel and full-scale data. Figure 1.5 from Richards et al. (2007) shows that there is a reasonable agreement between the full-scale and wind-tunnel mean pressure coefficients, but the full-scale peak pressure coefficients are markedly larger than those obtained from the wind-tunnel. However, a better agreement is obtained if the peak pressures are normalized by using a peak dynamic pressure. It is also evident that area averaging is effective in reducing fullscale peak pressure coefficients in the highest-pressure areas under the roof vortex (Peterka et al., 1998). 


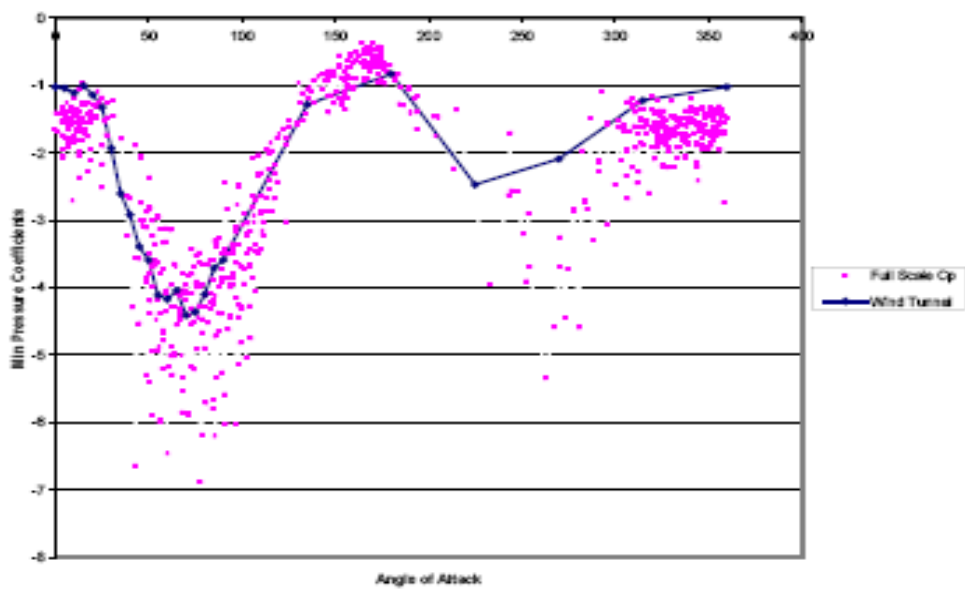

Figure 1.4: Graph Comparing Pressure Coefficients (Min. Cp) between Average Model Scale (Continuous Line) and Full Scale (Dotted Values) for Tap 10013; X-Axis: Angle of Attack, Y-Axis: Min. Cp (Long et al., 2006)

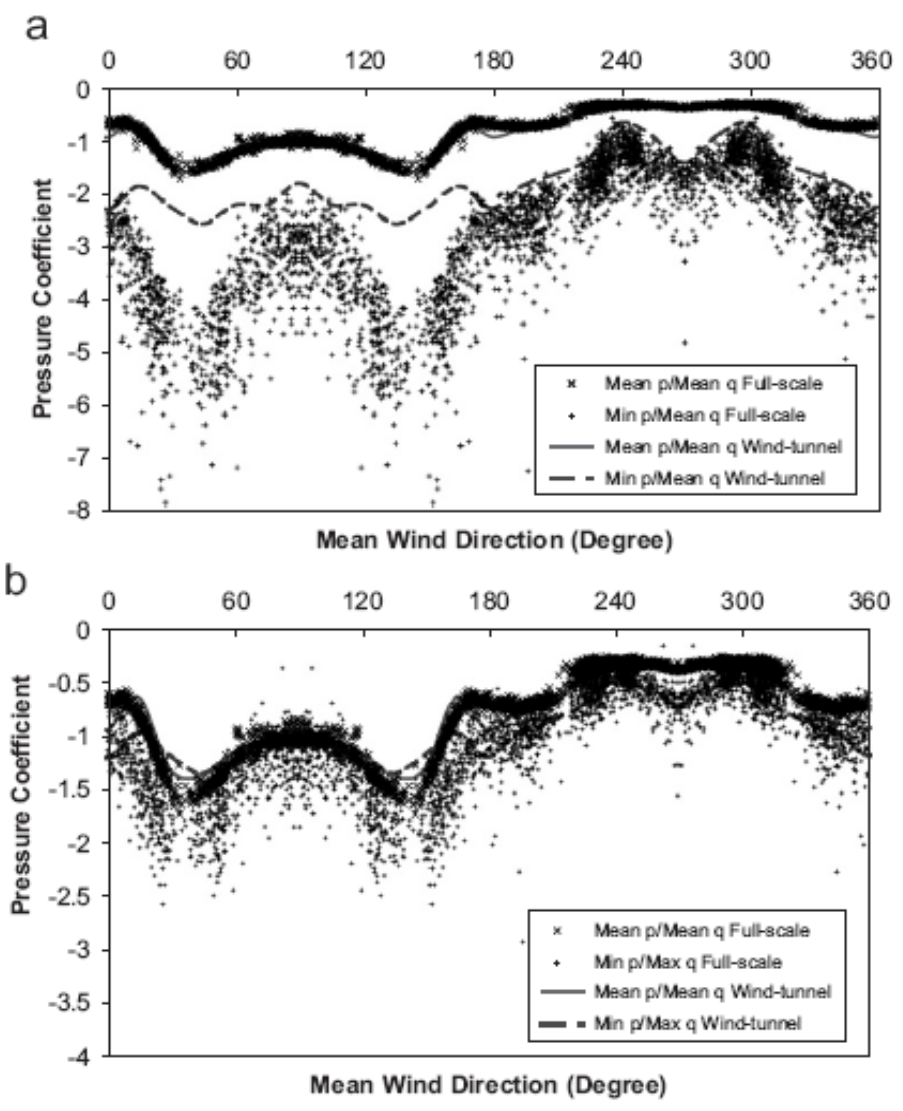

Figure 1.5: Roof Tap 6 Mean and Peak Minimum Pressures. The Peak Minimum Pressures are Shown Normalized by Either (a) The Mean Dynamic Pressure at Cube Height for Each Run or (a) The Maximum Dynamic Pressure at Cube Height that Occurred During the Run. 
The current code provisions for low buildings, based on small-scale wind tunnel test results, could significantly underestimate pressures on building envelopes, especially near roof corners, eaves and ridges. Such underestimation is consistent with damage initiation typically observed at critical areas - roof tiles and shingles failing at ridges and edges; envelope failures at soffits; and wall cladding failures at corners.

Even though there are some full-scale tests, such as Aylesbury experiment building, Silsoe structures building, and Texas Tech University (TTU) building, and others, it is to be noted that many of the previous experiments were performed on a limited number of building shapes and with low resolution of pressure taps (Kopp et al., 2005). High spatial resolution of pressure taps at critical roof regions for different roof pitches and wind directions (Uematsu et al., 1999) will allow the determination of detailed area-averaged loads without the inherent uncertainty in low spatial resolution pressure measurements. Even though good comparison of wind tunnel and full-scale point pressures and area-average pressures is found in a roof vortex region for 5:12 gable roof under non-hurricane winds (Peterka et al., 1998), it is still essential to study the effects of tropical cyclones and hurricane winds.

For different roofing materials, including tiles and shingles, the wind-induced uplift mechanism, caused by the negative pressures associated with separation and conical vortices (Wu et al., 2001), is not the same as the uplift on the roof sheathing without the roofing materials (Peterka et al., 1997; Okada, 2009). In addition, current building codes used to designing low-rise building are mostly based on wind tunnel testing on scaled models which barely considered the effects of architectural shape of roofing materials on aerodynamic loads. Especially, the internal pressure under the 
roofing material, which is ignored, might affect the net negative peak pressure significantly. Therefore, it is necessary to study the effects of roofing material on roof pressure distributions and peak pressure.

Studies have been performed on fragility curves for different roof components and cladding (FPHLM, 2005). However, most of the wind loads for roof components are obtained from code provisions and effect of internal pressure under the roofing material has been neglected. It is necessary to study the effects of architectural features of roofing materials on net pressures that will influence the fragility curve or vulnerability curve.

\subsection{Goals and Objectives}

Damages from recent hurricanes have underscored the need for more research on wind effects on envelopes of low-rise buildings. For a better understanding of the building behavior under strong wind events, the current study focused on full-scale experimental to assess the effects of architectural shape of roofing materials and internal pressure on net loading. Also, effects of internal pressure on fragility curves were studied.

The research used repeatable, controllable and programmable full scale experimentation using 6-fan Wall of Wind (WoW) located at Engineering Campus, Florida International University. Figure 1.6 shows the 6-fan WoW testing configuration.

The objectives of this research are outlined as follows:

1. To determine, through full-scale testing under controlled and repeatable hurricane level wind conditions, aerodynamic effects on three typical residential roof configurations. The measurements will facilitate the development of a consolidated database on aerodynamic pressures. 
2. To determine the effects of architectural shapes of roofing materials on roof instantaneous peak pressures.

3. To determine the effects of internal pressures under roofing materials on roof instantaneous peak pressures. To compare results with large-scale wind tunnel testing.

4. To develop a more realistic fragility curves based on the results of wind tunnel and full-scale testing.

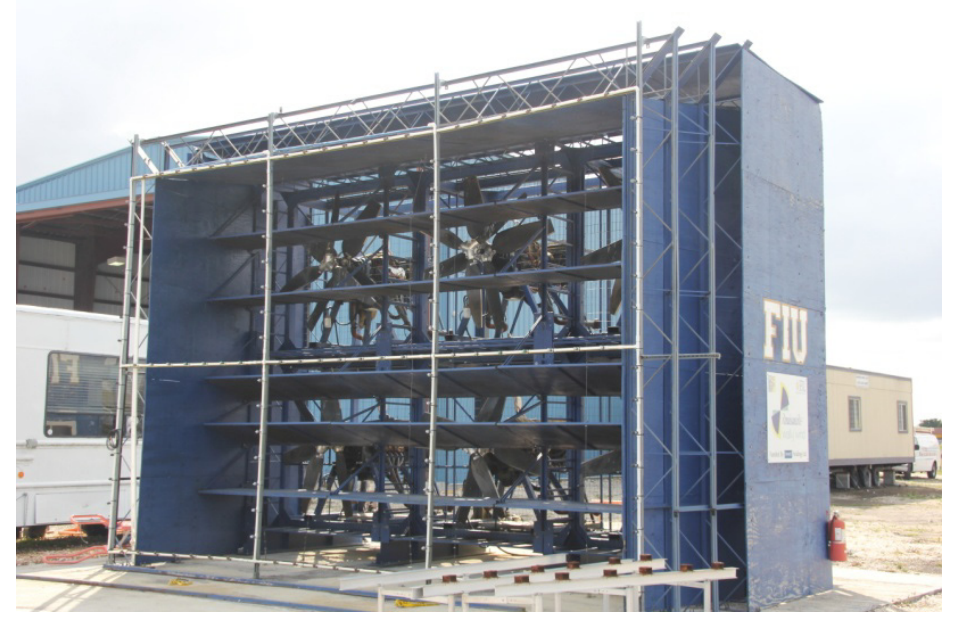

Figure 1.6: 6-fan Wall of Wind Testing Facility 


\section{Literature Review}

\subsection{Background}

In the past few decades, the study of wind effects on low-rise buildings have advanced through the combination wind tunnel testing and limited full-scale measurements in natural wind. However, post hurricane investigations show that low-rise buildings are the still the most vulnerable structures during high wind events such as hurricanes. Damage of building envelopes and subsequent water intrusion continue to raise concerns during hurricanes. The difficulty of assessing wind effects on low-rise buildings will be discussed in this section.

Current building design codes are mostly based on wind tunnel testing on scaled and simplified model which barely consider the effects of architectural shape of roofing materials. Especially, in American Society of Civil Engineering Minimum Design Loads for Buildings and Other Structures (ASCE 7-05) for air-permeable roof cladding comments, it is noticed that since the air-permeable roof or wall claddings allow partial air pressure equalization between the exterior and interior surfaces, the pressures specified in ASCE 7-05 could overestimate the load on air-permeable cladding elements. It is necessary to conduct appropriate full-scale pressure measurements on the applicable cladding elements when the differential pressure acting across the air-permeable cladding element is needed for design purposes (ASCE 7-05). Also, it is shown that there could be significant difference in peak pressures between full-scale measurements and scaled model test results for critical locations on the building envelope (long et al., 2006, 
Richardson, et al., 2007). Underestimation of peak pressures may lead to severe damages during hurricane.

Estimation of aerodynamic effects on low buildings can be significantly affected due to various uncertainties. Low-rise buildings are located in the lower part of atmospheric boundary layer where there are significant turbulence effects that could affect the wind loading (Holmes, 2001). Also, wind-structure interaction is highly affected by the geometry of various local components.

Figure 2.1 shows that the wind flow around a simple square building forms very complex wind flow patterns. The complexity increases if the building shape is irregular or if local components (roofing materials, wall claddings, roof top equipment, etc.) are interacting with the flow. Therefore, it is necessary to improve the understanding of the interaction of wind flow and building envelopes through full-scale testing to complement wind tunnel testing. Such knowledge will be critical for the development of mitigation guidelines and improvement of current building codes to make structures more sustainable and resilient and reduce property damage during hurricane.

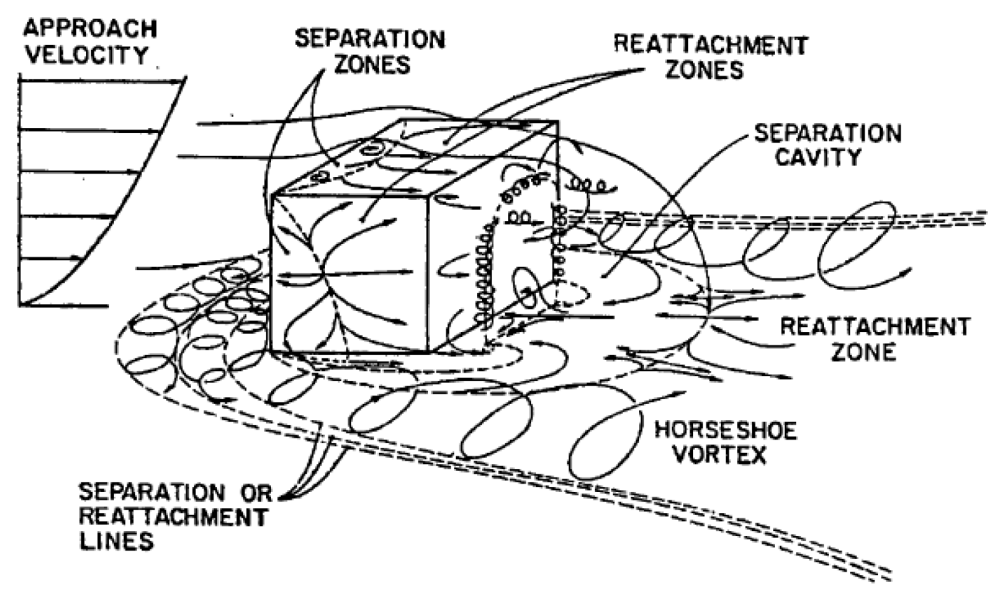

(a) Aerial view of flow streamline patterns 


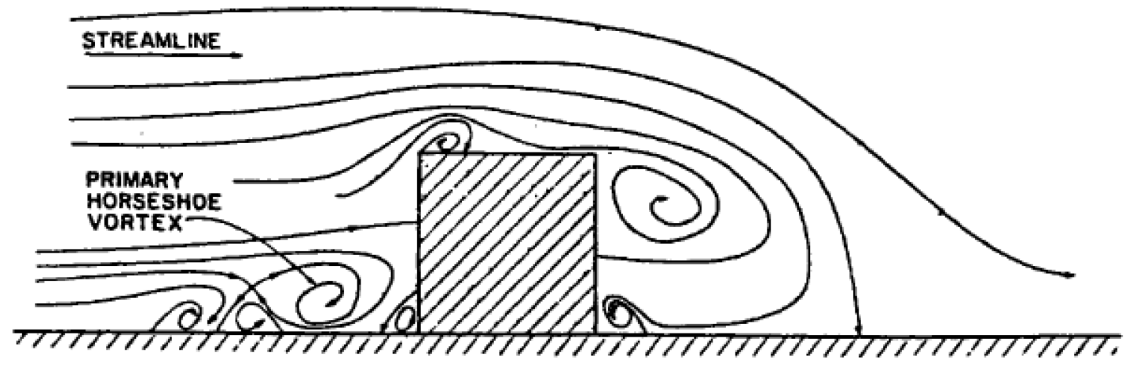

(b) Centerline flow streamline patterns

Figure 2.1: Wind Flow Streamline Patterns around a Simple Low-Rise Building (Woo et al. 1977, Hunt et al. 1978).

\subsection{Full-scale testing}

A variety of experimental methods for research and development are available to determine wind effects and loadings on structures. These include wind-tunnel testing of small-scale models, full-scale field testing in the natural environment, and testing of components and structures under simulated wind forces. To date, the experimental focus in wind engineering has been on the use of wind tunnels, mostly boundary-layer wind tunnels. Wind tunnel facilities have provided a wealth of data on the nature of wind loads for a wide range of structures. Effective studies of wind effects on full-scale buildings have been limited (Levitan and Mehta, 1992). Frequently, instrumentation, power sources, and recording devices fail in severe windstorms, leaving large uncertainties on the response. Nevertheless, field studies based on measurements conducted, e.g., in Gaithersburg (Marshall, 1977), Aylesbury (Eaton and Mayne, 1975), Silsoe (Richardson et al., 1997), and Texas Tech building (e.g., Long et al., 2006), have provided valuable findings and data, and contributed to the validation or otherwise of certain wind tunnel techniques. One conclusion of such studies is that Reynolds number effects cause peak 
pressures on low-rise buildings to be inadequately simulated in the wind tunnel. Some useful wind load data have been collected on roofs of residential homes during hurricanes through the Florida Coastal Monitoring Program (FCMP) (http://users.ce.ufl.edu/ fcmp/overview/house.htm).

Wind engineering research is currently undergoing dramatic changes with new large- and full-scale testing facilities being built worldwide to address windstorm induced economic losses. Some of these facilities are: "Three Little Pigs" (Kopp et al., 2010) and the Wind Engineering, Energy and Environment (WindEEE) Dome (Natarajan and Hangan, 2010) at the University of Western Ontario, wind generator at the University of Florida (Mensaha et al. 2011), the new multi-peril facility of the Institute of Business and Home Safety (IBHS) (Liu et al. 2011), and the Wall of Wind at the Florida International University (FIU). Some of the full-scale testing facilities are described in more details in the following sub-sections.

\subsubsection{Aylesbury Experimental Building}

To improve the pressure data used for designing low-rise building and to validate wind-tunnel testing procedure for low-rise buildings, the Aylesbury experimental building with adjustable gable roof pitches from $5^{\circ}$ to $45^{\circ}$ was constructed in England in the early 1970s (Sill et al., 1992). The building dimension is $7 m \times 13.3 m \times 5 m(B \times L \times h)$. Totally seventy-two differential pressure transducers were installed on four walls and the roof. Figure 2.2 shows the Aylesbury experimental building and its instrumented pressure transducers location. Experimental results from the Aylesbury site indicated that the highly fluctuating nature of the wind pressures could lead to the high-pressure peaks in 
separated flow regions near the roof eaves and ridge, and near the wall corners (Holmes, 2001).
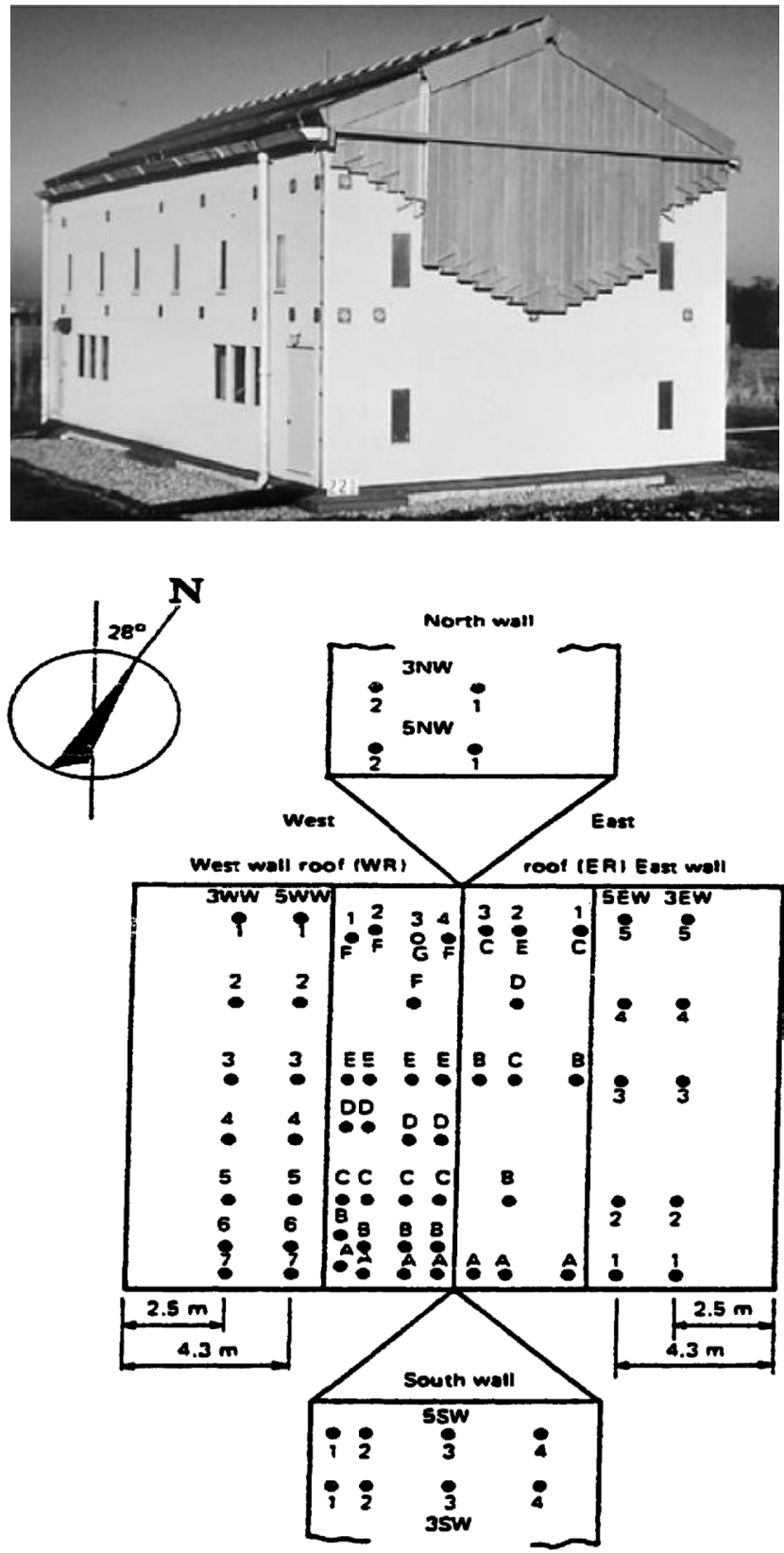

Figure 2.2: Aylesbury Experimental Building and Pressure Transducer Locations (Sill et al, 1989, Holmes, 2001) 
In addition, comparative wind tunnel experiments were undertaken at seventeen laboratories worldwide using the 1:100 identical model of this building. After various testing techniques were used to simulate the upwind flow, two conclusions were made from the comparison between full-scale and wind-tunnel data: 1. the similarity parameter-Jensen number—was not sufficient to ensure the similarity when meeting significant isolated local roughness; 2 . the variation in pressure coefficient for different laboratories was attributed to the difference in the method of data acquisition and the reference static and dynamic pressures (Sill et al, 1989, 1992). Holmes (1982) indicated that the turbulence intensity is an "important parameter to be scaled correctly in the wind tunnel test," while the longitudinal integral scale similarity "does not seem to be a parameter of the greatest importance."

\subsubsection{Silsoe Structure Building}

The Silsoe Structure Building (SSB), with dimensions of $24 \mathrm{~m}$ long by $12.9 \mathrm{~m}$ wide by $5.3 \mathrm{~m}$ ridge height, and roof pitch $\beta=10^{\circ}$, was constructed in the $1980 \mathrm{~s}$ and located on a flat, exposed, open-country site at Silsoe Research Institute (SRI), England. Two different eaves cladding details were tested, including curved and sharp eaves. Two different full-scale pressure measurements setup were made on the SSB. One was with seventy-seven pressure transducers installed on the building and measurements only sampled two pressures at one time. The other was instrumented with thirty-two pressure sensors and simultaneous measurements could be made (Richardson et al. 1997). In addition, twelve strain gauges were also installed along the building's centerline (Richardson and Surry, 1992). Comparing pressure results between the curved and sharp 
eaves, it was concluded that the eave configuration could significantly affect the pressure distribution on the roof. These full-scale measurements can also be used for validating wind tunnel experiments and numerical simulations as a benchmark data.

The wind-tunnel studies of Silsoe Structure Building were performed at Building Research Establishment (BRE) and University of Western Ontario (UWO). The comparison of full-scale and wind-tunnel measurements indicated that good agreement was obtained for mean pressure coefficients. However, the wind tunnel results from BRE underestimated the peak negative pressure while the results from UWO on peak negative pressures were overestimated.

In addition, a $6 \mathrm{~m}$ cube was also built in SRI. Surface pressure measurements were performed at the centerline across the building with additional tapping points on the roof. Simultaneous building surface pressure and wind dynamic pressure were measured. The results were compared to published wind tunnel data. There was a general agreement for the windward wall pressures but the roof and leeward wall pressures were underestimated by the wind tunnel testing and such deviation was attribute to Reynolds number sensitivity and/or relative roughness effects (Richards et al. 2001). Figure 2.3 shows the Silsoe Structure Buildings. 


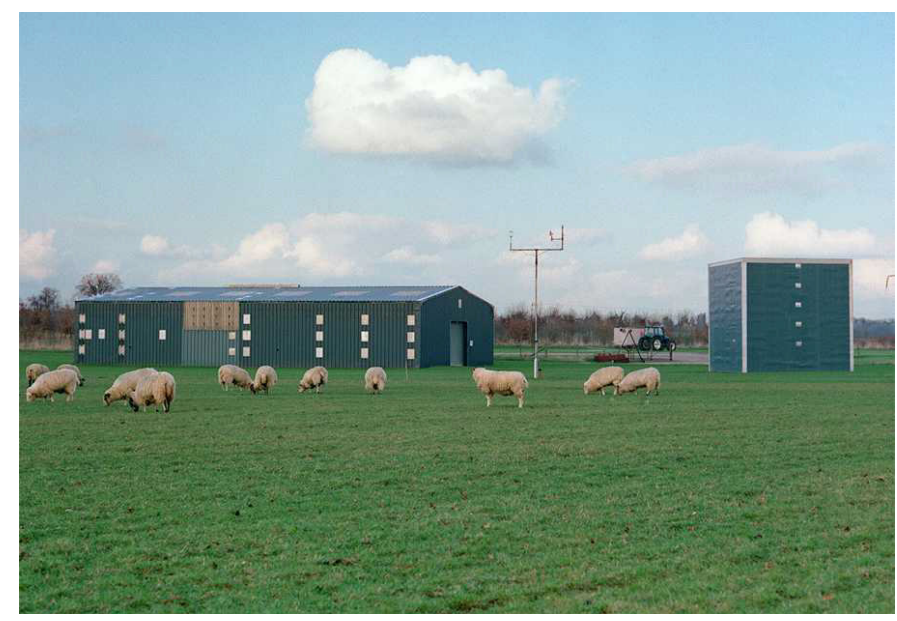

Figure 2.3: Silsoe Structure Buildings

Comparative experiments were also conducted in fifteen different European institutions. It was recommended that the turbulence-independent normalizing parameter should be used to the spectral comparison and the limited low-frequency because of the size of wind tunnel could affect the turbulence intensities leading to lower peak pressures. But a reasonable agreement could be obtained by referring the peak pressure to maximum dynamic pressure observed during the run.

\subsubsection{Texas Tech University Wind Engineering Research Field Laboratory}

In order to obtain reliable data and improve the technique of wind-tunnel simulation, the Texas Tech University (TTU) experimental building, with $9.1 \mathrm{~m}$ wide by $13.7 \mathrm{~m}$ long and $4 \mathrm{~m}$ eave height, was constructed on an open field at TTU. This experimental building could be controlled by a rigid frame undercarriage and the angle of attack could be adjusted according to the natural wind direction. The field facility also includes a $49 \mathrm{~m}$ tall meteorological tower which measures the wind speed at different heights on the building site (Levitan, 1992). Figure 2.4 shows the TTU Wind Engineering Research Field Laboratory Building. 


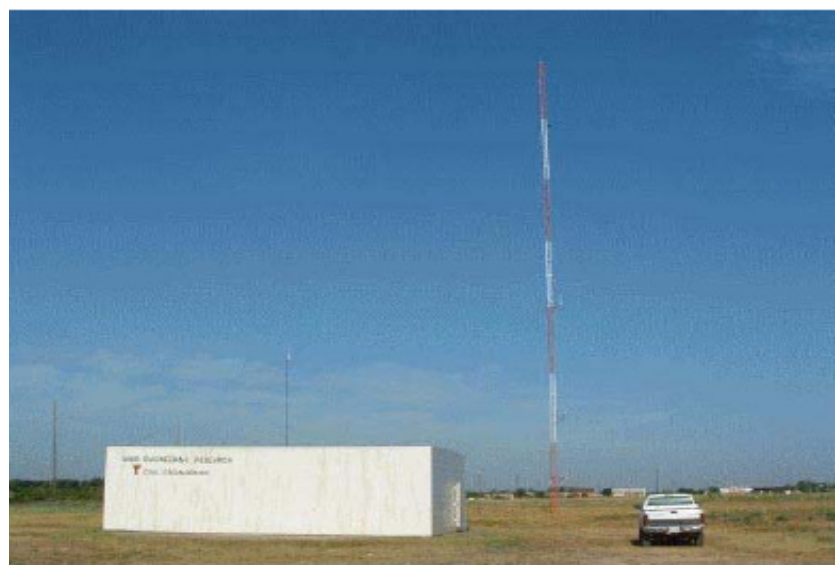

Figure 2.4: TTU Wind Engineering Research Field Laboratory Building

The comparison of wind-tunnel results with full-scale measurements indicated that most of the mean pressure coefficients were in good agreement but the peak and root-mean-square pressure coefficients were different than those obtained from wind tunnel results. However, Cheung (1997) showed that a better matching of peak negative pressure coefficients may be obtained with larger model scales.

\subsubsection{Jan Smuts Experiment}

Milford et al. (1992a) conducted a full-scale experiment on a portion of a large aircraft hangar at Jan Smuts Airport. In total, fifty differential pressure transducers were instrumented at one corner of the hangar. Wind-tunnel tests were also undertaken at the Division of Building Technology, Council for Scientific and Industrial Research (CSIR), for different wind angles of attack. Through the comparison of full-scale and wind-tunnel measurements, it was concluded that the mean and the root-mean-square pressure coefficients matched in general, but the agreement of peak pressure coefficients were less satisfactory. In some cases, a noticeable shift between full-scale and wind-tunnel mean 
pressure coefficients was observed (Milford et al., 1992b). Figure 2.5 shows the view and geometry of the hangar from Jan Smuts Airport.
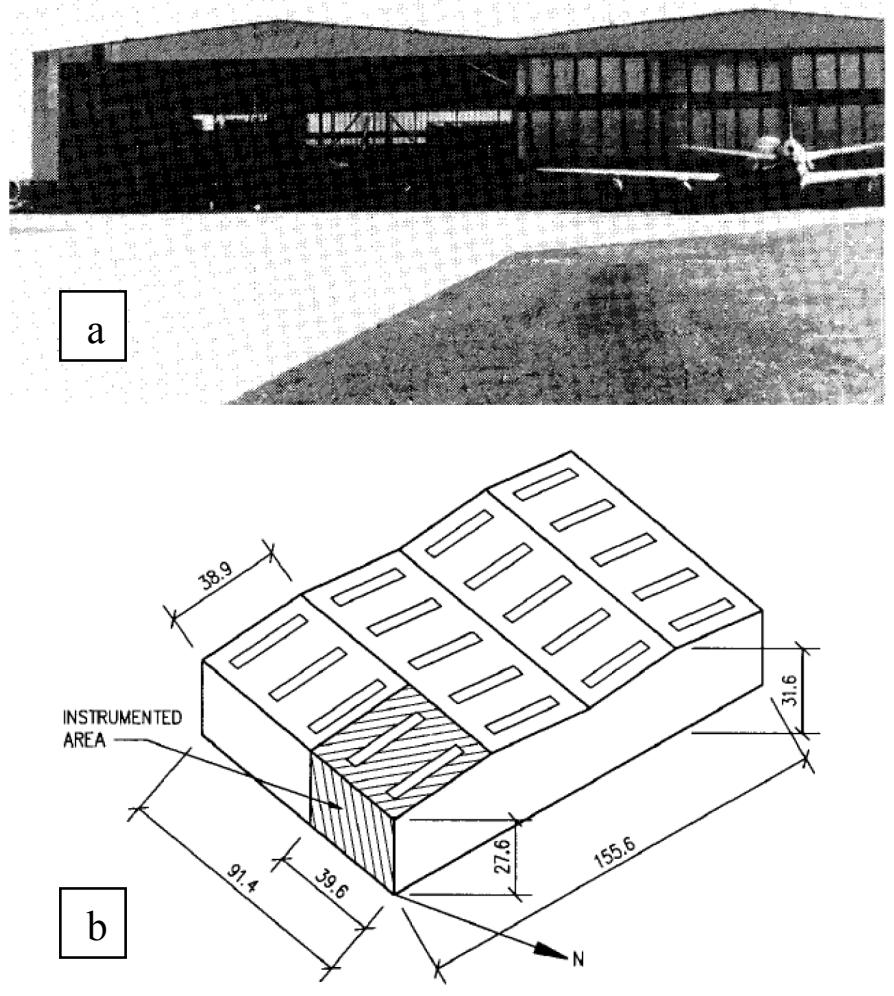

Figure 2.5: Jan Smuts Airport View and Geometry of Hangar: a. Jan Smuts Airport Hanger Front View; a. Geometry and Instrumented Area View Of Hanger (Milford et al., 1992a)

\subsubsection{C-130 Aircraft}

Zhu (2006) conducted controlled full-scale experiments on two low-rise residential buildings under the simulated wind flows generated by the propellers of a C130 aircraft. Figure 2.6 shows the C-130 aircraft testing setup. The wind speed anemometers were installed on the building roofs. Two wind-tunnel tests were conducted at the TTU boundary layer wind-tunnel. Some differences between C-130 simulation wind flows and boundary layer wind-tunnel simulation flows was observed regarding 
turbulence intensity and roughness length. Through the comparison to ASCE7-02, it was concluded that ASCE7-02 provided an upper limit to current results, but a few exceptions were observed on the roof leading edge. The influence of reference pressure measurements in the full-scale tests was considered, and the correction of its influence was performed. It was demonstrated that the influence of buildings could be ignored when wind speed anemometer was located on the side of building models.

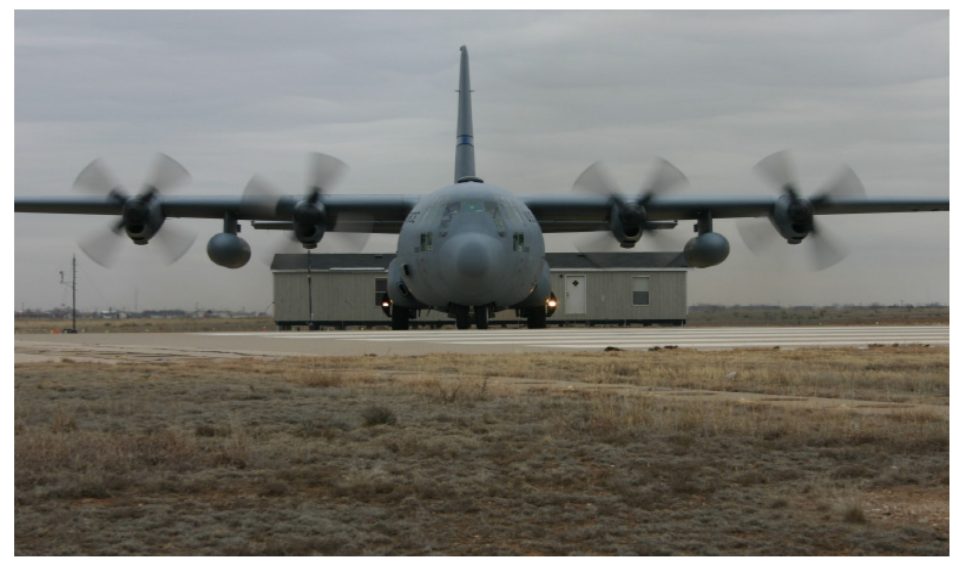

Figure 2.6: C-130 Aircraft Testing Setup (Zhu, 2006)

\subsection{6 "Three Little Pig” Testing Facility}

The Insurance Research Lab for Better Homes, also named "Three Little Pigs", with approximately $50 m \times 22 m$ in plan and $12 m$ high, is a test facility for subjecting a fullscale specimen house to simulated extreme environmental loading due to wind, snow, and rain. The facility will permit the application of realistically simulated time and spatially varying wind loads to full-scale houses, in a controlled manner, up to failure. While under simulated loads, the specimen itself will be instrumented to capture forces in essential components and global and local deformations. Under simulated wind and rain, the specimen will be instrumented to capture the external and internal pressures, rain 
characteristics and moisture penetration data, the growth and airborne propagation of mold. Research results will be implemented by: "1. modifying building codes to advance safer, yet less expensive houses; 2. working with the insurance industry and government to develop implementation strategies; 3 . developing cost-effective mitigation devices for retrofitting the existing housing stock; and 4. developing quality-control strategies to minimize human error in construction" (Surry et al., 2005). Figure 2.7 shows the "Three Little Pigs".

Some testing results are reported by Kopp et al. (2010). The pressure load actuators (PLA) with airbags were used to apply the wind pressure load obtained from wind tunnel testing to the testing structure. The test results indicated good performance of the loading system and also were used to integrate with the computational models accounting for the variability in construction and in materials. However, since the PLA can only simulate the wind pressure field but not the flow field, for some building components, such as roofing materials, there are some limitations.

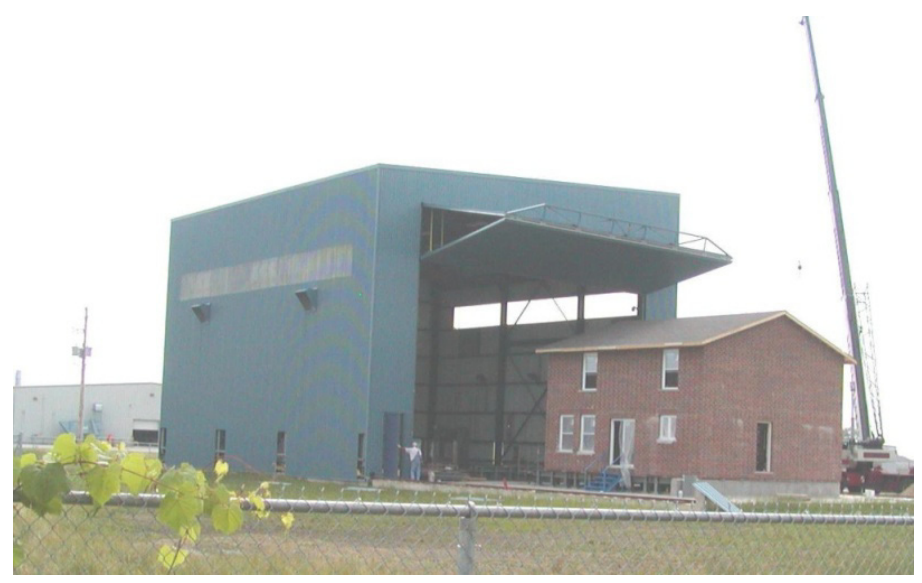

Figure 2.7: The "Three Little Pigs" 


\subsubsection{Wall of Wind at Florida International University}

A new full-scale testing apparatus, namely the Wall of Wind (WoW), was constructed at the Engineering Campus, Florida International University (FIU) in 2007. The WoW facility is a part of the Laboratory for Wind Engineering Research (LWER) under the International Hurricane Research Center (IHRC) at FIU. The WoW has the capability of testing full and large-scale low-rise building models of site-built or manufactured housing and small commercial structures under a controllable, programmable, and repeatable hurricane environment. The 6-fan WoW system as shown in Figure 2.8 can generate wind speeds up to $125.5 \mathrm{mph}$ (Blessing et al., 2009). The WoW can simulate controlled hurricane level winds with the wind-driven rain simultaneously that acts on a test building. This capability provides researchers a better understanding of wind-structure interaction and vulnerability of building envelope components under the action of wind and wind-driven rain. More details on the WoW are presented in Chapter 3.

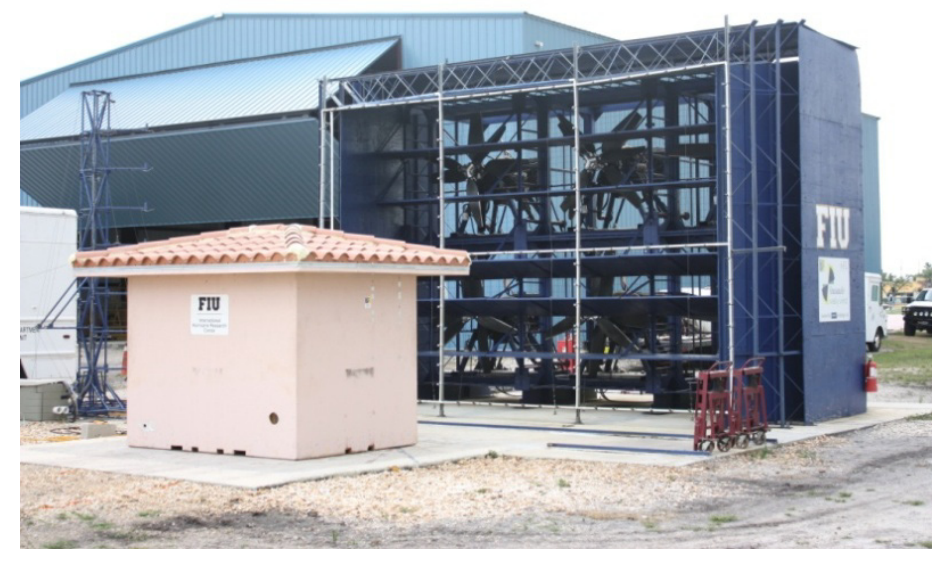

Figure 2.8: 6-fan Wall of Wind with a Testing Specimen

\subsection{Effects of Roofing Materials on Roof Wind Loading}


Based on the building performance observed during the 2004-05 hurricanes, the most vulnerable building envelope component that, in most cases, continues to perform poorly is roofing material. The performance of roofing materials in hurricanes continues to raise concerns - roof tiles (clay and concrete) and roof shingles damage was predominant, especially at several 'hot spots', such as the ridge, corner and edge regions. While some of the weaker hurricanes of recent years (e.g., Wilma in 2005) caused little or no structural damage, they have all significantly affected roof tiles (MDC-BCCO 2006).

Current building codes used for designing low-rise buildings provide aerodynamic coefficients based on wind tunnel testing using simple building models which barely consider the finer geometric details of roofing materials (tiles and shingles). It is hypothesized that roofing materials, such as tiles and shingles, might significantly influence the roof pressure distribution and local flow patterns through their architectural features. Therefore, it is necessary to determine the effects of geometric details of roofing materials on low-rise building roof peak pressures.

\subsubsection{Roof Tiles}

Hazelwood (1981) studied the wind forces on roof tiles laid over a lowpermeability underlay by conducting wind tunnel testing. It was indicated that two principal mechanisms should be taken into account in the analysis -- the force due to the airflow over the roof tile surface and the force due to the internal flow between the tile and underlayment. In addition, it was also suggested that the details of tiles and overall roof shape could affect the forces. The application of these two forces in the British 
Standards BS5534 was also studied by Hazelwood (1980). Kramer and Gerhardt (1983), Amano et al. (1988), and Gerhardt et al. (1990) also studied the characteristics of wind pressure on the loose-laid roof tiles through wind tunnel tests.

Kawair and Nishimura (2003) took field measurements on both external and internal pressures to investigate instantaneous uplift force on hip roof tiles in natural wind. It is found out that the internal pressure in the leeward roof could balance the external peak suction pressures. For windward roofs, two cases, with or without sealing the eave, were studied. It was concluded that the peak uplift pressure from sealed case was smaller than the case without the seal. Robertson et al. (2007) studied the load distribution between tiles and underlays through selected external and internal pressure measurements at tiled gable roof under natural wind. Such load distribution was also dependent on the internal pressure. Huang et al. (2009) performed full-scale tile external pressure measurements on monoslope roof with 4:12 slope at two-fan WoW to assess the roof tile performance and identify the failure mode of roof tile under hurricane conditions. Five different tile configurations were tested. It was demonstrated that the roof tile architectural shape could significantly influence the external pressure distributions. Also, the workmanship was the major factor for roof tile performance. Comparative wind tunnel data on roof tiles were fed into computational fluid dynamic model to evaluate the wind load on entire roof system (Huang et al., 2009). It was found that the staggered setting of concrete tiles could significantly increase the resistance to hurricane. Okada (2009) studied the lift displacement of tile, which is the wind-induced tile dislocation with respect to the original tile position, as a criterion for evaluating the wind performance of tiled roof. However, studies focusing on the effects of roof tiles on roof 
peak pressure through the comparison of results obtained from testing building models using bare and tiled roof decks are still limited.

Tecle (2012) investigated the aerodynamic performance of three types of roof tiles (both ridge and field tiles) focusing on the tiles' underside pressure; and performed computational evaluation of internal pressure for low-rise buildings using $C F D$ simulations and compared the results with experimental data to assess their suitability for such applications. He found that the contribution of internal pressure underneath the roof tile was observed to be significant wherein which it dampens the net suction pressure unless the underneath openings were exposed to different pressure compared to the main external pressure on the tiles. In addition, the surface geometry of an individual tile was observed to have a significant impact on both the external pressure on the roof surface as well as the internal pressure underneath the tiles and the geometry of the roof could also affect tiles' underside pressure.

\subsubsection{Pavers and Asphalt Shingles Roofing}

Bienkiewicz and Sun (1997) studied the effects of space between and beneath pavers on the wind resistance of the air-permeable systems. It was concluded that the space between pavers improves the wind resistance of the loss-laid roofing paver system and the higher the ratio of space-between to space-underneath pavers and the larger the pavers, the higher the wind resistance of the system. Peterka et al (1997) and Jones et al (1999) studied a quantitative wind uplift model for asphalt shingles. Figure 2.9 shows the uplift mechanism of asphalt roof shingle. This uplift mechanism was investigated using both wind tunnel and full scale testing. In wind tunnel testing, the pressure taps were 
installed in upper and lower surfaces of several asphalt shingles. The quasi-steady pressure approximation method was used. It was suggested that the shingle uplift pressures from full scale measurements were in general agreement with the wind tunnel measured uplift forces.

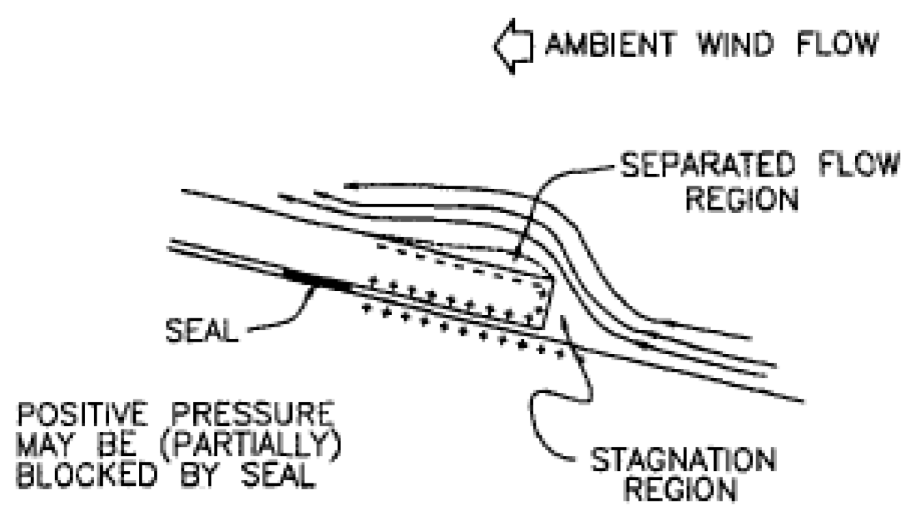

Figure 2.9: Local Wind Flow over Shingles Showing Uplift Mechanism (Peterka et al. 1997)

Marshall et al. (2010) reviewed the wind uplift models and its mechanism and discussed several factors that could affect the uplift resistance of asphalt shingles, including the type of shingle, design and workmanship, etc. Additionally, Cobin (2000) studied a new method to measuring the wind resistance of asphalt roof shingles, named "Local Model", by conducting wind-tunnel and full-scale testing.

\subsection{Fragility Curve}

Fragility curve or vulnerability curve is used to measure the ability of certain components/structures to resist the wind-induced load. Fragility curve shows a certain damage level of probability at given wind speed. Vulnerability curve shows the mean damage level corresponding to different wind speed. 
Many researchers have done valuable studies on vulnerability/fragility of lightframe buildings' components. Shinozuka et al. (2000) performed statistical analysis of structure fragility curves by considering both empirical and analytical methods for earthquake motions. In addition, the methods of testing the goodness of fit of the fragility curves were also presented. Rosowsky and Ellingwood $(2002,2004)$ used an analytical method for fragility analysis of wood frame housing exposed to various levels of natural and man-made hazards. Pinelli et al. (2004) suggested a hurricane damage prediction model for residential structures by using Monte Carlo simulation method and illustrated its application for a specific building type with hypothetical probability input. Li and Ellingwood (2006) developed a fully coupled reliability analysis method that integrates the structural fragility models with hurricane wind hazard models. The structure resistances, including few sets of root-to-wall connections, roof panel and glass, were determined by laboratory tests in this study. Henderson and Ginger (2007) presented vulnerability model of an Australian high-set house subjected to cyclonic wind loading. This study focused on the load transfer paths through connections from the roofing cladding fixings to the sub-floor bracing and demonstrated the use of probabilistic method for estimating percentage of cyclone wind induced high-set houses damages and related failure modes. Dao and Van de Lindt (2010) studied a combined methodology, including nonlinear structural analysis, computational fluid dynamics, reliability theory and particle dynamics, to develop fragility curves and fragility surfaces for the volume of rainwater intrusion and demonstrated on an example structure.

Researchers working on the Florida Public Hurricane Loss Model (FPHLM) (FPHLM, Eng. Report Volume II, 2005) systematically and comprehensively studied the 
residential buildings' vulnerability in Florida (Pinelli et al., 2004, 2008, 2009 and 2010, Pita et al., 2009). A detailed survey was performed on residential building characteristics for manufactured and site-built homes from nine counties in Florida. The wind load was from selected modification of ASCE 7-98 based on engineering judgment. For determining fragility curves for roof covering only external pressure was considered and effects of internal pressure was neglected. However, it is hypothesized that the fragility curves for roof covering will be affected by the net pressures acting on the roof elements. Capacities of building components were selected from available literature and manufacturers' data. The fragility curves for different damage levels were presented and validated by the application of national Association of Home Builders Research Center (NAHB) (1993) assessment of Hurricane Andrew damage data. Figure 2.10 shows the detailed structural damage simulation engine flowchart.

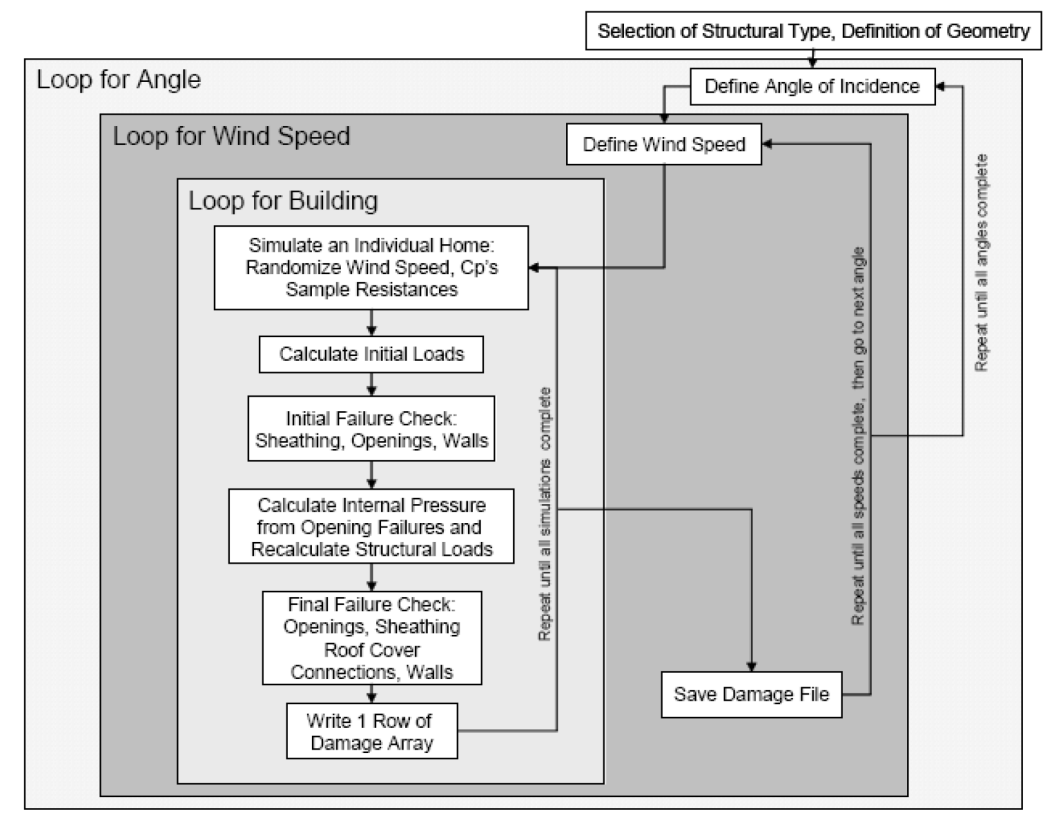

Figure 2.10: Structural Damage Simulation Engine Flowchart (FPHLM, Engineering Team Final Report, Volume II, 2005) 


\section{Experiment Testing Apparatus and Setup}

This research is used to determine hurricane wind induced pressures on three typical residential building configurations for various wind directions through full-scale testing (6-fan Wall of Wind) under controllable and repeatable environment. The effects of architectural features of roofing materials, such as asphalt shingle and tile, on roof pressure distribution and local flow pattern were studied in detail. The internal pressures under the tile cavity or between the layers of shingle were carefully measured to understand their effects on roof net peak pressure. The related experiment setup is presented in this chapter.

\subsection{Background}

Due to the limitation of investigating the effects of roof components on roof pressures, such as roofing materials and roof top equipment, in wind tunnel and in order to better understand the wind-structure interaction during hurricane, the International Hurricane Research Center (IHRC) at Florida International University (FIU) has developed a open jet testing facility, namely Wall of Wind, for large- and full-scale testing. Figure 3.1 shows the Wall of Wind with test specimen. The Wall of Wind is capable of simulating the atmospheric boundary layer wind characteristics and performing full-scale testing with real roof components under different wind speed level with and without wind-driven rain (Gan Chowdhury et al. 2009 and Bitsuamlak et al. 2009). 

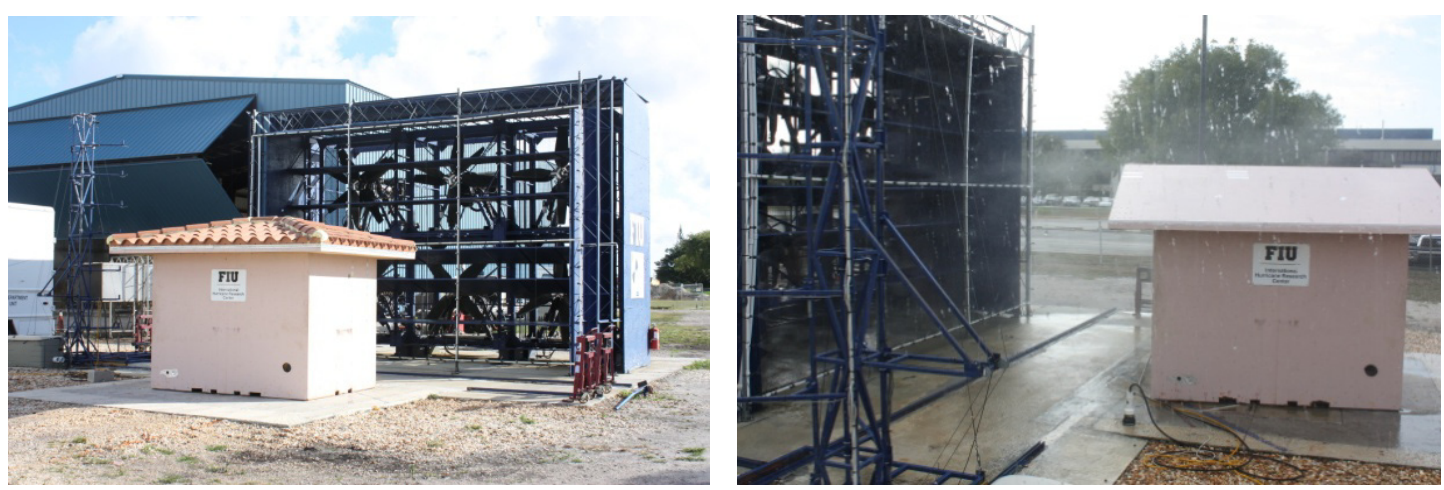

Figure 3.1: Full- or Large- Scale Testing Facility - Wall of Wind

This full scale research is envisioned to address two high priority investment categories for hurricane research as suggested by the National Science Board (NSB), namely, 'Impacts and interactions' and 'Preparedness and Building Resiliency,' (NSB, 2007). The WoW facility at FIU has made a significant impact on hurricane mitigation through extensive research, education and outreach activities conducted by the wind engineering team of FIU International Hurricane Research Center and Dept. of Civil and Environmental Engineering. The development of the WoW has been completed in stages, an incremental strategy that has enabled FIU researchers to gain experience in the development, testing, and operation of the facility, and helped reduce unnecessary expenses.

The first phase includes airboat propellers and two marine-grade Chevrolet 496 fuel injected engines generating a flow field measuring $4.88 \mathrm{~m}$ high by $2.44 \mathrm{~m}$ wide. This testing system was used to investigate the WoW approach of full scale testing and develop an active control system for future WoW expansion.

The second phase of WoW includes six fans powered by gasoline engines and is capable of generating $125 \mathrm{mph}$ wind speeds in the original configuration (Blessing et al., 2009). The dimension of flow field is $4.88 \mathrm{~m}$ high by $7.32 \mathrm{~m}$ wide. To obtain realistic 
aerodynamic wind flow characteristics, including atmospheric boundary layer, wind speed, turbulence intensity, integral length scale and wind spectra, the 6-fan WoW was modified by adding active and passive control devices. The detailed preliminary and modified 6-fan are shown at Figure 3.2.

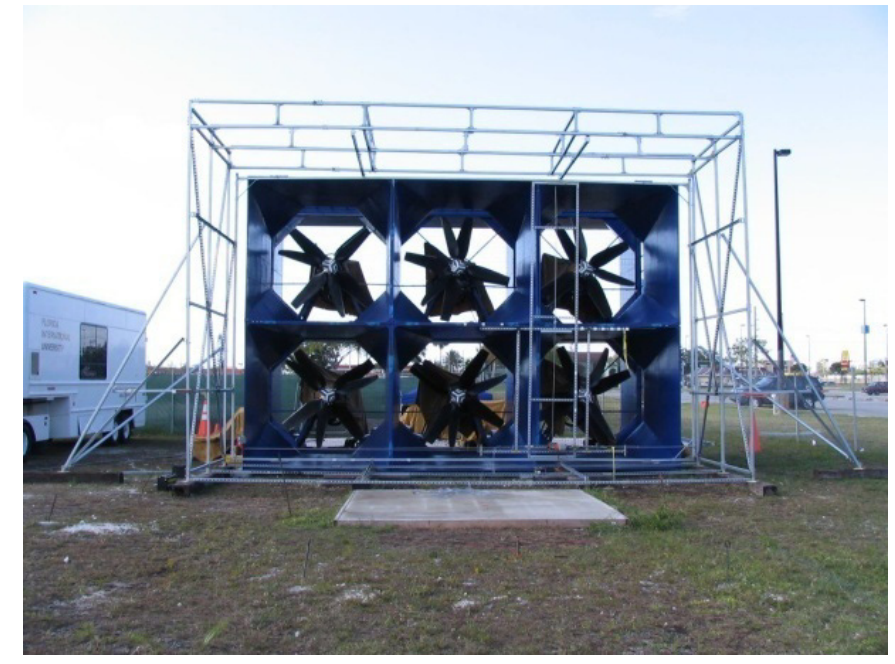

a. Preliminary 6-fan WoW

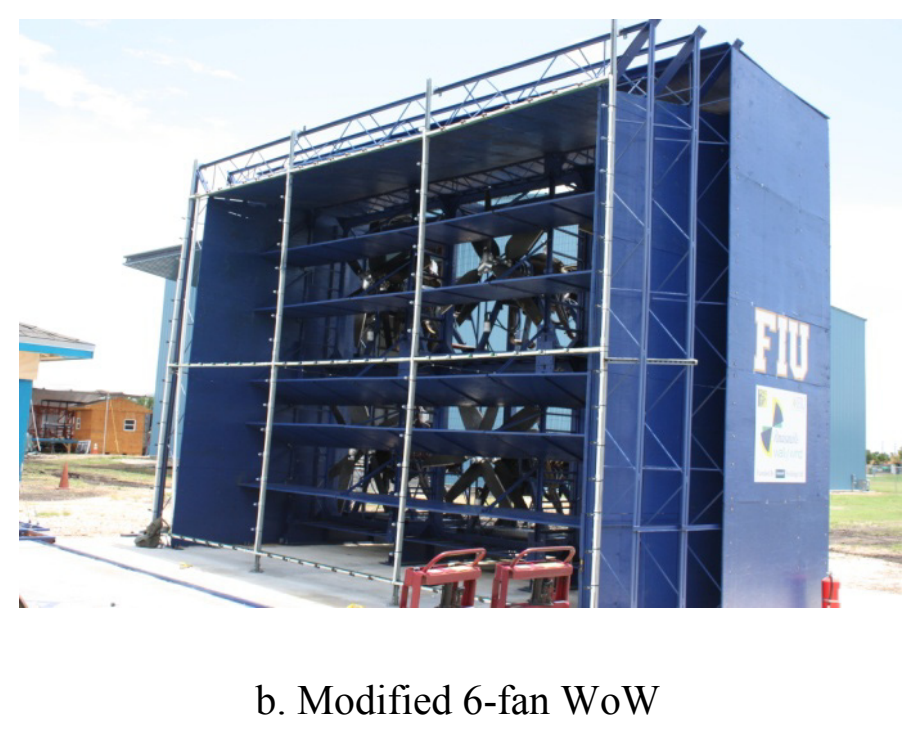

Figure 3.2: Preliminary and Modified 6-fan WoW

The final phase of WoW comprises of twelve electric fan-motor units controlled by two variable frequency drives (VFDs). The 12 -fan WoW is designed to generate 
sustained wind speed up to $63 \mathrm{~m} / \mathrm{s}(140 \mathrm{mph})$ (Category 4 wind speed being 59-69 m/s [131-155 mph]). Construction of the 12 -fan WoW is completed and the commissioning is planned to be concluded by the beginning of year 2012. The initial testing including the wind flow characteristic generation and wind pressure validation were conducted using a 1:15 scale model of the 12-fan WoW (Aly et al., 2010, Fu et al., 2011). Figure 3.3 shows the full-scale 12-fan WoW.

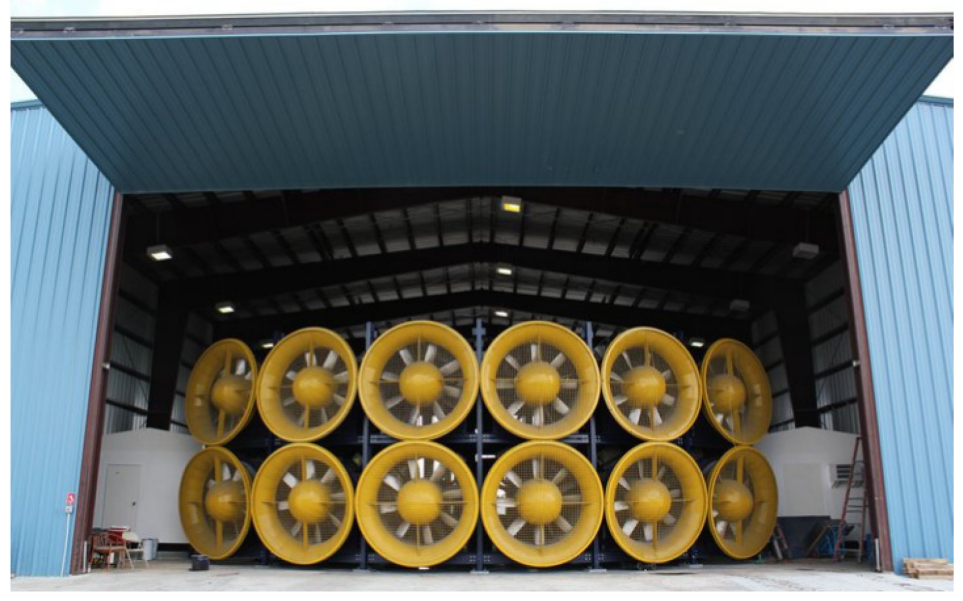

Figure 3.3: Full-scale 12-fan WoW

\subsection{6-fan WoW Testing Facility}

The current research was conducted using the 6-fan WoW testing apparatus. The 6-fan system was funded by Federal and State agencies and private industry, and constructed at FIU Engineering Campus in 2007. Six big block carbureted Chevrolet 502 fuel engines were combined into a two by three array as shown in Figure 3.2. A pair of counter rotating propellers, powered by each engine, was used to reduce the amount of propeller generated swirl in the flow and the overall propeller torque on the engine. The preliminary configuration included a "diffuser section" for channeling the wind flow into a square section to help combine the flow generated by each fan. Each engine had the 
capability of changing the wind speed by changing each engine's revolutions per minutes (rpm) which could be controlled by predefined waveforms. The maximum sustained wind speed is approximately $56.1 \mathrm{~m} / \mathrm{s}$ with all engines running at $4500 \mathrm{rpm}$. The wind characteristics from initial configuration were measured and analyzed (Huang et al., 2009c). Table 3.1 shows the detailed comparison of wind characteristics for the 6-fan WoW (preliminary configuration) generated wind and those obtained for tropical cyclones through the Florida Costal Monitoring Program (FCMP) (Yu et al., 2008).

Table 3.1: Wind Characteristics Comparison between Preliminary Wow at $4000 \mathrm{rpm}$ and FCMP (Huang et al., 2009)

\begin{tabular}{ccccc}
\hline \hline Case & $\begin{array}{c}\text { Mean wind speed } \\
(\mathrm{m} / \mathrm{s})\end{array}$ & $\begin{array}{c}\text { Turbulence } \\
\text { Intensity }\left(\mathrm{TI}_{w}\right) \\
(\%)\end{array}$ & $\begin{array}{c}\text { Gust Factor } \\
\mathrm{GF}(\mathrm{T}, \mathrm{t})\end{array}$ & $\begin{array}{c}\text { Integral } \\
\text { Length Scale, } \\
\mathrm{L}_{\mathrm{u}}^{\mathrm{x}}(\mathrm{m})\end{array}$ \\
\hline $\begin{array}{c}36.3 \\
\text { Preliminary } \\
\text { WoW }\end{array}$ & $\begin{array}{c}36.0 \\
(1-\mathrm{min} \text { mean speed })\end{array}$ & 6.0 & $\mathrm{GF}(6 \mathrm{~min}, 3 \mathrm{sec})=1.09$ & 59.6 \\
\hline FCMP* & $\begin{array}{c}17.8 \\
(1-\mathrm{hr} \text { mean speed }) \\
22.3\end{array}$ & 17.8 & $\begin{array}{c}\mathrm{GF}(1 \mathrm{hr}, 3 \mathrm{sec})=1.59 \\
\mathrm{GF}(6 \mathrm{~min}, 3 \mathrm{sec})=1.43\end{array}$ & 98.7
\end{tabular}

To obtain reliable aerodynamic testing results at the WoW facility, it is very important to replicate realistic wind characteristics such as those obtained from measurements during tropical cyclones. The detailed target wind flow generation at WoW was presented by Huang et al. (2009c). The 1:8 small scale model of 6-fan WoW was first constructed to help replicate the target wind characteristics by using the active and passive control methodologies. The passive controls included a contraction, an outer frame, inclined horizontal plates, and raised height of the WoW. The active control of the fan rpm was achieved by inputting a quasi-periodic waveform based on real tropical cyclone data obtained from FCMP. The resulted wind characteristics are presented in detail in Table 3.2. The suburban atmospheric boundary layer wind profile and quasi- 
periodic waveform (W4 - using superposition of three sinusoidal signals) was used in this research.

The 6-fan WoW was able to generate wind-driven rain which could be used to simulate real hurricanes accompanied by heavy rain. A steel frame was mounted to the WoW outer frame. Spray nozzles and high pressure hosing were installed on the steel frame. Water for this injection system was pumped from the water tanks. This whole testing system could combine the hurricane level wind with wind-driven rain acting simultaneously on test buildings under controlled conditions. The detailed wind-driven rain system is described by Bitsuamlak et al. (Bitsuamlak et al., 2009). Figure 3.4 shows the wind-driven rain simulation at 6-fan $\mathrm{WoW}$.

Table 3.2: Comparison of Wind Characteristics of Modified 6-Fan Wow (Huang et al., 2009)

\begin{tabular}{|c|c|c|c|c|c|}
\hline $\begin{array}{c}\text { Case } \\
\text { (Waveform; mean rpm) }\end{array}$ & $\begin{array}{l}\text { Wind speed } \\
(\mathrm{m} / \mathrm{s})\end{array}$ & $\begin{array}{l}\mathrm{TI}_{\mathrm{u}} \\
(\%)\end{array}$ & $\begin{array}{l}\mathrm{TI}_{\mathrm{W}} \\
(\%)\end{array}$ & $\mathrm{GF}(\mathrm{T}, \mathrm{t})$ & $\begin{array}{l}\mathrm{L}_{\mathrm{a}}^{\mathrm{x}} \\
(\mathrm{m})\end{array}$ \\
\hline $\begin{array}{c}\text { Revised WoW } \\
\text { (Flat waveform; 4,000) }\end{array}$ & $\begin{array}{c}36.7 \\
\text { (1-min mean speed) } \\
38.2 \\
\text { (3-sec peak gust) }\end{array}$ & 4.6 & 5.4 & $\begin{array}{l}G F(6 \mathrm{~min}, 3 \mathrm{sec})=1.06 \\
G F(1 \mathrm{~min}, 3 \mathrm{sec})=1.04\end{array}$ & 36.6 \\
\hline $\begin{array}{l}\text { Revised WoW } \\
\text { (W3 sinusoidal } \\
\text { waveform; 3,500) }\end{array}$ & $\begin{array}{c}33.7 \\
\text { (1-min mean speed) } \\
41.8 \\
\text { (3-sec peak gust) }\end{array}$ & 19.9 & 6.7 & $\begin{array}{l}G F(6 \mathrm{~min}, 3 \mathrm{sec})=1.33 \\
G F(1 \mathrm{~min}, 3 \mathrm{sec})=1.24\end{array}$ & 134.7 \\
\hline $\begin{array}{l}\text { Revised WoW } \\
\text { (W4 quasi-periodic } \\
\text { waveform; 2,855) }\end{array}$ & $\begin{array}{c}28.8 \\
\text { (1-min mean speed) } \\
38.3 \\
\text { (3-sec peak gust) }\end{array}$ & 23.8 & 7.1 & $\begin{array}{l}G F(6 \mathrm{~min}, 3 \mathrm{sec})=1.42 \\
G F(1 \mathrm{~min}, 3 \mathrm{sec})=1.33\end{array}$ & 89.9 \\
\hline $\begin{array}{c}\text { Preliminary WoW } \\
\text { (Flat waveform; } 4,000 \text { ) }\end{array}$ & $\begin{array}{c}36.3 \\
\text { (1-min mean speed) } \\
38.5 \\
\text { (3-sec peak gust) }\end{array}$ & 6.0 & - & $\begin{array}{l}G F(6 \mathrm{~min}, 3 \mathrm{sec})=1.09 \\
G F(1 \mathrm{~min}, 3 \mathrm{sec})=1.06\end{array}$ & 59.6 \\
\hline FCMP* & $\begin{array}{c}22.3 \\
\text { (1-min mean speed) } \\
28.3 \\
\text { (3-sec peak gust) }\end{array}$ & 17.8 & 7.0 & $\begin{array}{c}G F(1 \mathrm{~min}, 3 \mathrm{sec})=1.27 \\
G F(6 \mathrm{~min}, 3 \mathrm{sec})=1.43 \\
G F(1 \mathrm{hr}, 3 \mathrm{sec})=1.59\end{array}$ & 98.7 \\
\hline
\end{tabular}




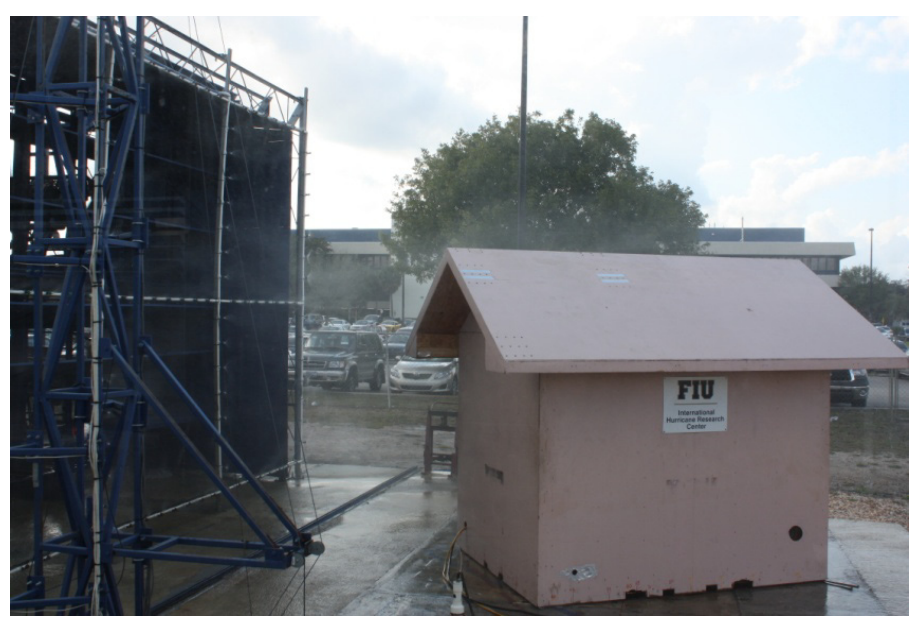

Figure 3.4: Wind-Driven Rain Simulation at 6-Fan Wow

\subsection{6-Fan WoW Pressure Field Validation}

In order to ascertain that the open jet WoW tests generate realistic aerodynamic pressure distribution on roof models, in addition to simulating the requisite wind characteristics, pressure measurement validation for bare decks was necessary before performing the study on wind effects on tiled roofs. For this purpose, in addition to the 5:12 gable roof model (mentioned earlier), a low-slope (1:12) full-scale gable roof model was also built. The two gable models with bare roof decks were tested under wind parameters as described in Section 3.2 and pressure data were measured. Next, two small scale (1:20) gable roof models (with 1:12 and 5:12 slopes) were built replicating the two bare deck roof models tested at WoW. These small-scale models were tested in a $2.43 \mathrm{~m}$ by $1.98 \mathrm{~m}$ Rowan Williams Davies and Irwin Inc.'s (RWDI) atmospheric boundary layer wind tunnel (Miramar, Florida) under similar flow conditions as used in the WoW testing. In wind tunnel, the mean wind speed profile had a power-law coefficient value $\bar{\alpha}$ $=1 / 4.0$. The longitudinal turbulence intensity was $22.3 \%$ at an equivalent full scale height of $3 \mathrm{~m}$. Seven different wind angles of attack $\left(0^{\circ}, 15^{\circ}, 30^{\circ}, 45^{\circ}, 60^{\circ}, 75^{\circ}\right.$ and $\left.90^{\circ}\right)$ were 
tested for each of the bare deck model in the wind tunnel and the results were compared with those for the corresponding full-scale model tested in the WoW. The area-averaged peak pressures (selected locations to facilitate the comparison, see Fig. 3.5) were obtained by probabilistic analysis (Sadek and Simiu 2002) of the pressure data obtained by instantaneous spatial averaging of the measured point pressure time histories for the relevant taps. A reasonable agreement between the wind tunnel and WoW test results for the bare deck roof models was achieved. For brevity, results for $45^{\circ}$ wind angle of attack are shown in Fig. 3.6a and $b$ for the 1:12 and 5:12 slope models, respectively.

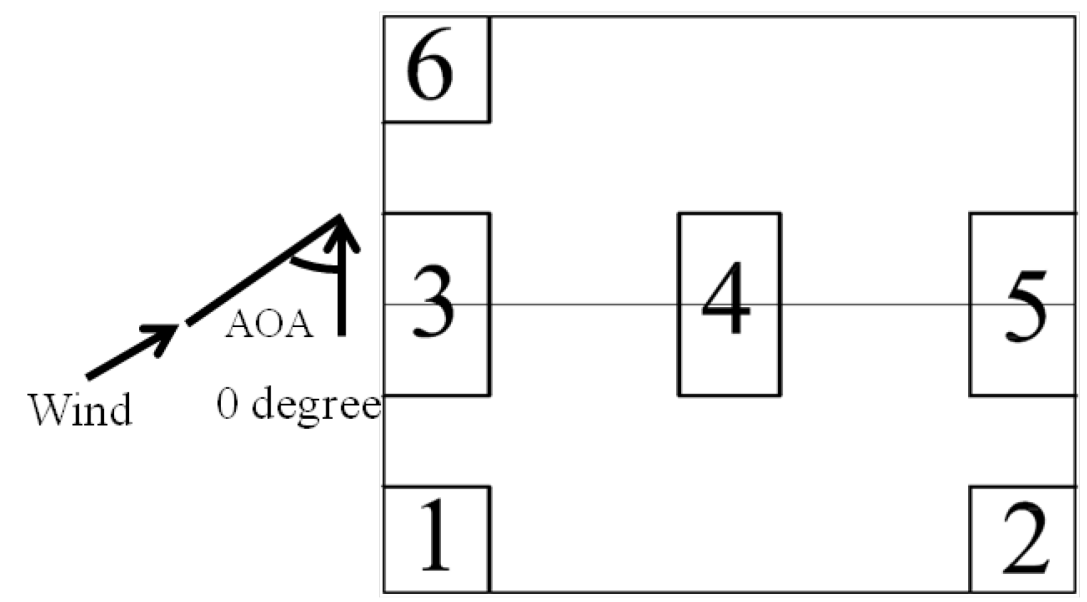

Figure 3.5: Selected Locations to Facilitate the Area-Averaged Pressure Comparison
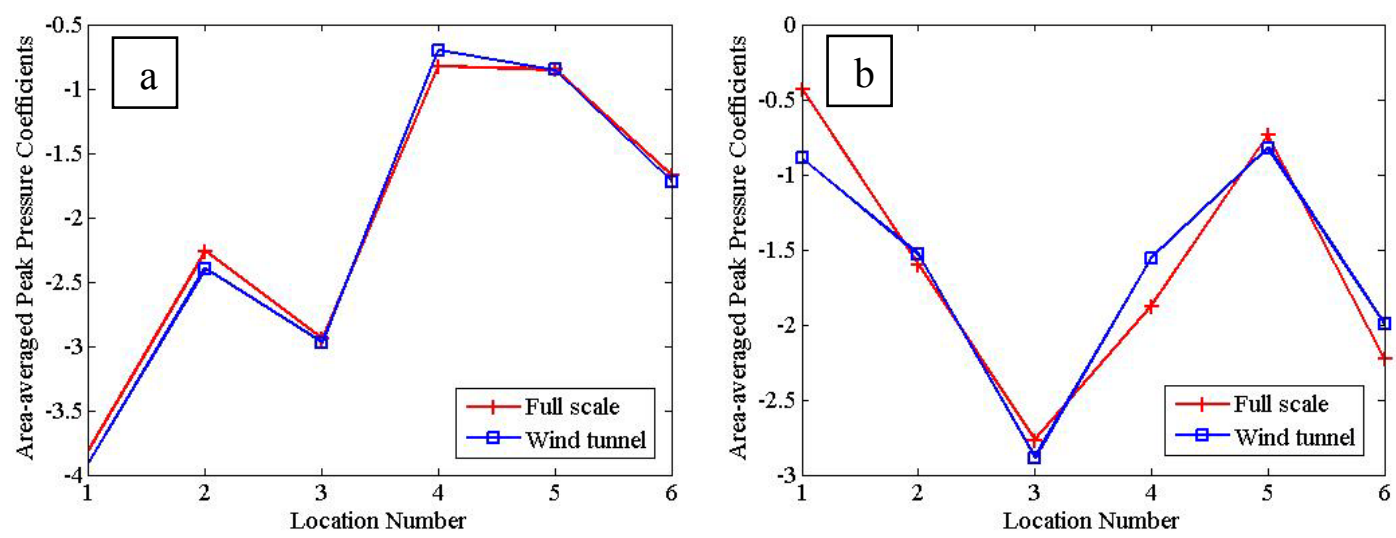

Figure 3.6: Comparison of Area-Averaged Pressure Coefficients from Wind Tunnel and Wow for $45^{\circ}$ : (a) Gable Roof with 1:12 Slope; (b) Gable Roof with 5:12 Slope 


\subsection{WoW instrumentations and data acquisition system}

The Setra model 265 bidirectional transducers were used to measure both positive and negative wind pressures on roof and walls of test buildings. The Setra transducers have a full-scale range of \pm 0.90 psi. Each transducer has two ports: one is the reference port for ambient pressure and the other is connected to the testing structure to measure the fluctuating pressure on model surfaces. The reference pressure measurement was taken from a pit at about $15 \mathrm{~m}$ away from the testing building. The manifold was connected to the pit and distributed the reference pressure through $6 \mathrm{~m}$ long silicon tube, functioning as restrictor tubing, to each pressure transducer. Detailed reference pressure and dynamic pressure port connection setups are presented by Blessing (2007) and Huang et al. (2009a).

Each pressure transducer was calibrated using hand-held Omega PCL-1B with module PCL-MA-50BWC. Calibration curves were obtained through fitting the pressure data versus voltage data. Using the curves, the Data Acquisition (DAQ) system converted the voltage signal into pressure signal for each transducer.

The data acquisition system using Compact RIO (cRIO) (see Figure 3.7) was installed inside the testing building. The design and construction of the DAQ system was based on the National Instruments (NI) Compact RIO platform (see Figure 3.8). A cRIO system with eight 32-channel voltage input modules were provided. Totally, two hundred fifty six channels in the cRIO could be used to measure pressures simultaneously. An Ethernet cable was connected from the cRIO to the desktop inside the control room. The DAQ software in the desktop was used to collect and save all the data measured at each 
transducer. All of the LabVIEW-based control and DAQ software were developed by PrimeTest Automation, Inc.

All the pressure data were sampled at $100 \mathrm{~Hz}$ and filtered at $20 \mathrm{~Hz}$ using low-pass filter. Before each test, to ascertain the reliability of the pressure data, the troubleshooting procedure is performed, including (i) checking the connector, the reference and active tubes connected to the right port, (ii) data quality check to minimize the natural wind effects, and (iii) minimizing noise issues.

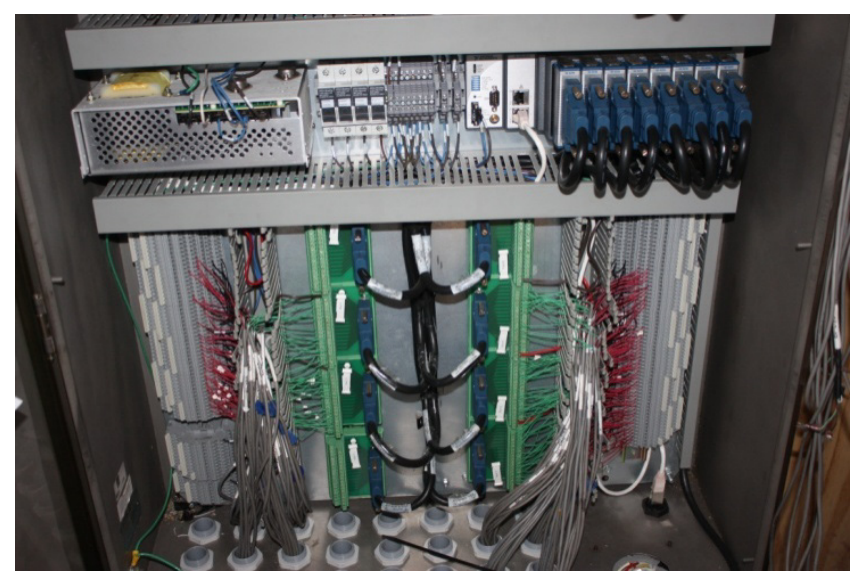

Figure 3.7: Data Acquisition System

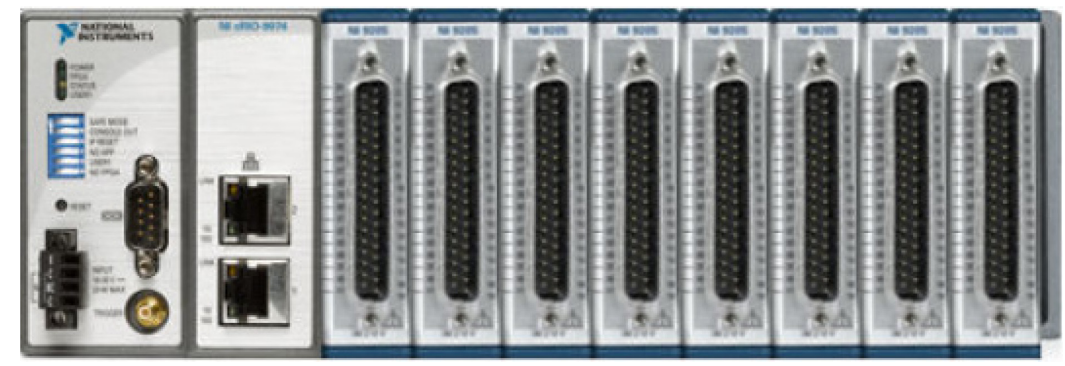

Figure 3.8: NI cRIO DAQ Platform

\subsection{Test specimens}

The open jet full- and large-scale testing facility, like WoW, is a new wind testing technology. To obtain reasonable and realistic pressure measurements, such testing 
technology still has some challenges need to be addressed, such as the blockage effects. Bitsuamlak et al. (2010) used computational fluid dynamics (CFD) and Aly et al. (2011) performed physical experiments to evaluate the blockage effects for open jet facilities. The results indicated the capability of open jet tests to reproduce reasonable roof pressures for low buildings under relatively high blockage ratios, approximately $15 \%$, compared to those for wind tunnels (Aly et al. 2011). Based on the wind field generated by 6 -fan WoW and consider the blockage effects, the testing building base with $2.74 \mathrm{~m}$ long by $2.13 \mathrm{~m}$ wide by $2.13 \mathrm{~m}$ height and four different interchangeable roofs with $0.46 \mathrm{~m}$ wide overhang were built at Engineering Campus, FIU. The four roofs, including a monoslope roof with 4:12 slope, a gable roof with 5:12 slope and two hip roofs with 3:12 and 5:12 slopes, were considered based on four different roof slope ranges specified in ASCE 7-05 (Figure 6-11). Especially, the 5:12 gable roof is considered to be the most representative roof slope for the population of site-built homes in Florida (FPHLM, Volume II, 2005). Two windows, each $0.53 \mathrm{~m}$ long by $0.43 \mathrm{~m}$ wide, were symmetrically placed on either side of the door with the dimension of $1.65 \mathrm{~m}$ high by $0.75 \mathrm{~m}$ wide. The windows were used to simulate a partially enclosed building condition (ASCE7-05 2006) as will be discussed later. For each test, the model building was fixed to the ground by connecting it to ground-secured angle through four guide steel wires. An uplift jack was used to rotate the model building for testing at different angles of attack.

In order to study the effects of overhang dimension on roof pressure distributions, an extra wall was designed for adding to the original building which changed the soffit dimension from $0.457 \mathrm{~m}$ to $0.152 \mathrm{~m}$, (thus covering two typical overhang dimensions). 
Figures 3.9 and 3.10 show the original and modified test structure (in front of the 6-fan WoW), respectively.

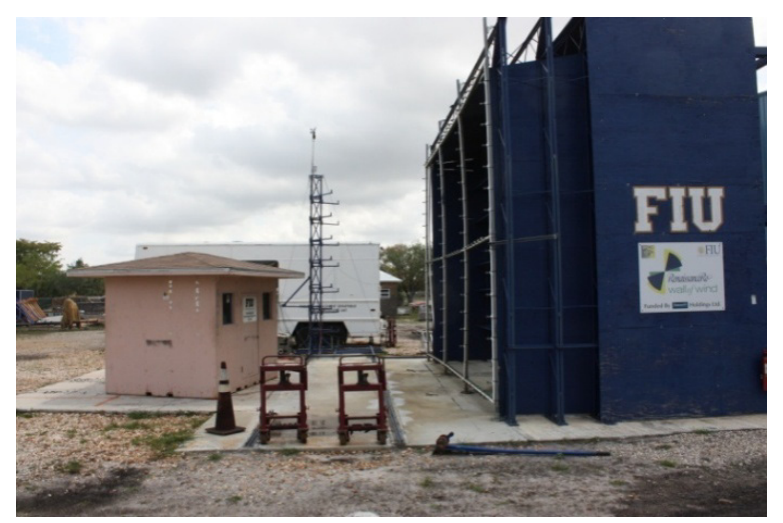

Figure 3.9: Original Testing Structure with the 6-Fan WoW

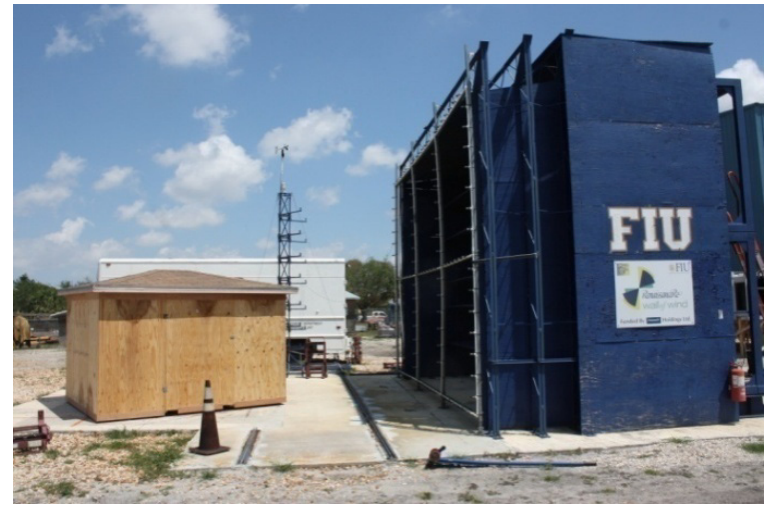

Figure 3.10: Modified Testing Structure with the 6-fan WoW

All the roof configurations were tested for bare roof deck with plywood sheathing only (referred as bare deck case) and tiled roof deck installed with Santafe Spanish "S" clay roof tiles (Notice of Acceptance (NOA) \# 07-0626.03) using foam adhesive set over asphalt based underlayment over plywood sheathing (referred as tiled deck case). Two of the four roof configurations (monoslope roof with 4:12 slope and hip roof with 3:12 
slope) were also tested for shingled roof deck installed with asphalt shingles (referred as shingled deck case). The installation of clay tiles was performed as regulated by Section 1507.3 and 1518.8 of the Florida Building Code (FBC 2007), and the installation of asphalt shingle was regulated by section 1507.2 and 1518.7 of the Florida Building Code (FBC 2007). They should comply with the recommendation by the Florida Roofing, Sheet Metal and Air Conditioning Contractors Association (FRSA) and the Tile Roofing Institute (TRI). In addition, Miami-Dade County further requires that all building products and components being considered for installation within its jurisdiction must be approved by the county's Product Control Division (FBC, 2007, Section 1515). Moreover, Product Approvals and FBC (2007) do not require mechanical fasteners for roofing materials when the roof slope is less than 6:12. Figures $3.11-3.13$ show an example of bare, tiled and shingled roof decks for hip roof with 3:12 slope.

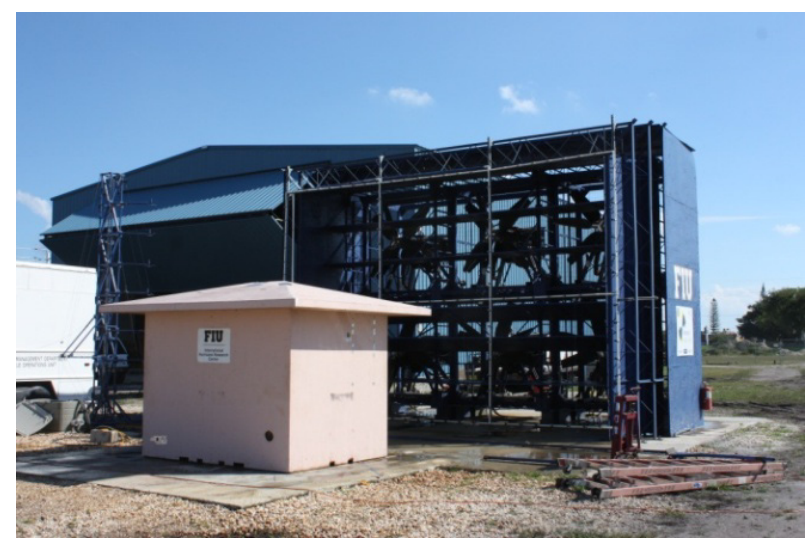

Figure 3.11: Bare Roof Deck 


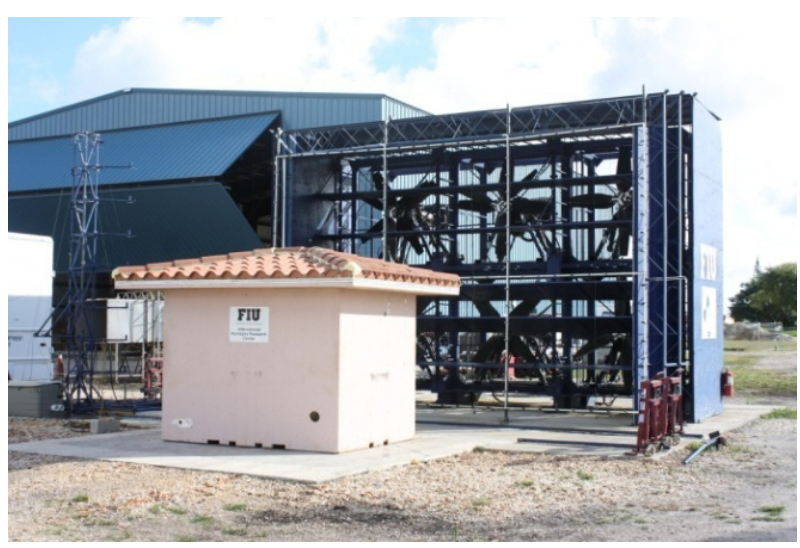

Figure 3.12: Tiled Roof Deck

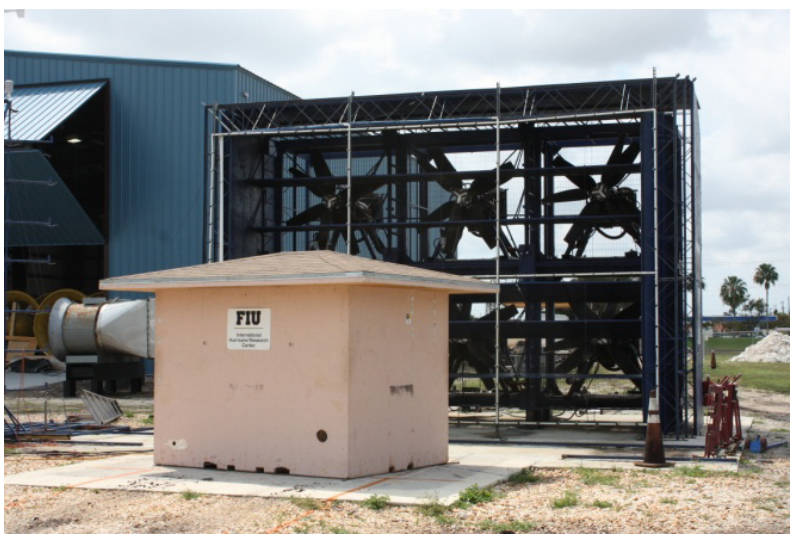

Figure 3.13: Shingled Roof Deck

In addition, the overall background leakage of the particular test specimen was also estimated using American Society for Testing and Materials "Standard Test Method for Determining Air Leakage Rate by Fan Pressurization" testing protocol (ASTM E 779 - 03, 2007). The $\mathrm{ACH}_{50}$ (air changes per hour leakage when the house is depressurized or pressurized to 50 Pascal with respect to outdoors) value for the test specimen was about 14.3. Thus the testing model was leakier compared to average single family residential homes in Florida $\left(\sim 5.2 \mathrm{ACH}_{50}\right)($ Swami et al. 2006) 


\subsection{Pressure tap layout}

The pressure tap layout configuration for each type of roof (monoslope or hip or gable) followed the same pattern on the horizontal projection of the roof for bare, shingled, and tiled roof decks to facilitate one to one comparisons of area-averaged pressures. The bare, tiled, and shingled roof decks were instrumented at nine locations. Each location had twelve external pressure taps and at least one internal tap which measured differential pressures using Setra model 265 low differential pressure analog transducers. The nine locations and the external pressure taps are shown in Figures 3.14 3.16. The nine locations were selected based on representative 'hot spots' on the roof areas considered to experience high peak suctions due to flow separation and vortex generation (such as near the corners, eaves, and ridges of the roofs). All four roofs were tested with bare and tiled roof deck. In addition, two roofs were tested with shingled roof deck, including a monoslope roof (4:12 slope) and a hip roof (3:12 slope)

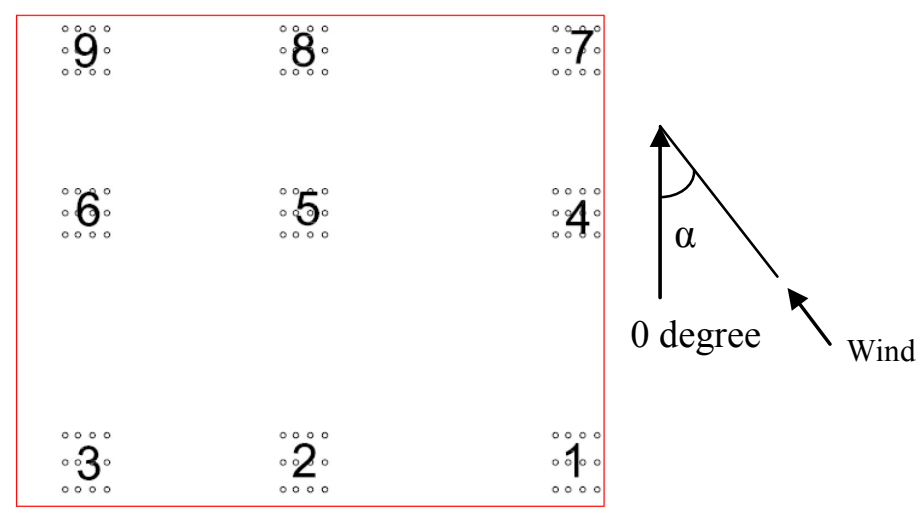

Figure 3.14: 4:12 Monoslope Roof Pressure Tap Layout 


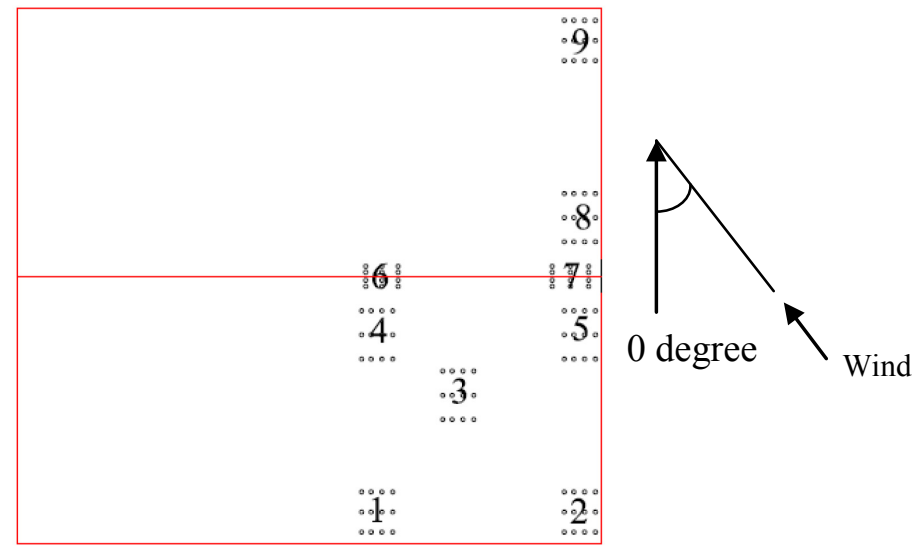

Figure 3.15: 5:12 Gable Roof Pressure Tap Layout

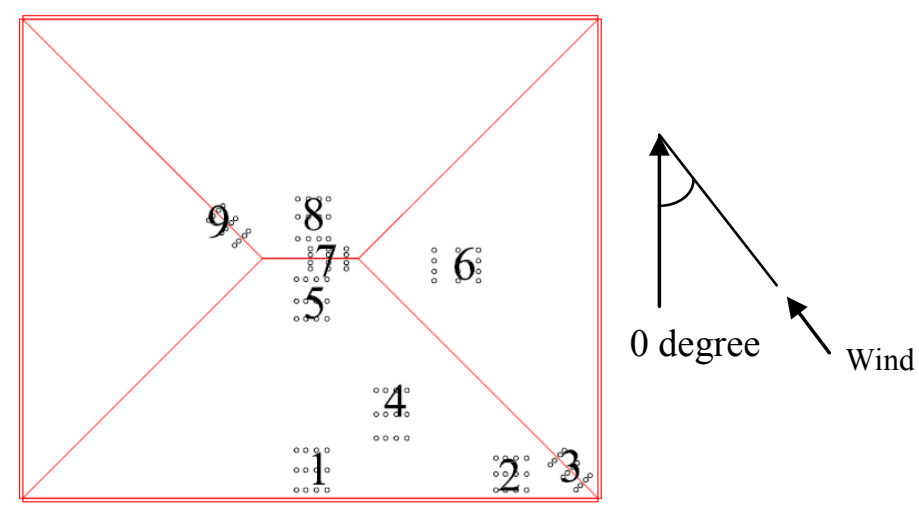

Figure 3.16: 3:12 and 5:12 Hip Roofs Pressure Tap Layout

Internal pressures were studied in detail for their contribution to the roof areaaveraged net peak pressures. Three kinds of internal pressure taps were used for tiled roof deck. The first is the pressure tap, located under the tile batten space, and applied to all the tiles; the second is located at the tile joint overlaps, and applied to the tiles located in the middle of the roof; the third is the external tap placed at the birdstep sheeting but treated as internal tap, and applied to the tiles at the roof edge by considering the same mechanism of the high correlation between soffit and wall pressures (Vickery, 2008). The detailed third internal tap location is shown in Figure 3.17. 


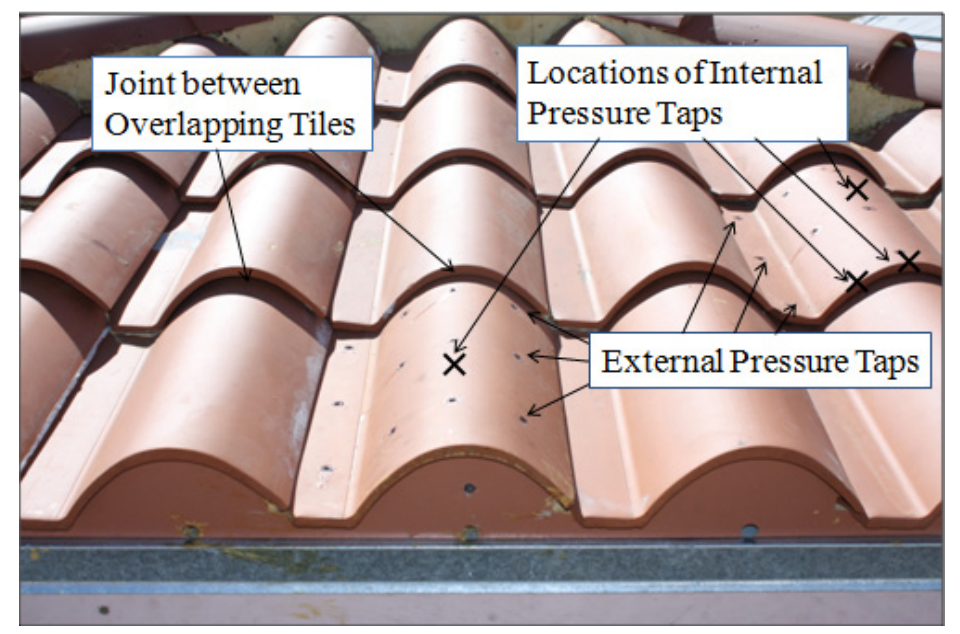

Figure 3.17: Internal Pressure Tap Located at the Birdstep

For shingled roof deck, the internal pressures between the layers of shingle were studied. All the internal taps were installed at the region cantilevered downslope from the sealant of the asphalt shingle. For 3:12 hip roof, each location was instrumented with three internal pressure taps. However, for 4:12 monoslope roof, only locations 1, 2, 5, and 7 were instrumented internal taps. Figure 3.18 shows the external and internal pressure taps of location 1 from 3:12 hip roof.

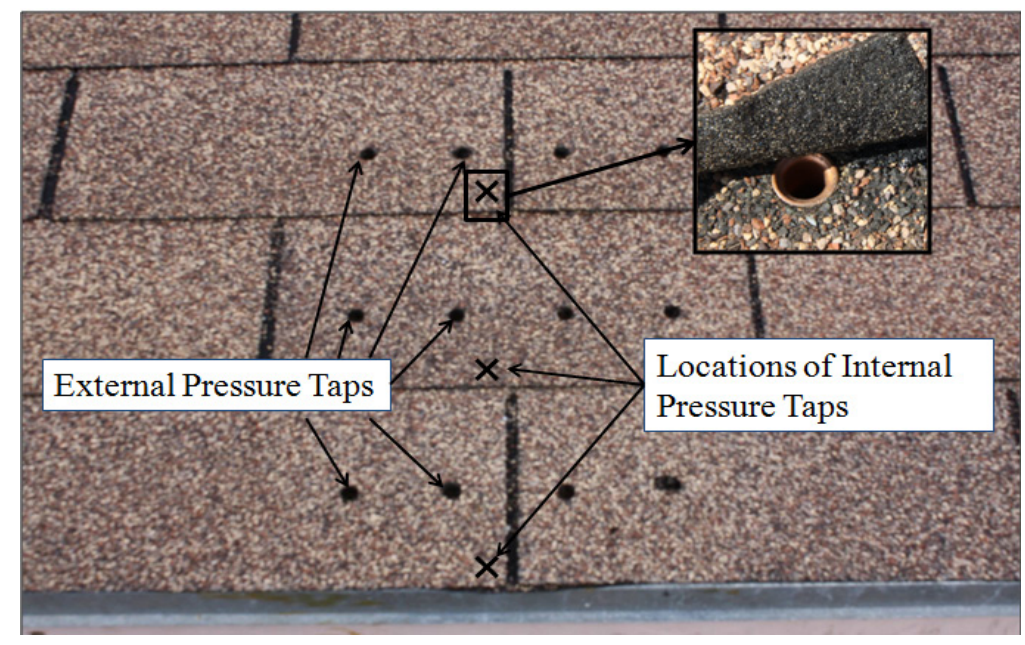

Figure 3.18: An Example of the External and Internal Tap Locations for Shingled Roof Deck 
In addition, to study pressure equalization between the internal pressure under the tile's cavity (or between the layers of shingles) and the internal pressure inside the building, two pressure transducers were installed inside the building to measure the internal pressure for two scenarios: enclosed and partially enclosed building.

\subsection{Testing protocol}

To obtain reasonable pressure measurement on low-rise building, optimizing the distance of the test model from the contraction exit where the flow becomes open to atmosphere is another challenge inherent in open-jet facilities in addition to the blockage effects. Extensive computational fluid dynamics (CFD) simulations for open jet facilities was also used to assessing the effect of distance to the pressure measurements and concluded that the distance of the test building model from open jet contraction exit should be approximately equal to the wind field height at the exit (Bitsuamlak et al. 2010). The windward wall pressure could be exaggerated due to block effects if the model is placed closer. The roof aerodynamic pressures appear less sensitive compared to the windward wall pressures. Based on this finding and considering the development of wind flow and the wind speed requirement, the current testing was performed with the windward face (or windward corner in case of oblique wind angle of attack) of the building model located at a distance approximately equal to the height of the wind field at the exit.

All the pressure measurements were taken at various wind angles of attack (AOA) with a sampling rate of $100 \mathrm{~Hz}$ over 3 minutes duration. The peak 3 -sec gust wind speed values and other wind characteristic parameters are shown in Table 3.2 for W4 quasi- 
periodic waveform case. Based on model configuration and cross checking of results for selected aerodynamically symmetric cases (say, for $\mathrm{AOA}=0^{\circ}$ and $180^{\circ}$ for a gable roof model), different wind angles of attack were tested for each type of roof. The detailed testing protocol is presented at Table 3.3. According to Simiu et al. (2007), Category 1 hurricanes on the Saffir-Simpson scale correspond to a minimum of approximately $1.07 \mathrm{x}$ $33.1 \mathrm{~m} / \mathrm{s}=35.4 \mathrm{~m} / \mathrm{s}(79.2 \mathrm{mph})$ peak 3 -s gust speed at $10 \mathrm{~m}$ above open terrain. Therefore, for the current testing the wind speeds corresponded to Category 1 hurricane conditions.

Table 3.3: Detailed Testing Protocol

\begin{tabular}{|c|c|c|c|}
\hline Roof type & $\begin{array}{l}\text { Roof } \\
\text { slope }\end{array}$ & $\begin{array}{l}\text { Roofing } \\
\text { materials }\end{array}$ & Testing wind angles of attack (degree) \\
\hline \multirow{3}{*}{$\begin{array}{l}\text { Monoslope } \\
\text { roof }\end{array}$} & \multirow{3}{*}{$4: 12$} & Underlayment & $0,15,30,45,75,90,135,180$ \\
\hline & & Shingle & $\begin{array}{c}0,15,30,45,55,65,75,90,112.5,135,157.5, \\
180\end{array}$ \\
\hline & & Tile & $\begin{array}{c}0,15,30,45,55,65,75,90,112.5,135,157.5 \\
180\end{array}$ \\
\hline \multirow{2}{*}{ Gable roof } & \multirow{2}{*}{$5: 12$} & Underlayment & $0,20,40,55,60,65,70,80,90,135,180,270$ \\
\hline & & Tile & $0,20,40,55,60,65,70,80,90,135,180,270$ \\
\hline \multirow{5}{*}{ Hip roofs } & \multirow{3}{*}{$3: 12$} & Underlayment & $0,15,22.5,30,45,60,75,90$ \\
\hline & & Shingle & $0,15,22.5,30,45,60,75,90$ \\
\hline & & Tile & $0,15,22.5,30,45,60,75,90$ \\
\hline & \multirow{2}{*}{$5: 12$} & Underlayment & $\begin{array}{c}0,15,22.5,30,45,60,75,90,135,180,270, \\
315\end{array}$ \\
\hline & & Tile & $\begin{array}{c}0,15,22.5,30,45,60,75,90,135,180,270, \\
315\end{array}$ \\
\hline
\end{tabular}

3.8 Data processing 
The pressure coefficient at the $i^{\text {th }}$ tap is estimated as follows:

$$
C_{P i}=\Delta P_{i} / \frac{1}{2} \rho U^{2}
$$

where $\Delta P_{i}$ is the differential (external minus internal) pressure; $\rho$ is the air density; and $U$ is the 3 -sec gust wind speed at the mean roof height, except that eave height shall be used for roof slope $\theta \leq 10^{\circ}$. The pressure coefficients determined for the bare roof deck were only calculated from external pressures measured at the plywood surface (referred to as surface peak pressure coefficients in this dissertation). The net pressure coefficients for the tiled roof decks were determined by using the vector sum of the external pressures measured on the tiles' exterior surfaces and the cavity internal pressures measured underneath the tile and also in the tile joint overlap region. The net pressure coefficients for the shingled roof decks were determined by vector sum of the external pressures measured on the shingles' exterior surfaces and the internal pressures measured underneath the surface layer of shingle. It is to be noted that the net peak pressure coefficients are not equivalent to the net pressure coefficients described in ASCE 7-05 which include the contribution of the internal pressure coefficients inside the building.

To remove the uncertainties inherent in the randomness of the peaks, probabilistic analysis was applied to all the analysis using an automated procedure developed by Sadek and Simiu (2002) for obtaining estimated statistical peak pressure coefficients for different durations using the observed pressure time histories. Because estimates obtained from this approach are based on the entire information contained in the time series, they are more stable than the "observed peaks" in the time histories. However, it is not the point peak pressures but the area-averaged peak pressures over the area of the tile that are 
of interest to the designer. The estimated area-averaged peak pressure coefficients were obtained by applying the Sadek and Simiu method to a new time history obtained by instantaneous spatial averaging of the point pressures measured at all taps placed on a tile (or shingle). Such estimated area-averaged peak pressure coefficients (e.g., $\left.\hat{C}_{p, \text { external,tiled deck }}, \hat{C}_{p, \text { internal,tiled deck }}, \hat{C}_{p, \text { net,tiled deck }}\right)$ used in the following comparisons were obtained using the 3-minute experimental data and generating estimates for a 1-hr storm duration with 95\% quantiles (probabilities of non-exceedence $\mathrm{P}=0.95)$. 


\section{An Experimental Study on Wind Effects on Tiled Roof}

\subsection{Introduction}

Following the pressure validation study described in Section 4.5, WoW tests were performed to study the wind effects on tiled roofs. The effects of architectural details of high profile roof tiles on net pressures were investigated through full-scale and wind tunnel experimentation. Four different roof models (4:12 monoslope, 3:12 and 5:12 hip, 5:12 gable) with bare and tiled roof decks were tested at full-scale (6-fan WoW). Internal pressures in the cavity region between the tile and the underlayment and in the joint space between two overlapping tiles were measured to understand their effects on the net peak pressures. The estimated area-averaged peak pressure coefficients (e.g., $\hat{C}_{p, \text { external }}$, $\left.\hat{C}_{p, \text { cavity_internal }}, \hat{C}_{p, \text { net }}\right)$ obtained for bare and tiled roof decks were compared. Wind tunnel tests on a tiled roof deck model were conducted at RWDI atmospheric boundary layer wind tunnel (Miramar, Florida) to verify the effects of tiles' cavity internal pressure. Both the full-scale and the wind tunnel test results showed that the tiles' geometric configuration and the cavity internal pressures could significantly affect the tiled roof net peak pressures. Such effects were found to be dependent on the tile joint (joint between two overlapping tiles) orientation with respect to the wind angle of attack. Aerodynamic loading on low-rise buildings' roofs can thus be more accurately evaluated by considering the effects of the roofing components. 


\subsection{Effects of Tile Cavity Internal Pressure on Tiled Roof Net Peak Pressure}

The effects of tile cavity internal pressure on net peak pressures were investigated through the comparison of area-averaged external and net uplift peak pressure coefficients obtained for the tiled roof decks. To estimate the adequacy of fewer number of pressure taps for obtaining the area-averaged cavity internal pressure for each tile, the coefficient of variation (CV) of the mean and peak pressure coefficients obtained from individual cavity taps were determined. The CV values were low for all tiles examined (e.g., 5:12 gable roof location 3: for $\mathrm{AOA} 0^{\circ}, \mathrm{CV}=4.7 \mathrm{E}-04$ (for mean) and 2.5E-02 (for peak); for $\mathrm{AOA} 180^{\circ}, 1.9 \mathrm{E}-04$ (for mean) and $8.9 \mathrm{E}-03$ (for peak)). These low values showed that there were not any significant spatial gradients on the underside pressure of a tile. The spatial gradients on the underside pressure of roof pavers as reported by Bienkiewicz and Sun (1997) were dependent on the ratio of the space-between to spaceunderneath the pavers. Unlike the roof tiles studied in this paper, the roof paver systems had interconnected open spaces underneath and gaps between adjacent pavers. This could possibly explain the difference in spatial gradients on the underside pressure of a roof tile and a paver system. However, further study is needed to better quantify such differences.

Figure 4.1 shows the comparison of area-averaged external and net uplift peak pressure coefficients obtained for the tiled roof decks for 4:12 monoslope roof with tiled roof deck for two oblique wind angles of attack, $\mathrm{AOA}=30^{\circ}$ and $135^{\circ}$. The results show significant contribution of the cavity internal pressure on the net peak pressure. For AOA $=30^{\circ}$ all the tile joints (joints between overlapping tiles, see Fig. 4.8) had nearly windward orientation and faced the approaching wind and the tiles' cavity internal pressures were positive (e.g., for location 7, the peak and mean cavity internal pressure 
coefficients were $\hat{C}_{p, \text { cavity_internal }} \approx 2.2, \bar{C}_{p, \text { cavity_internal }} \approx 0.39$, respectively). Thus the cavity internal pressure on the underside of the tile was acting in the same direction as the external uplift pressure on the upper surface of the tile. This contributed to an increased (in magnitude) net uplift peak pressure on the tile (e.g., Figure 4.1a, location 7, $\hat{C}_{p, \text { net }} \approx-$ 1.8 versus $\hat{C}_{p \text { external }} \approx-0.6$ ). However, when the tile joints had leeward orientation and were sheltered from the approaching wind, such as for $\mathrm{AOA}=135^{\circ}$, the cavity internal pressures were negative (e.g., for location 7, the peak and mean cavity internal pressure coefficients were $\hat{C}_{p \text {,cavity_internal }} \approx-2.5, \bar{C}_{\text {, cavity_internal }} \approx-0.9$, respectively), acting in the opposite direction as the external uplift pressure on the upper surface. This contributed to a reduced (in magnitude) net uplift peak pressure (e.g., Figure 4.1b, location $4, \hat{C}_{p, \text { net }} \approx-1.1$ versus $\hat{C}_{p \text {,external }} \approx-2.3$ and location $7, \hat{C}_{p, \text { net }} \approx-2.0$ versus $\hat{C}_{p, \text { external }} \approx-3.2$ ). Figure 4.2 shows another two oblique wind angles of attack, AOA $=$ $15^{\circ}$ and $180^{\circ}$, for $4: 12$ monoslope roof with tiled roof deck to strengthen the above findings.
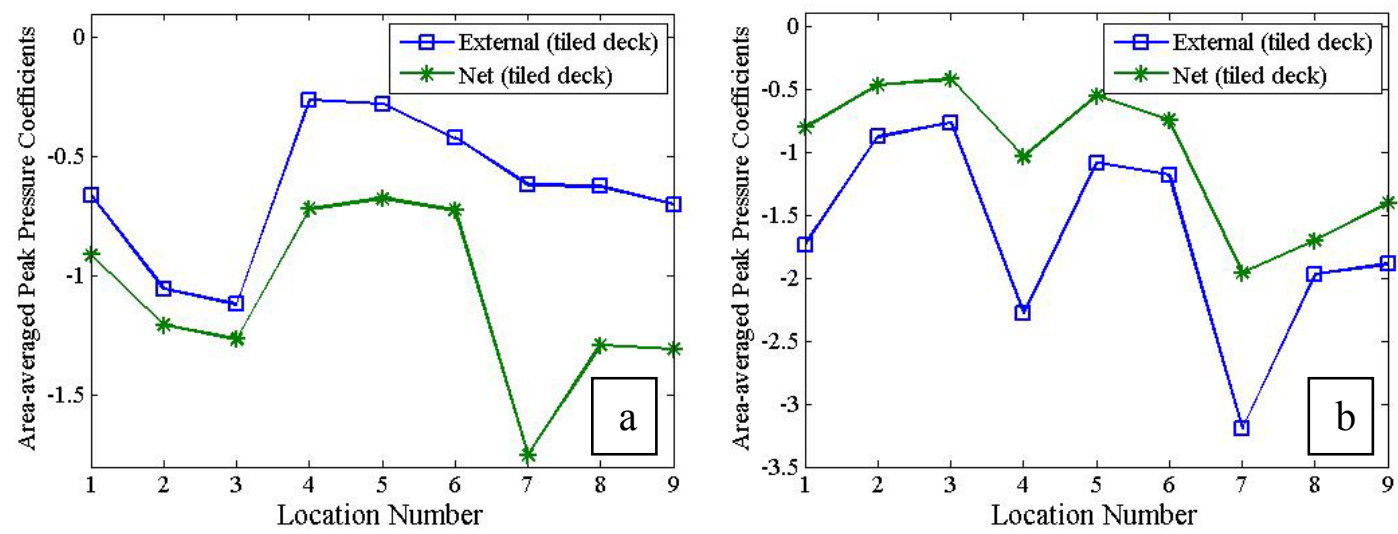

Figure 4.1: Comparison of Estimated Area-Averaged External and Net Peak Pressure Coefficients for 4:12 Monoslope Roof: (a) $\mathrm{AOA}=30^{\circ}$, (b) $\mathrm{AOA}=135^{\circ}$ 

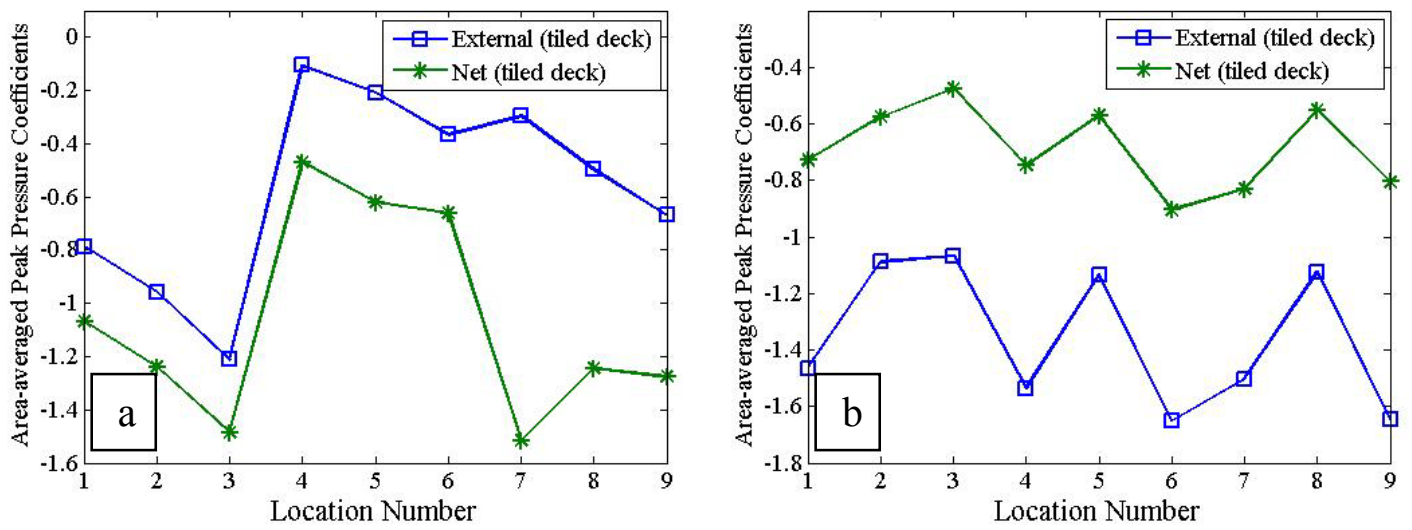

Figure 4.2: Comparison of Estimated Area-Averaged External and Net Peak Pressure Coefficients for 4:12 Monoslope Roof: (a) $\mathrm{AOA}=15^{\circ}$, (b) $\mathrm{AOA}=180^{\circ}$

Figure 4.3 shows the comparison of area-averaged external and net uplift peak pressure coefficients for the 3:12 and 5:12 hip tiled roofs for $\mathrm{AOA}=15^{\circ}$ (wind nearly normal to the windward eave). For both cases for the windward tiles (at locations 1, 2, 3, 4, and 5) the tile joints were oriented windward and the cavity internal pressure contributed to an increased net uplift peak pressure (e.g., Figure $4.3 \mathrm{a}$, location $2, \hat{C}_{p, n e t} \approx$ -2.2 versus $\hat{C}_{p \text {,external }} \approx-0.8$, Figure $5.3 \mathrm{~b}$, location $1, \hat{C}_{p, \text { net }} \approx-1.3$ versus $\hat{C}_{p \text {,external }} \approx-$ 0.3). However, for the leeward tiles (at locations 8 and 9) the tile joints were oriented leeward and the cavity internal pressure contributed to a reduced net uplift peak pressure (see Figs. 6.3a and 6.3b). In addition, for 3:12 hip roof ridge tile at location 7 the effect of internal pressure on net peak pressure was minimal. However, for 5:12 hip roof ridge tile at location 7 the cavity internal pressure effect was significant (Figure 4.3b, location 7 , $\hat{C}_{p, \text { net }} \approx-1.9$ versus $\hat{C}_{p, \text { external }} \approx-1.0$ ). Thus no definitive conclusions could be made for tiles on the top ridge of a roof and further research is needed. Figure 4.4 shows comparison of area-averaged external and net uplift peak pressure coefficients for the 3:12 and 5:12 hip tiled roofs for $\mathrm{AOA}=30^{\circ}$ to strengthen the above findings. 

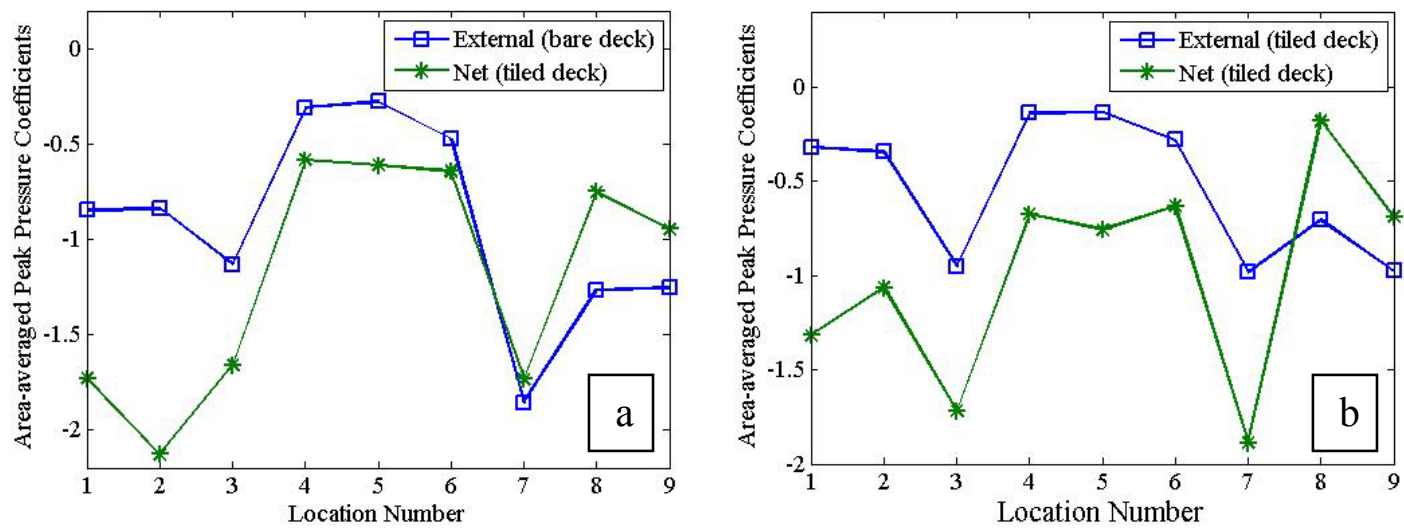

Figure 4.3: Comparison of Estimated Area-Averaged External and Net Peak Pressure Coefficients for $\mathrm{AOA}=15^{\circ}$ : (a) 3:12 Hip Roof, (b) 5:12 Hip Roof
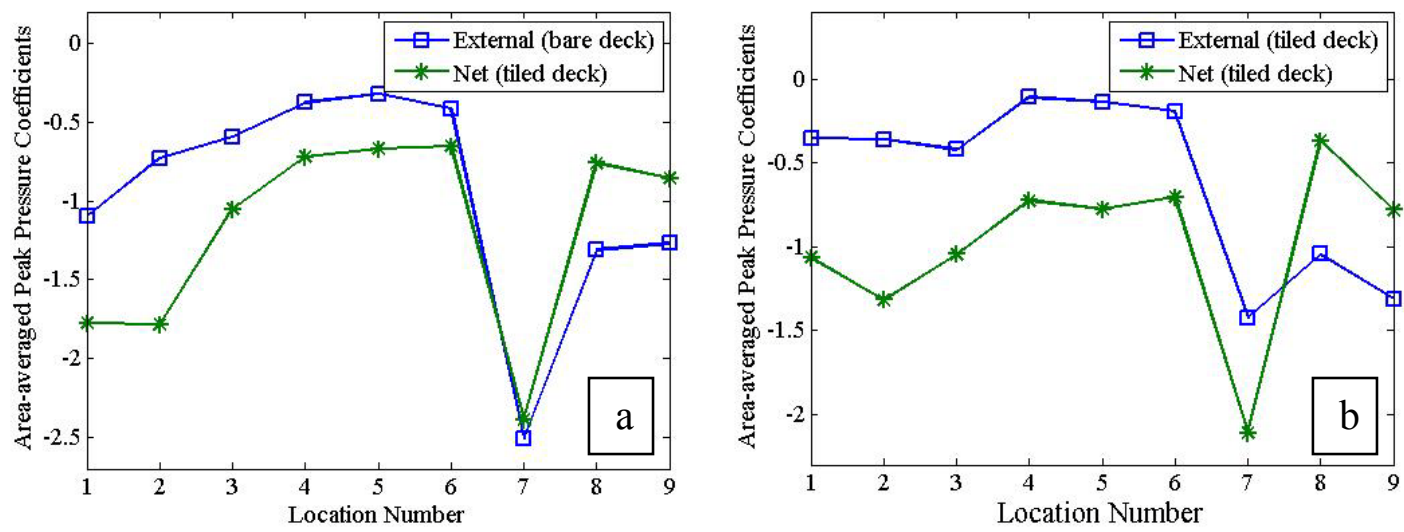

Figure 4.4: Comparison of Estimated Area-Averaged External and Net Peak Pressure Coefficients for $\mathrm{AOA}=30^{\circ}$ : (a) 3:12 Hip Roof, (b) 5:12 Hip Roof

Figure 4.5 shows the effect of cavity internal pressures on net peak pressures for 5:12 gable tiled roof for $\mathrm{AOA}=20^{\circ}$ (wind nearly normal to the windward eave) and $\mathrm{AOA}=180^{\circ}$ (wind normal to the windward eave). For some of the instrumented windward tiles for $\mathrm{AOA}=20^{\circ}$ the cavity internal pressure contributed to an increased net uplift peak pressure (e.g., Figure $4.5 \mathrm{a}$, locations 3 and $4, \hat{C}_{p, \text { net }} \approx-1.0$ versus $\hat{C}_{p, \text { net }} \approx-$ 0.1). However, for the leeward tiles (at locations 8 and 9) the cavity internal pressure contributed to a reduced net uplift peak pressure (see Fig. 6.5a). For the ridge tiles (at 
locations 6 and 7), the effects of cavity internal pressure were minimal. For $\mathrm{AOA}=180^{\circ}$, the cavity internal pressure contributed to an increased net uplift peak pressure for the windward tiles at locations 8 and 9 and a reduced net uplift peak pressure for the leeward tiles at locations 1, 2, 3, 4, and 5 (see Fig. 6.5b). For ridge tiles at locations 6 and 7 net uplift peak pressures were alleviated.
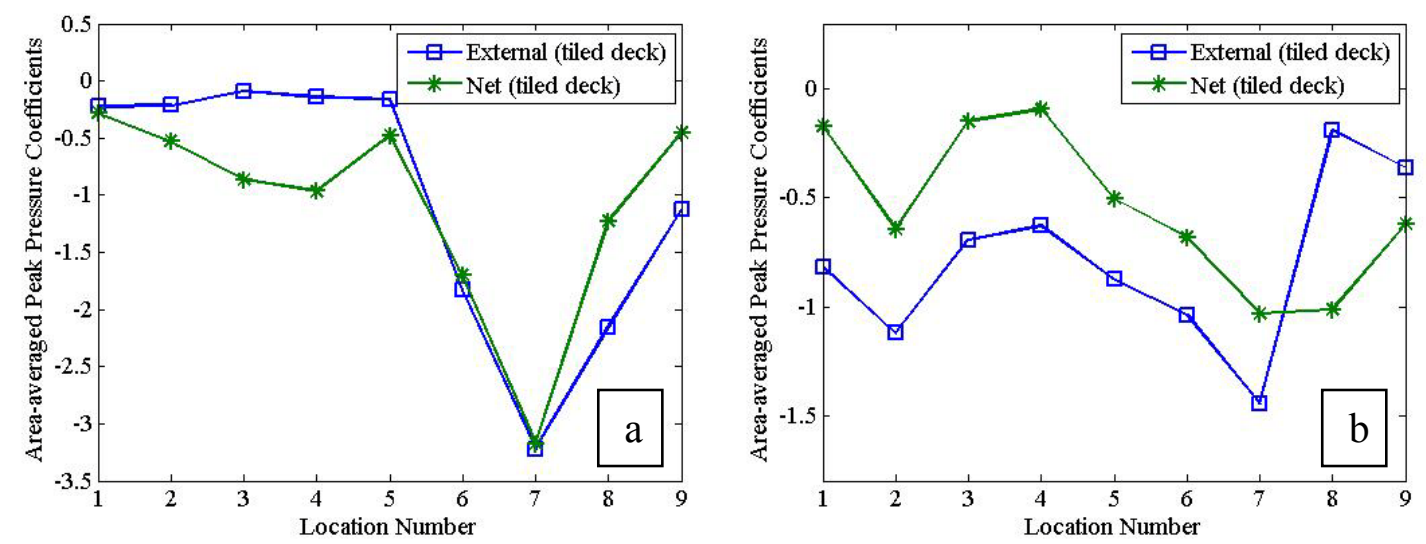

Figure 4.5: Comparison of Estimated Area-Averaged External and Net Peak Pressure Coefficients for 5:12 Gable Roof: (a) $\mathrm{AOA}=20^{\circ}$, (b) $\mathrm{AOA}=180^{\circ}$

Results for all the three different types of tiled roofs (monoslope, hip, and gable), for wind being oblique, nearly normal, and normal to the windward eave, showed that the estimation of realistic net aerodynamic uplift loading (often the cause of roof components failures during extreme wind events) on tiled roof needs careful modeling of the tile cavity internal pressure. The cavity internal pressure could contribute to an increased area-averaged net uplift peak pressure for tiles having windward oriented tile joints and reduced net pressure for tiles having leeward oriented tile joints. Thus tile cavity internal pressure could either aggravate or alleviate wind loading on a tile based on its orientation on the roof with respect to the wind angle of attack. Neglecting the effect of cavity internal pressure could lead to the underestimation of the net peak 
pressure by as much as $60 \%$. This finding is in agreement with the results presented by Kawai and Nishimura (2003) based on full-scale field measurements carried out at Shionomisaki Wind Effect Laboratory of Kyoto University on an experimental house with a hip roof (roof pitch: 4.5/10; house dimensions: $4.1 \mathrm{~m}$ long x $3.1 \mathrm{~m}$ wide $\mathrm{x} 2.8 \mathrm{~m}$ height).

\subsection{Effects of Tile Geometry on Tiled Roof Peak Pressures}

The effects of the geometry of roof tiles on area-averaged net uplift peak pressures were studied through the comparisons of peak pressure coefficients for bare and tiled decks. Figure 4.6 shows the comparison of external area-averaged uplift peak pressure coefficients for 4:12 monoslope bare and tiled roof decks for $\mathrm{AOA}=0^{\circ}$. The figure also shows the net area-averaged uplift peak pressure coefficients for the tiled deck case. The external area-averaged uplift peak pressure on a high profile tile surface could be larger than that for a flat surface as modeled by the bare deck (e.g., Figure 4.6, locations 2 and $3, \hat{C}_{p, \text { external,tiled deck }} \approx-1.0$ versus $\left.\hat{C}_{p, \text { external,bare deck }} \approx-0.6\right)$. Such findings support the conclusion presented in Huang et al. (2009a) that surface geometry of the high profile tiles can generate higher peak pressures as compared to those for flatter roofing components owing to the effect of component geometric profile on the local flow pattern. The finding also supported the conclusion made by Kawai and Nishimura (2003) and Morisaki et al. (1994) that external pressure on a tile was strongly influenced by local flow pattern over the tile surface. Also, the net uplift peak pressure on a tiled roof deck model could be significantly larger than that for a bare 
roof deck model (e.g., Figure 4.6, locations 7 and $8, \hat{C}_{p, \text { net,tiled deck }} \approx-1.3$ versus $\hat{C}_{\text {p,external,bare deck }} \approx-0.3$ ).

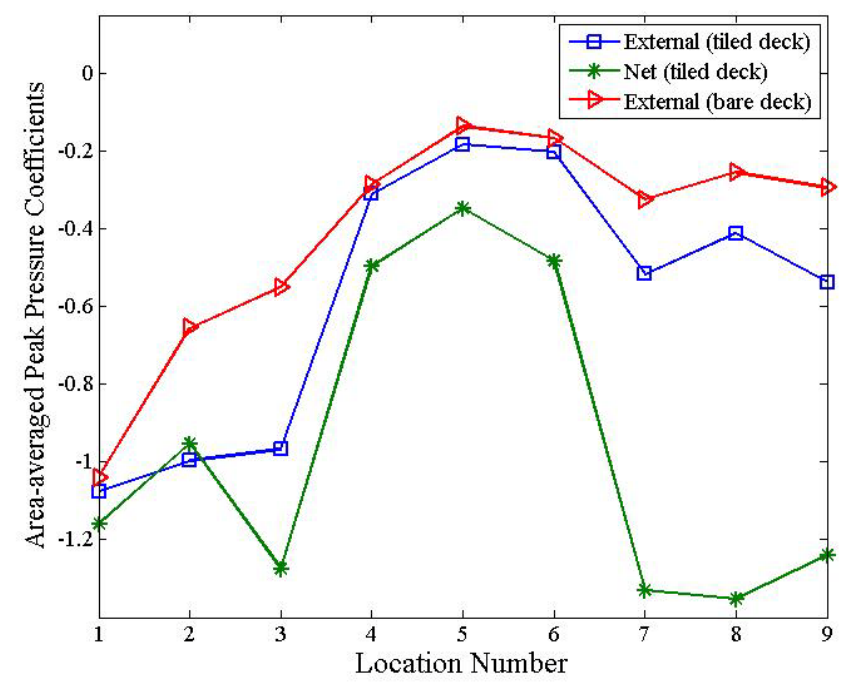

Figure 4.6: Comparison of Estimated Area-Averaged External and Net Peak Pressure Coefficients for 4:12 Monoslope Roof for $\mathrm{AOA}=0^{\circ}$

Figure 4.7 shows the comparison of external area-averaged uplift peak pressure coefficients for 3:12 hip bare and tiled roof decks for $\mathrm{AOA}=90^{\circ}$ (wind parallel to the ridge). The figure also shows the net area-averaged uplift peak pressure coefficients for the tiled deck case. The results show that the external peak pressure on a high profile tile surface could be larger than that for the bare deck (e.g., Figure 5.7, location 3, $\hat{C}_{p, \text { external,tiled deck }} \approx-1.5$ versus $\left.\hat{C}_{p, \text { external,bare deck }} \approx-0.9\right)$. Also, the net uplift peak pressure on a tiled deck model could be larger than that for a bare deck model (e.g., Figure 4.7 , location $3, \hat{C}_{p, \text { net,tiled deck }} \approx-1.6$ versus $\hat{C}_{p \text {,external,bare deck }} \approx-0.9$, location $7, \hat{C}_{p, \text { net,tiled deck }} \approx-1.2$ versus $\hat{C}_{p, \text { external,bare deck }} \approx-0.6$ ). 


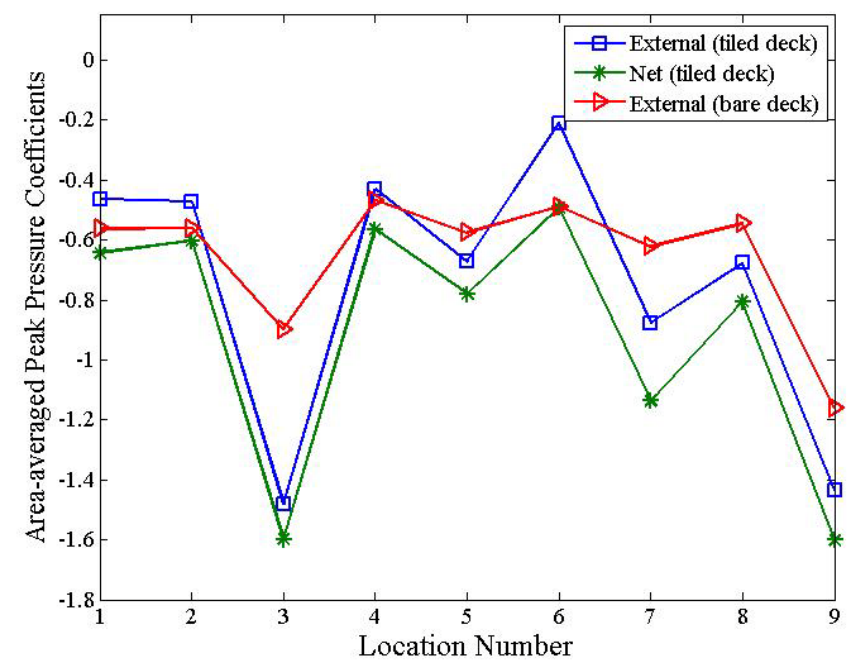

Figure 4.7: Comparison of Estimated Area-Averaged External and Net Peak Pressure Coefficients for 3:12 Hip Roof for $\mathrm{AOA}=90^{\circ}$

Through the comparisons of peak pressure coefficients obtained on bare and tiled roof decks, it was demonstrated that the geometric features of roofing components could significantly affect the net peak pressure coefficients. In addition to the effect of the cavity internal pressure (see Sect. 5.2), the effect of the external geometry of the roofing components on net peak pressure could be significant. In some cases the peak pressures obtained on bare roof deck models could underestimate the peak pressures acting on roof tiles by as much as $50 \%$. This indicates the importance of careful consideration of roofing components modeling, as opposed to simplified (bare surface) modeling in traditional experiments, for realistic estimation of wind loading on roofs.

\subsection{Cavity Internal Pressure versus Building Internal Pressure}

Limited research has been performed to study the batten space internal pressure (e.g., pressure in the space between the roof sheathing and roof covering Robertson and Hoxey (2007).In absence of test-based data, some researchers and loss estimation 
modelers use roof external pressure coefficients given in code provisions and assume zero internal pressure while estimating wind loading on roof coverings. As an example, the Florida Public Hurricane Loss Model (FPHLM) ignores the cavity internal pressure effects and assumes zero internal pressure in the simulation of vulnerability curves for roof covering (FPHLM, 2005, Volume II, pg. 55). The hypothesis being that for properly sealed ceilings there may not be any degree of equalization between the building internal pressure (as estimated by internal pressure coefficients given in code provisions, such as in ASCE 7-05) and the batten space internal pressure.

As described in Section 4.1, the background leakage of the particular test specimen built (indicated by $14.3 \mathrm{ACH}_{50}$ ) for this study was relatively high as compared to that for average single family residential homes $\left(\sim 5.2 \mathrm{ACH}_{50}\right)$. To test the above mentioned hypothesis, the tiles' cavity internal pressure and the internal pressure inside the building were measured simultaneously using two different models with tiled roof decks, including a gable roof (5:12 slope) and a hip roof (5:12 slope). The goal was to assess whether there could be any degree of pressure equalization between the attic space underneath the roof deck and tiles' cavity space. If the hypothesis is proven to be correct for the test specimen with higher leakage, then it should be also valid for average single family residential homes that are more airtight.

Two building enclosure classifications were simulated for experimentation enclosed and partially enclosed building conditions (ASCE 7-05 2006). The tests were conducted for $\mathrm{AOA}=0^{\circ}$ with and without dominant windward openings to simulate the partially enclosed and enclosed building conditions, respectively. The internal pressure inside the building model (estimated by averaging the data from the two internal pressure 
taps inside building model) was compared to the tiles' cavity pressures. Figure 4.8 shows such comparative results for the 5:12 gable roof deck model. The results showed that the internal pressure within the building for both enclosed and partially enclosed building conditions was significantly different than the tiles' cavity internal pressures for most locations. Thus the building internal pressure coefficients specified in the code provisions may not be used for estimating net wind uplift on roof tiles and this finding should be applicable for average single family residential homes. Further research is needed to include cavity (or batten space) internal pressure coefficients in the wind provisions to facilitate realistic estimation of wind loading on various roofing components.
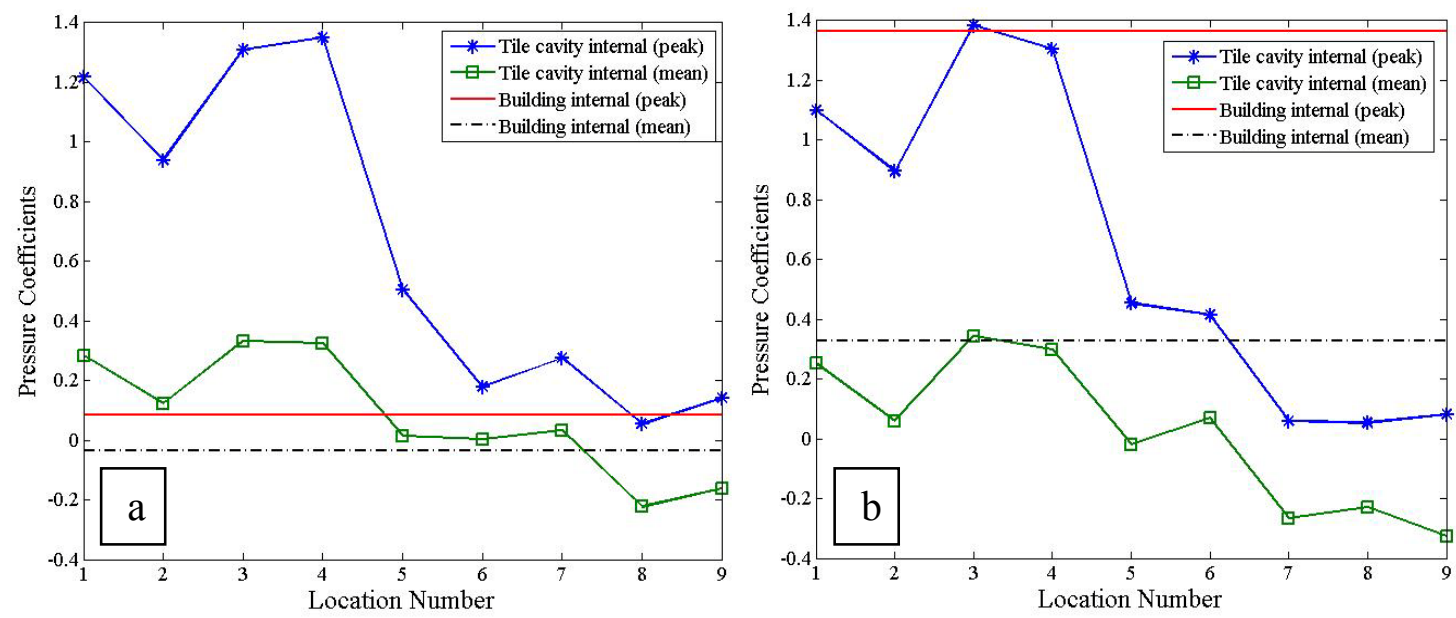

Figure 4.8: Comparison of Building Internal Pressure and Tiles' Cavity Internal Pressure Coefficients for 5:12 Gable Roof Model for AOA $=0^{\circ}$ : (a) Enclosed Building Condition, (b) Partially Enclosed Building Condition

\subsection{Wind Tunnel Testing Setup and Results}

In order to verify the effects of tiles' cavity internal pressure on net peak pressures, a selected set of testing was conducted at RWDI atmospheric boundary layer wind tunnel (Miramar, Florida). The test section dimension of the wind tunnel was 2.44 
$\mathrm{m}$ high by $1.98 \mathrm{~m}$ wide. Testing was performed for a typical residential building with a hip roof (3:12 slope). The equivalent full-scale dimensions of the building were: $18.3 \mathrm{~m}$ (60ft) length $\times 9.2 \mathrm{~m}(30 \mathrm{ft})$ width $\times 5.1 \mathrm{~m}(16.7 \mathrm{ft})$ roof ridge height. The 1:15 scale model's roof was built using especially molded plastic roof covering (see Fig. 6.9) laid over Plexiglas panel roof deck to replicate high profile roof tiles and cavity zones underneath the roof covering. The wind tunnel blockage was about $8.5 \%$ (close to the maximum blockage of $8 \%$ given in ASCE 7-05 2006). Selected tiles were instrumented for measuring tile surface external and tile cavity internal pressure using multichannel Scanivalve pressure scanner. A typical open terrain profile was generated with $\bar{\alpha}=1 / 6.5$ and a turbulence intensity of about $20 \%$ at the mean roof height. The atmospheric boundary layer and turbulence profiles used for the wind tunnel testing are shown in Fig. 6.10. It is to be noted that the building dimensions and the target terrain profile for the wind tunnel testing were different from those for the full-scale testing. However, the purpose of the wind tunnel study was not to quantify (or compare with the full-scale data) roof pressure coefficients on tiles but to study the phenomenon pertaining to the effects of the tiles' cavity internal pressures on net peak pressures as was observed from the fullscale results. The Reynolds numbers for wind tunnel testing was approximately $2.24 \times 10^{5}$ (as compared to $3.2 \times 10^{6}$ for WoW testing). 


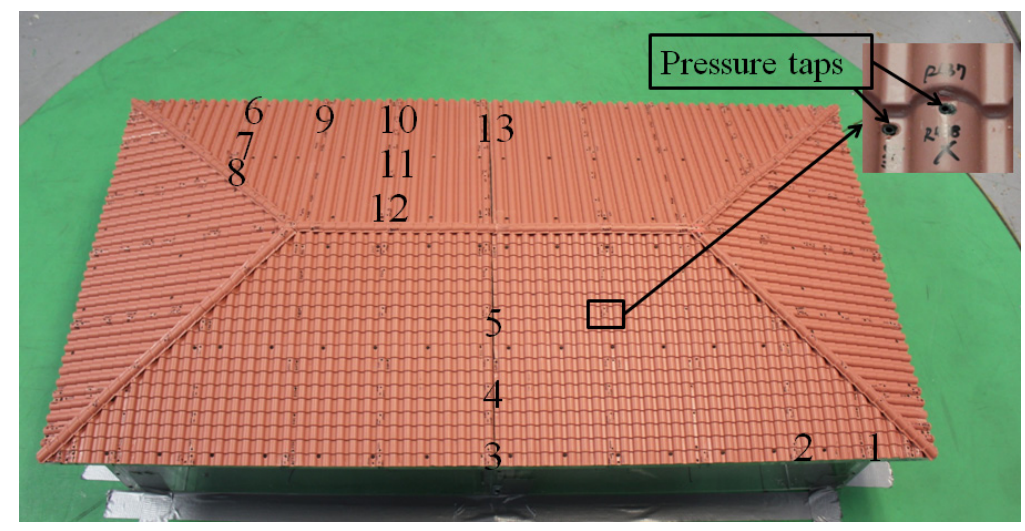

Figure 4.3: Top View of Wind Tunnel Testing Model for 3:12 Hip Tiled Roof Deck

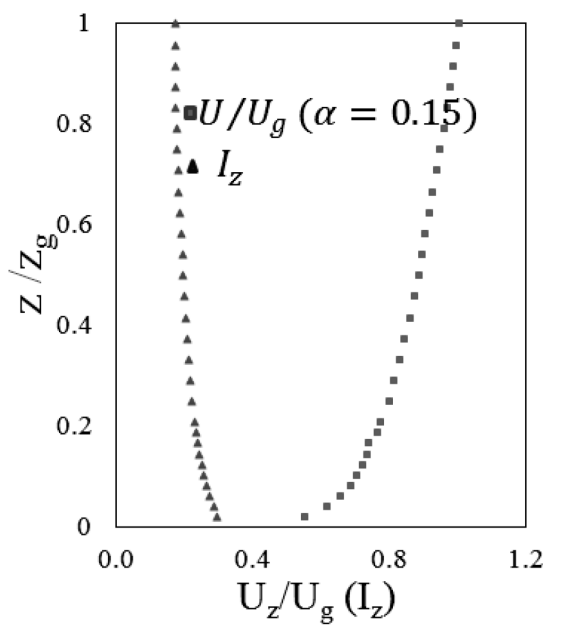

Figure 4.4: Mean Wind Speed and Turbulence Intensity Profiles for RWDI Wind Tunnel

Thirteen tiles located at the windward and leeward part of the roof were instrumented (see Fig. 6.9 for locations). Due to size limitation, each tile had one or two external taps to measure the exterior surface pressure and one internal tap to measure the tile cavity internal pressure. The model was tested for $\mathrm{AOA}=0^{\circ}, 10^{\circ}, 20^{\circ}$, and $30^{\circ}$ to study such effect for the wind being normal to slightly oblique to the windward eave. The external, cavity internal, and net peak pressure coefficients were obtained from the pressure time histories using similar procedures used for analyzing the Wall of Wind test data. It is to be noted that using one or two external taps per tile precluded the estimation 
of area-averaged peak pressure over the tile surface as was possible for the full-scale tiles for which area-averaging resulted in reduction of the external pressure on a tile. Figure 4.11 shows the comparison of the estimated uplift peak (external and net) pressure coefficients obtained for the 3:12 hip roof with tiled roof deck for $\mathrm{AOA}=0^{\circ}$ and $10^{\circ}$. It was noted that for most of the windward tiles (at locations 1 to 5) the cavity internal pressure contributed to an increased net uplift peak pressure (e.g., Figure 4.11b, location 2, $\hat{C}_{p, n e t} \approx-3.8$ versus $\hat{C}_{p, e x t e r n a l} \approx-2.9$ ). However, for the leeward tiles (at locations 6 to 13) the cavity internal pressure contributed to a reduced net uplift peak pressure (see Figs. 6.11a and 6.11b). Similar findings were obtained for the other two wind angles of attack. The wind tunnel results were in agreement with the conclusion made from the full-scale experimentation results that the cavity internal pressure could contribute to an increased or reduced net uplift peak pressure based on the tiles' orientation with respect to the wind angle of attack. The limited wind tunnel tests provided only a preliminary validation of the findings from full-scale experimentation and more extensive wind tunnel testing will be performed on tiled roof models in the future to facilitate a more comprehensive comparison. 

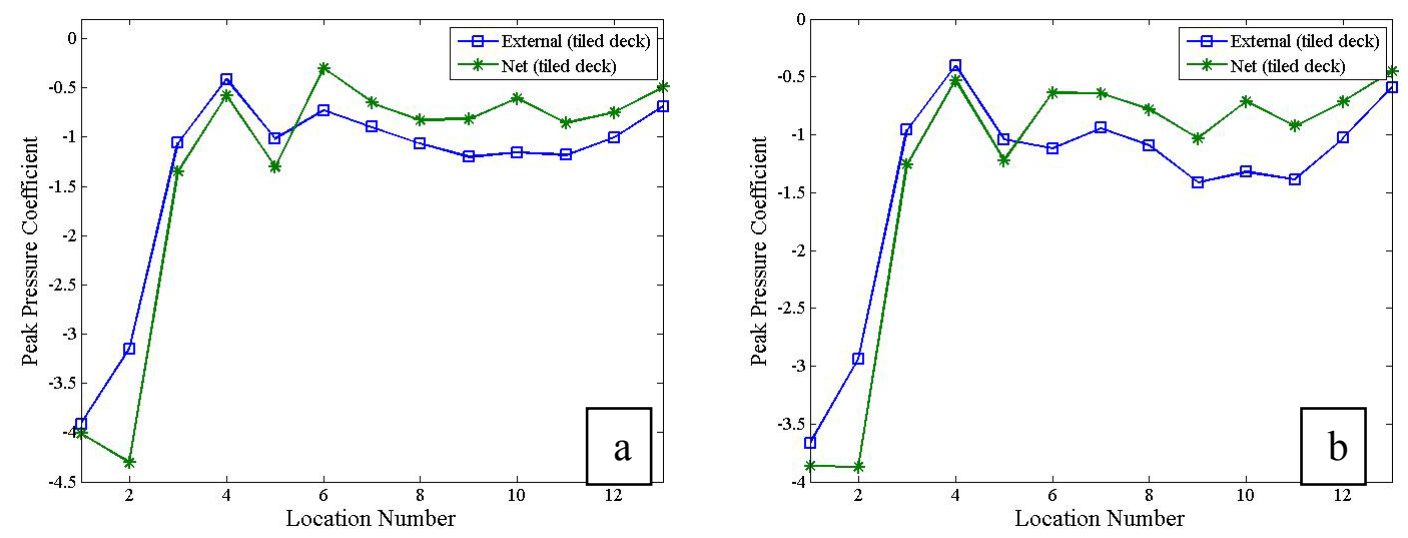

Figure 4.5: Comparison of Estimated External and Net Peak Pressure Coefficients for 3:12 Hip Tiled Roof Model (Wind Tunnel Testing) for: (a) $\mathrm{AOA}=0^{\circ}$, (b) $\mathrm{AOA}=10^{\circ}$.

\subsection{Conclusions}

The experimental results conducted on roof deck models simulating high profile roof tiles showed that the geometric configuration of the roofing materials and the tiles' cavity internal pressures could affect the net peak pressures. Estimation of and designing for these peak pressures is important for reducing tiled roof damage in hurricanes. The tiles' cavity internal pressure was dependent on the tile joint (joint between two overlapping tiles) orientation with respect to the wind angle of attack. For wind being oblique, nearly normal, and normal to the windward eave, the cavity internal pressure contributed to: (i) an increased net uplift peak pressure when the tile joints had windward orientation, (ii) a reduced net uplift peak pressure when the tile joints had leeward orientation. Thus tile cavity internal pressure could either aggravate or alleviate wind loading on a tile based on its orientation on the roof with respect to the wind angle of attack. Neglecting the effect of cavity internal pressure could lead to the underestimation of the net peak pressure by as much as $60 \%$. 
The surface geometry of the high profile tiles could generate higher peak pressures as compared to those for a bare deck owing to the effect of component geometry profile on the local flow pattern. In some cases the peak pressures obtained on bare roof deck models could underestimate the peak pressures acting on roof tiles by as much as $50 \%$. It was also shown that without the presence of high background leakage (for properly sealed ceilings) the internal pressure within the building could be significantly different than the tiles' cavity internal pressures. Thus the internal pressure coefficients specified in the code provisions are not applicable for estimating net wind uplift on roof tiles. Further research is needed to include cavity (or batten space) internal pressure coefficients in the wind provisions to facilitate realistic estimation of wind loading on various roofing components.

In summary, the effects of the tiles' cavity internal pressure and tiles' surface external pressure could result in net uplift peak pressure on a tiled deck being much larger than that for a bare deck. This indicates that aerodynamic testing to estimate realistic roof pressures for low-rise buildings entails careful modeling of the roofing components (such as roof tiles for tiled roofs) as opposed to simplified modeling replicating only the overall geometry but not simulating the finer architectural details of the components.

This research is not intended to suggest tiled roof pressure coefficients for wind load provisions but is a preliminary effort to show how modeling of roofing components could play an important role in wind tunnel or full-scale testing based estimation of wind loading on roofs. The current research was limited to pressure measurements to evaluate the differences between pressure coefficients on bare and tiled roofs. Detailed local flow 
field measurements are needed to determine whether such differences apply to both separated flow near the roof edge or in the field of the roof where there is attached flow. This important aspect will be studied in the future when hot-film anemometry and requisite flow visualization capability will become available at the WoW facility. Such study will help show how the local flow field around a tile induces the uplift.

More detailed research is needed in the future to develop an extensive database on the effects of various roofing components (e.g., tiles and shingles) on roof peak pressures. Such estimation can improve the aerodynamic load provisions for low-rise building roofs by considering the effects of the roofing components which are often damaged during extreme wind events. 


\section{An Experimental Study on Wind Effects on Shingled Roofs}

\subsection{Introduction}

As described the effects of architectural features of roof tile on roof peak pressures in previous chapter, this chapter focused on the effects of architectural features of roof shingle on roof peak pressures. Full-scale experimentation was conducted under high winds to investigate the effects of architectural details of asphalt shingles on net pressures that are often responsible for damage to these roofing materials. Different roof models with shingled roof decks were tested. Pressures acting on both top and bottom surfaces of the roof shingles were measured to understand their effects on the net uplift loading. The area-averaged peak pressure coefficients obtained from shingled roof decks were compared with the results obtained from bare and tiled roof decks. For shingles, the underside pressure could aggravate wind uplift if the shingle is located near the center of the roof deck. In addition, the shingle bottom surface pressure also compared to the building internal pressure to check if the building internal pressure specified in ASCE 7 is applicable to estimate the shingle bottom surface pressure. Also, the effect of overhang dimension to the wind uplift pressure was also studied by testing two different overhang dimensions.

\subsection{Effects of Shingle Bottom Surface Pressure}

Air-permeable roofing materials allow partial air pressure equalization between the exterior (top) and interior (bottom) surfaces of the materials. Such effects for tiles and shingles were investigated based on the results of the WoW tests. Comparison of area- 
averaged top surface and net uplift peak pressure coefficients showed the effects of bottom surface pressure in terms of either alleviating wind uplift (through partial airpressure equalization) or aggravating wind uplift.

Figure 5.1 shows results for 3:12 hip shingled roof deck for $\mathrm{AOA}=75^{\circ}$ and $90^{\circ}$ and 4:12 monoslope shingled roof deck for $\mathrm{AOA}=0^{\circ}$ and $15^{\circ}$. For shingles near the center of the roof decks, the bottom surface pressures were positive (e.g., for location 6 of the hip at $\mathrm{AOA}=90^{\circ}$, and location 5 of the monoslope roofs at $\mathrm{AOA}=0^{\circ}$ $\hat{C}_{p, \text { bottom,shingled deck }} \approx 0.96$ and 0.85 , respectively, and $\bar{C}_{p, \text { bottom,shingled deck }} \approx 0.05$ and 0.17 , respectively). Thus for normal (or nearly normal) winds, the pressures on the top and bottom surfaces both acted to lift the shingles located near the center of the roofs. This contributed to an increased (in magnitude) net uplift peak pressure on the shingles (e.g., Figure $5.1 \mathrm{~b}$, location $6, \hat{C}_{p, \text { net,shingled deck }} \approx-0.7$ versus $\hat{C}_{p, \text { top,shingled deck }} \approx-0.4$ ). This phenomenon of increased wind uplift on shingles near the center of the roofs was observed for $\mathrm{AOA}= \pm 15^{\circ}$. This finding is in agreement with the results of pressure measurements on upper and lower surfaces of several shingles located near the center of a shingled deck tested in a wind tunnel (Peterka et al. 1997). However, for windward shingles located in other regions of the roof (locations 1 and 2 in Fig. 5.1c and 5.1d) and for leeward shingles (all locations except 6 in Fig. 5.1a and 5.1b), there was partial airpressure equalization that contributed to a reduced (in magnitude) net uplift peak pressure. 

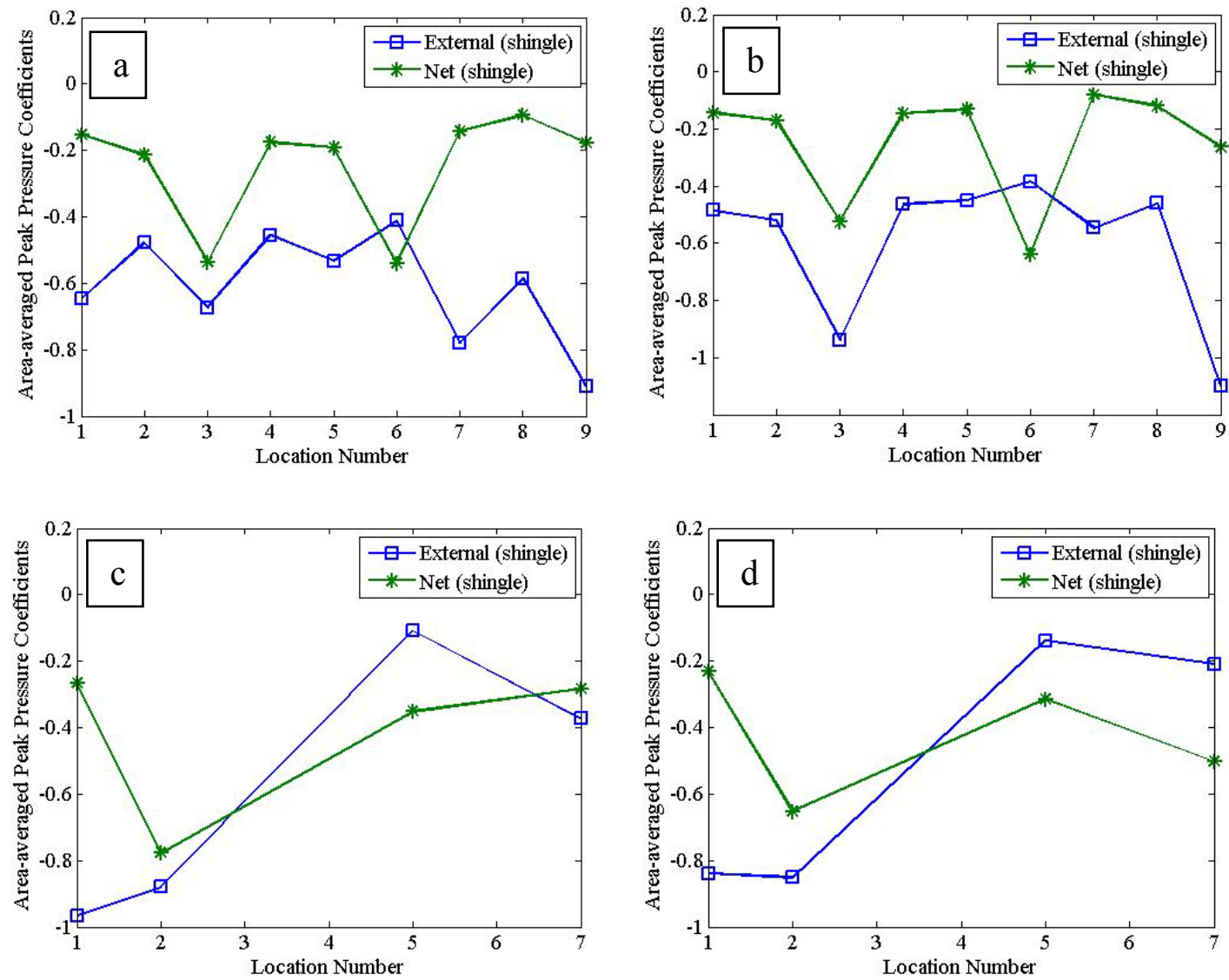

Figure 5.1: Comparison of Estimated Area-Averaged Net Peak Pressure Coefficients for Shingled roof decks: (a) 3:12 Hip Roof, $\mathrm{AOA}=75^{\circ}$, (b) 3:12 Hip Roof, $\mathrm{AOA}=90^{\circ}$, (c) 4:12 Monoslope Roof, $\mathrm{AOA}=0^{\circ}$, (d) 4:12 Monoslope Roof, $\mathrm{AOA}=15^{\circ}$

\subsection{Effects of Geometry of Roofing Materials on Roof Peak Pressures}

The full-scale experimentation results were also used to evaluate the effects of the architectural features of air-permeable roofing materials on pressures to ascertain the importance of modeling their geometric details for wind load estimation. To accomplish this objective, the area-averaged net uplift pressures on the tiled and shingled roof decks were compared to the area-averaged uplift pressures on bare roof decks (analogous to simplified models) that did not consider the effects of roofing materials. 
Figure 5.2 shows the comparison of area-averaged uplift peak pressure coefficients for $4: 12$ monoslope for $\mathrm{AOA}=0^{\circ}, 15^{\circ}, 30^{\circ}$ and $45^{\circ}$ and Figure 5.3 shows the comparison of area-averaged uplift peak pressure coefficients for 3:12 hip for AOA = $45^{\circ}, 60^{\circ}, 75^{\circ}$ and $90^{\circ}$ on bare, tiled, and shingled roof decks. It is to be noted that the net uplift peak pressure coefficients obtained for most locations on the tiled roof decks were significantly larger than those for the corresponding bare roof decks (e.g., Figure 5.2a, location $7, \hat{C}_{p, \text { net,tiled deck }} \approx-1.3$ versus $\hat{C}_{p \text {,external,bare deck }} \approx-0.3$, Figure $5.3 \mathrm{~d}$, location $3, \hat{C}_{p, \text { net,tiled deck }} \approx-1.6$ versus $\left.\hat{C}_{p, \text { external,bare deck }} \approx-0.9\right)$. Thus bare deck modeling can result in significant underestimation of estimating wind uplift loading on tiled roofs. On the other hand, the net uplift peak pressure coefficients obtained for most locations on the shingled roof decks were somewhat lower than those for the corresponding bare roof decks. However, the wind uplift for the windward shingles near the center of the roof decks (location 5 for 4:12 monoslope roof and location 6 for 3:12 hip roof) were marginally larger than those for the same locations on the corresponding bare roof decks. Thus for design purposes, bare deck modeling mostly applicable for estimating wind uplift loading on shingled decks other than for those windward shingles near the center of the decks. 

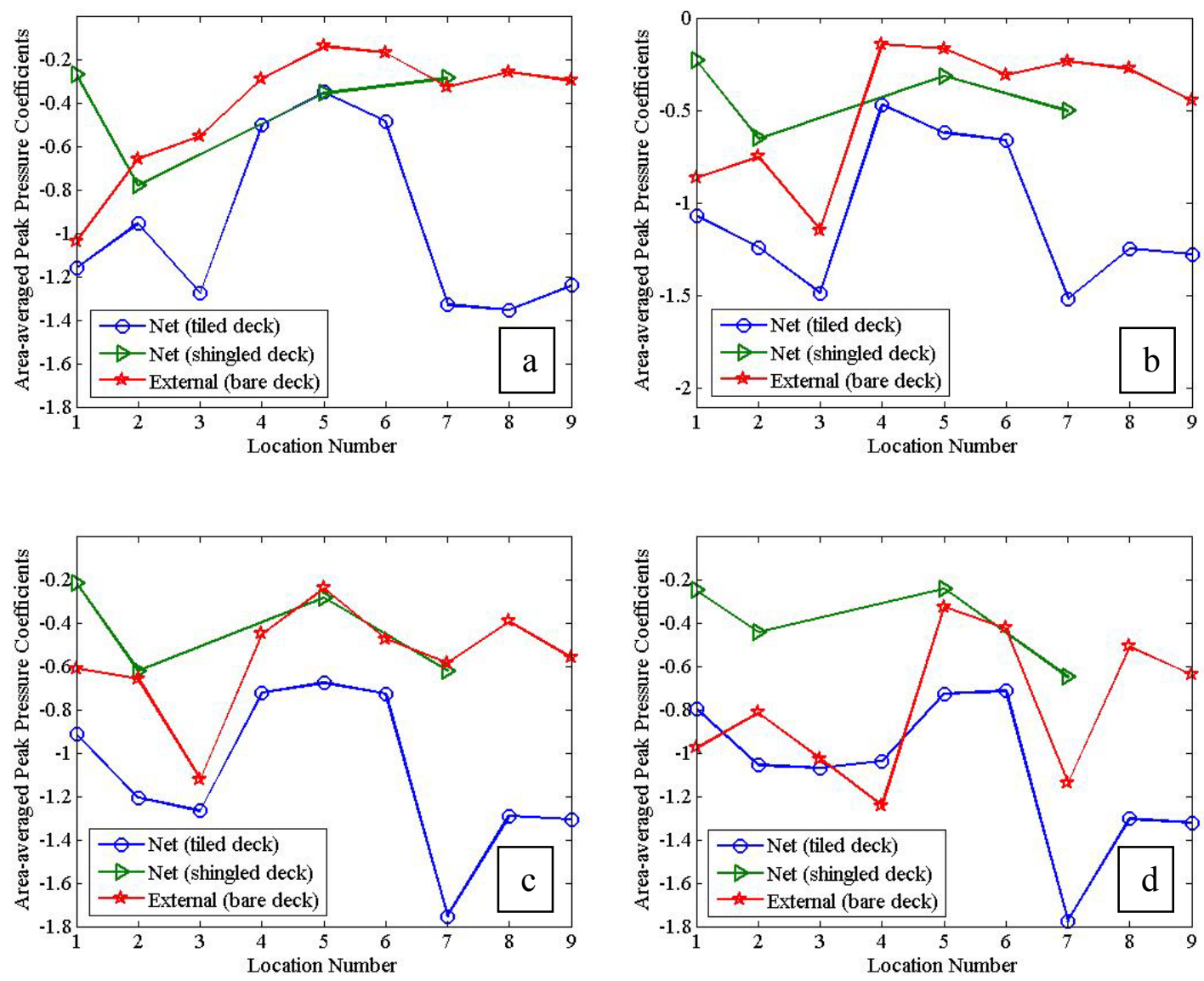

Figure 5.2: Comparison of Estimated Area-Averaged Net Peak Pressure Coefficients for 4:12 Monoslope Roof: (a) $\mathrm{AOA}=0^{\circ}$, (b) $\mathrm{AOA}=15^{\circ}$, (c) $\mathrm{AOA}=30^{\circ}$, (d) $\mathrm{AOA}=45^{\circ}$
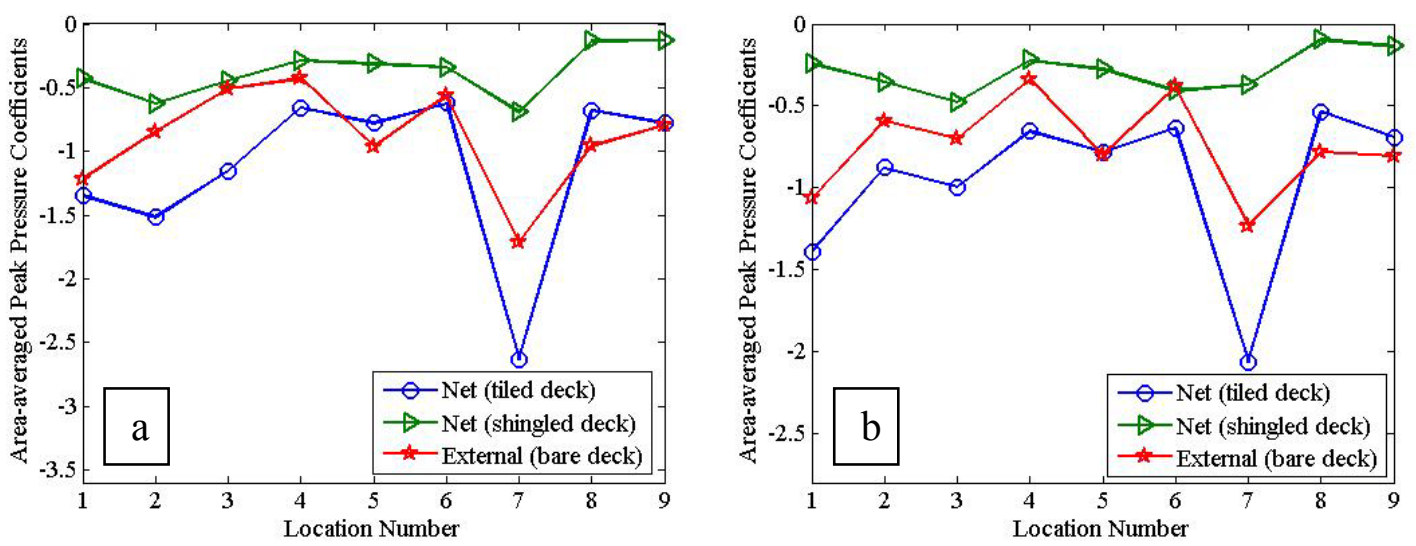

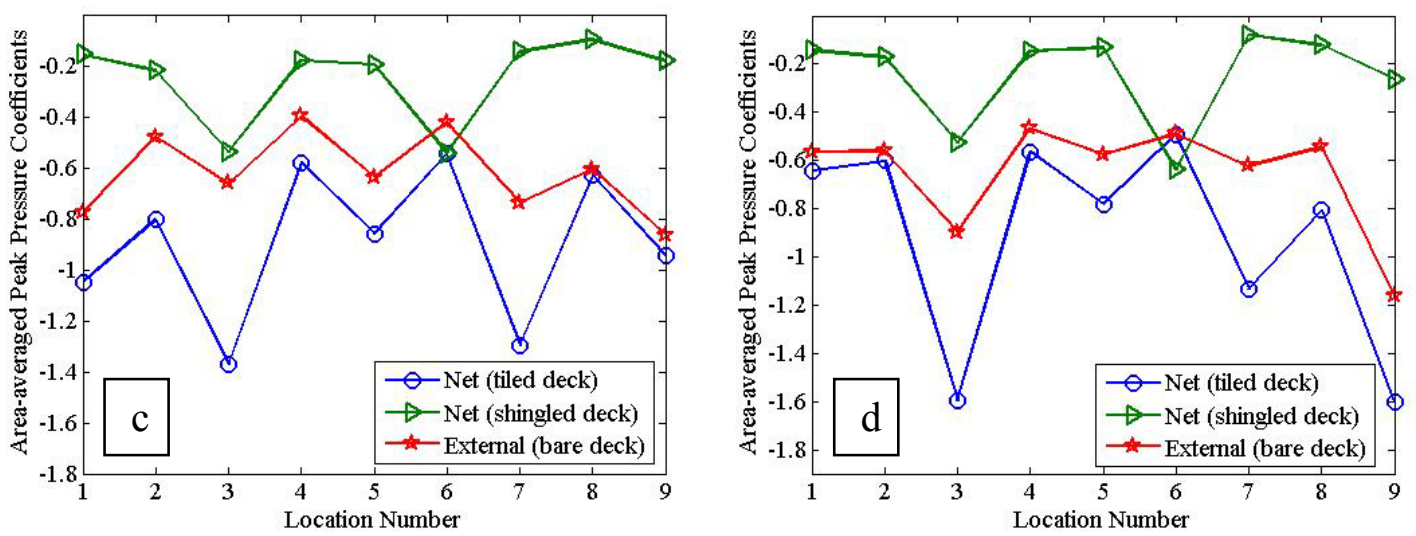

Figure 5.3: Comparison of Estimated Area-Averaged Net Peak Pressure Coefficients for 3:12 Hip Roof: (a) $\mathrm{AOA}=45^{\circ}$, (b) $\mathrm{AOA}=60^{\circ}$, (c) $\mathrm{AOA}=75^{\circ}$, (d) $\mathrm{AOA}=90^{\circ}$

Through the analysis of effects of the geometry of roof shingles on the wind uplift peak pressures, it was demonstrated that the geometry of roof shingle could significantly affect the load acting on the roofs. For shingled deck, top and bottom surface pressures can act in the same direction and aggravate the wind uplift loading for windward shingles located near the center of the roof deck. For windward shingles located away from the center region (field zone) and for all leeward shingles, partial air-pressure equalization alleviates the wind uplift loading.

\subsection{Bottom Surface Pressure versus Building Internal Pressure}

As described in Section 4.4, the tiles' cavity internal pressures were studied to evaluate if the building internal pressure specified in ASCE 7 (2006) is applicable to the cavity internal pressure. In this section, the similar study was also performed by comparing the shingle bottom surface pressure to the building internal pressure. To test the above mentioned hypothesis, the shingle bottom surface pressure and the internal pressure inside the building were measured simultaneously using two 4:12 monoslope 
roof (4:12 slope) model with shingled roof deck. Two building enclosure classifications were simulated for experimentation - enclosed and partially enclosed building conditions (ASCE 7 2006). The tests were conducted for $\mathrm{AOA}=0^{\circ}$ with and without dominant windward openings to simulate the partially enclosed and enclosed building conditions, respectively. The internal pressure inside the building model (estimated by averaging the data from the two internal pressure taps inside building model) was compared to the shingle bottom surface pressures. Figure 5.8 shows such comparative results for the $4: 12$ monoslope roof deck model. The results showed that the internal pressure within the building for both enclosed and partially enclosed building conditions was significantly different than the shingle bottom surface pressures for most locations. Thus the building internal pressure coefficients specified in the code provisions may not be used for estimating net wind uplift on roof tiles and this finding should be applicable for average single family residential homes. Further research is needed to include shingle bottom surface pressure coefficients in the wind provisions to facilitate realistic estimation of wind loading on various roofing components.
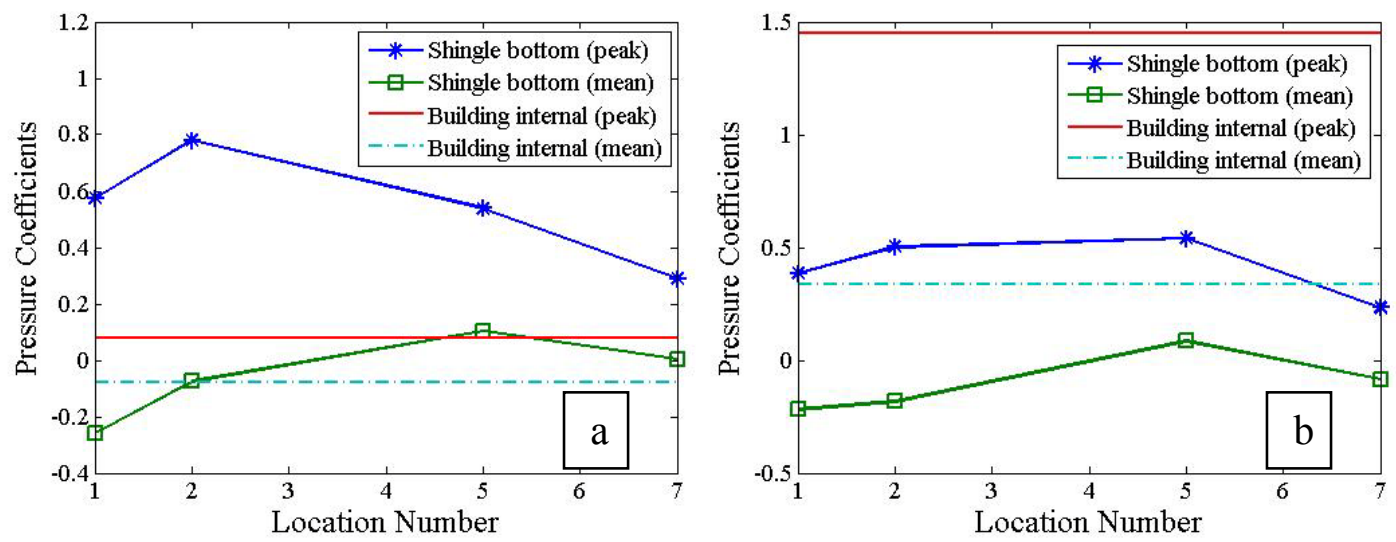

Figure 5.4: Comparison of Building Internal Pressure and Tiles' Cavity Internal Pressure Coefficients for 4:12 Monoslope Roof Model for AOA $=0^{\circ}$ : (a) Enclosed Building Condition, (b) Partially Enclosed Building Condition 


\subsection{Effects of Overhang Dimensions on Roof Peak Pressures}

The effects of overhang dimension on roof area-averaged peak pressure coefficients were investigated through the experimentation on 3:12 hip shingled roof deck with two different overhang dimensions, including $0.457 \mathrm{~m}$ (18 inches) and $0.152 \mathrm{~m}$ (6 inches). Five angles of attack were tested, including $30^{\circ}, 45^{\circ}, 60^{\circ}, 75^{\circ}$ and $90^{\circ}$. Nine different locations located at the edge, corner, ridge and middle of the roof. Each location was instrumented twelve external pressure taps with three internal pressure taps. The Instantaneous external and net area-averaged peak pressure coefficients were compared. Figures 5.5 shows the comparison between the external and net area-averaged peak pressure coefficients obtained from two different overhang dimensions for $30^{\circ}, 45^{\circ}, 75^{\circ}$, $90^{\circ}$. It was noticed that the external and net area-averaged peak pressure coefficients obtained from $0.152 \mathrm{~m}$ overhang dimension is very close to the peaks obtained from $0.457 \mathrm{~m}$ overhang dimension for most of the nine instrumented locations. Therefore, it was concluded that the effect of overhang dimension on roof shingle area-averaged peak is minimal. Such effects on other roof components still need to be carefully studied. 

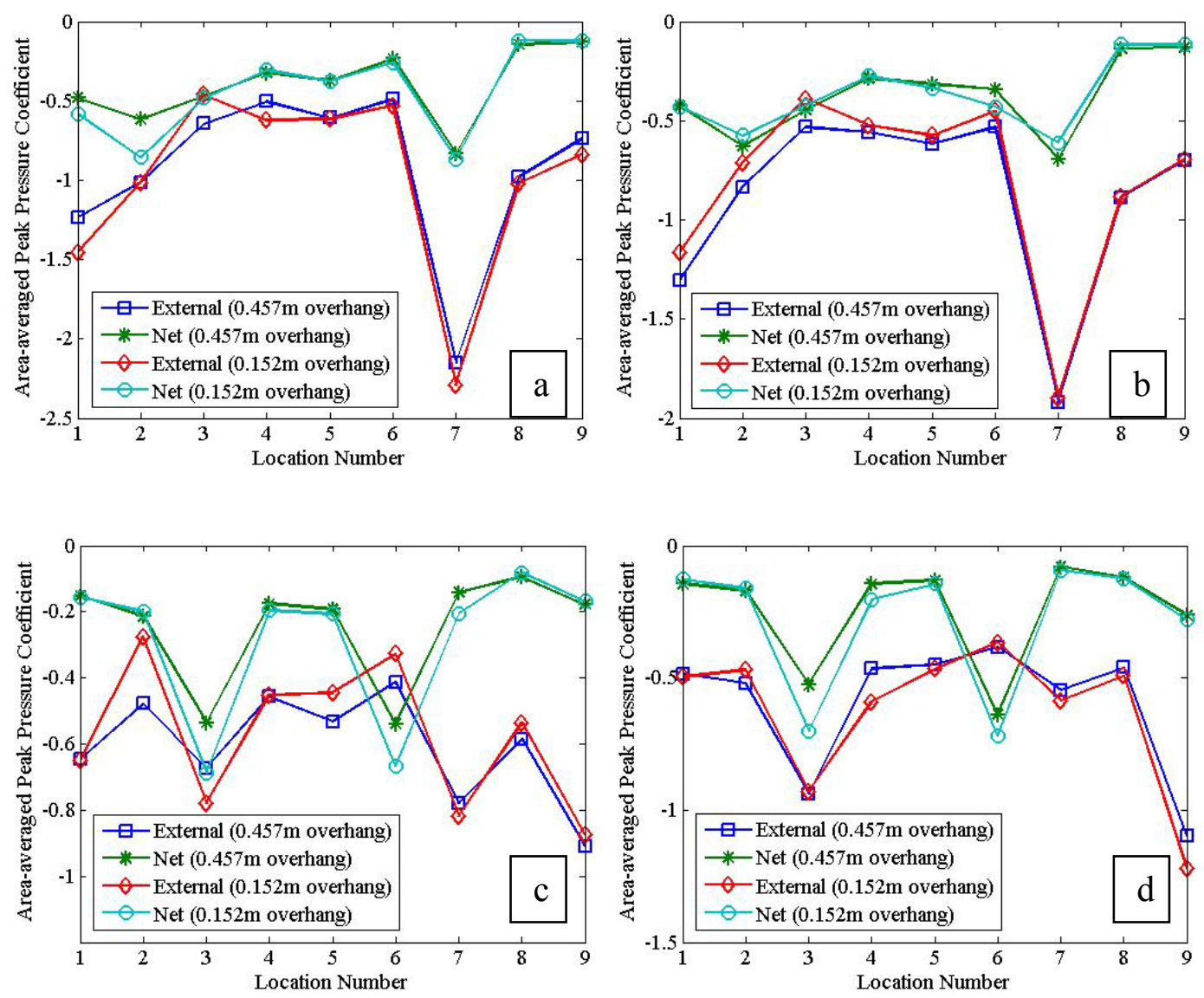

Figure 5.5: External and Net Area-Averaged Peak Pressure Coefficients Comparison for Two Different Overhang Dimensions from 3:12 Hip Roof with Shingle: (a) 30 degree, (b) 45 degree, (c) 75 degree, (d) 90 degree

\subsection{Conclusions}

For shingled deck, top and bottom surface pressures can act in the same direction and aggravate the wind uplift loading for windward shingles located near the center of the roof deck. For windward shingles located away from the center region (field zone) and for all leeward shingles, partial air-pressure equalization alleviates the wind uplift loading. In addition, it was also found that similar to the tiles' cavity internal pressure, the internal pressure coefficients specified in the code provisions are not applicable for estimating net wind uplift on roof shingle. Also, the effect of overhang dimensions on 
roof shingle area-averaged peak is minimal and further research on such effects still need to be carefully studied.

The results show that wind uplift on low-rise buildings' roof shingles can be more accurately evaluated by considering the effects of the geometric features of these roofing materials. The research work also suggested that for different air-permeable roofing materials, it is better to differentiate the design wind uplift load based on the type of materials being used (high profile tiles versus asphalt shingles). 


\section{Effects of Modeling Roofing Materials for Estimation of Wind uplift}

\subsection{Introduction}

Through the analysis of effects of the geometry of air-permeable roofing materials on the wind uplift peak pressures, it was demonstrated that the geometry of air-permeable roofing materials could significantly affect the load acting on the roofs (chapters 4 and 5). Such effects are barely considered in the current building codes for designing low-rise building roofs that are mainly based on testing results from building models which generally do not simulate the architectural features of roofing materials. Therefore, it is important to quantify these effects in terms of design purpose. The ratios of areaaveraged net uplift peak pressure coefficients obtained from tiled or shingled roof decks to the area-averaged surface peak pressure coefficients obtained from bare roof were used to quantify effects of architectural features of tiles and shingles on wind-induced uplift.

\subsection{Analysis Results}

Figure 6.1 shows these ratios for tiled versus bare decks for 4:12 monoslope roof and 3:12 hip roof for windward corner and edge locations. It is noted that the ratios for corner tiles could be as high as 1.5 and 1.8 for the 4:12 monoslope and 3:12 hip roofs, respectively, for oblique winds. In other words, bare deck modeling without considering the tile geometry effects could underestimate design wind uplift by as much as $45 \%$. Similar underestimation could occur for edge tiles. Figure 6.2 shows the ratios for 3:12 hip and 5:12 gable roofs for ridge loactions. The ratios were as high as 2.2 for the 3:12 hip roof (location 3) for cornering winds and 3.2 for the 5:12 gable roof (location 6) for 
normal winds. Thus for ridge tiles, the bare deck modeling could underestimate design wind uplift by $55-69 \%$.
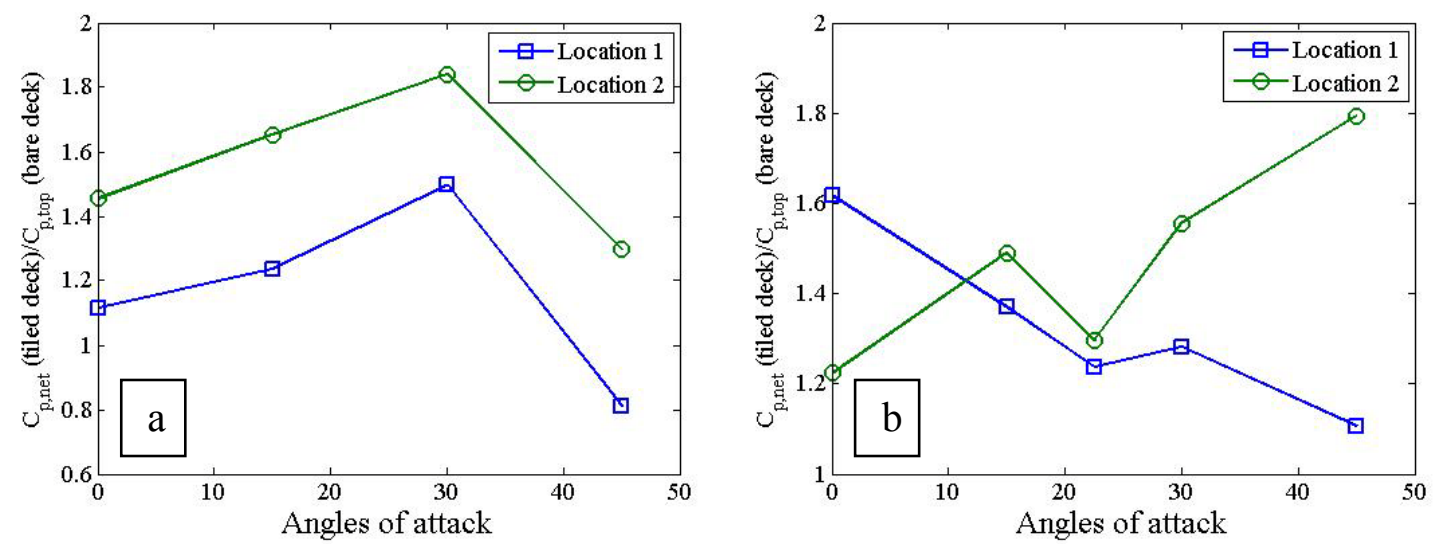

Figure 6.1: Ratio of Area-Averaged Net Peak Pressure Coefficients Obtained from Tiled Versus Bare Roof Decks for Locations 1 And 2: (a) 4:12 Monoslope Roof, (b) 3:12 Hip Roof
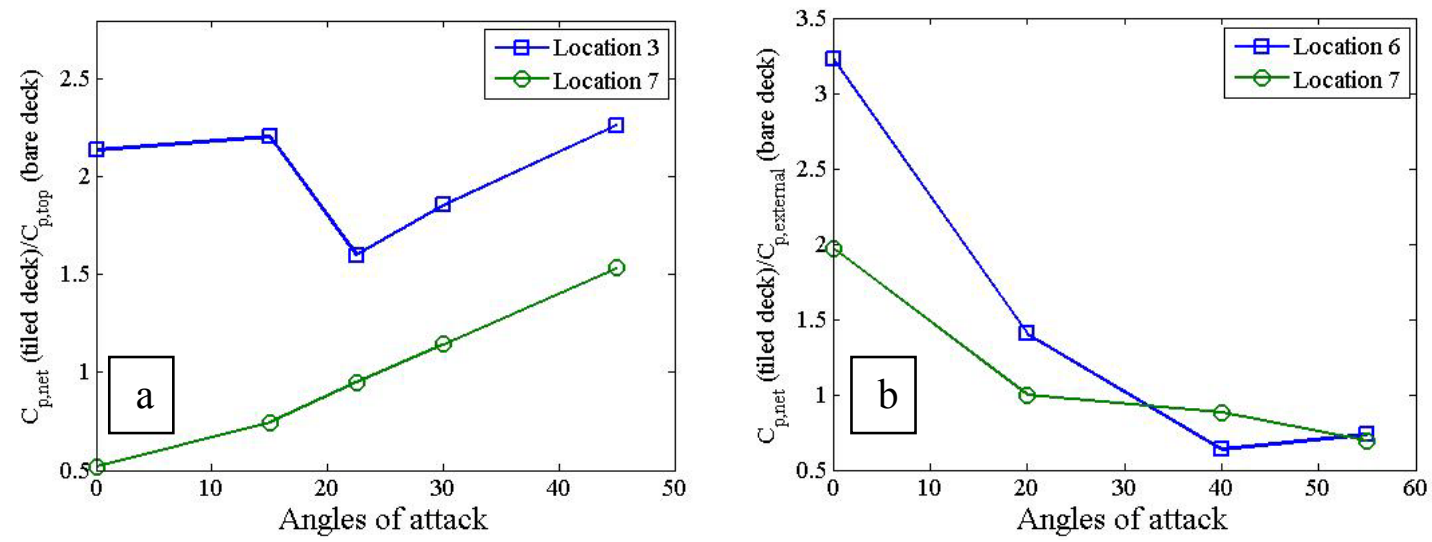

Figure 6.2: Ratio of Area-Averaged Net Peak Pressure Coefficients Obtained from Tiled Versus Bare Roof Decks: (a) 3:12 Hip Roof for Locations 3 and 7, (b) 5:12 Gable Roof for Locations 6 and 7

Figure 6.3 shows the ratios for shingled versus bare decks for 4:12 monoslope and 3:12 hip roofs for near the center of the deck (field) locations. It is to be noted that the ratios could be as high as 2.6 for 4:12 monoslope roof (loation 5) and 1.4 for 3:12 hip roof (location 6); underestimation being 60\% and 30\%, respectively. Thus, bare deck 
modeling to estimate design wind uplift on shingled decks may be acceptable for corner, edge, and ridge locations but not for field loactions where top and bottom surface pressures could both contribute to the uplift of the shingles.

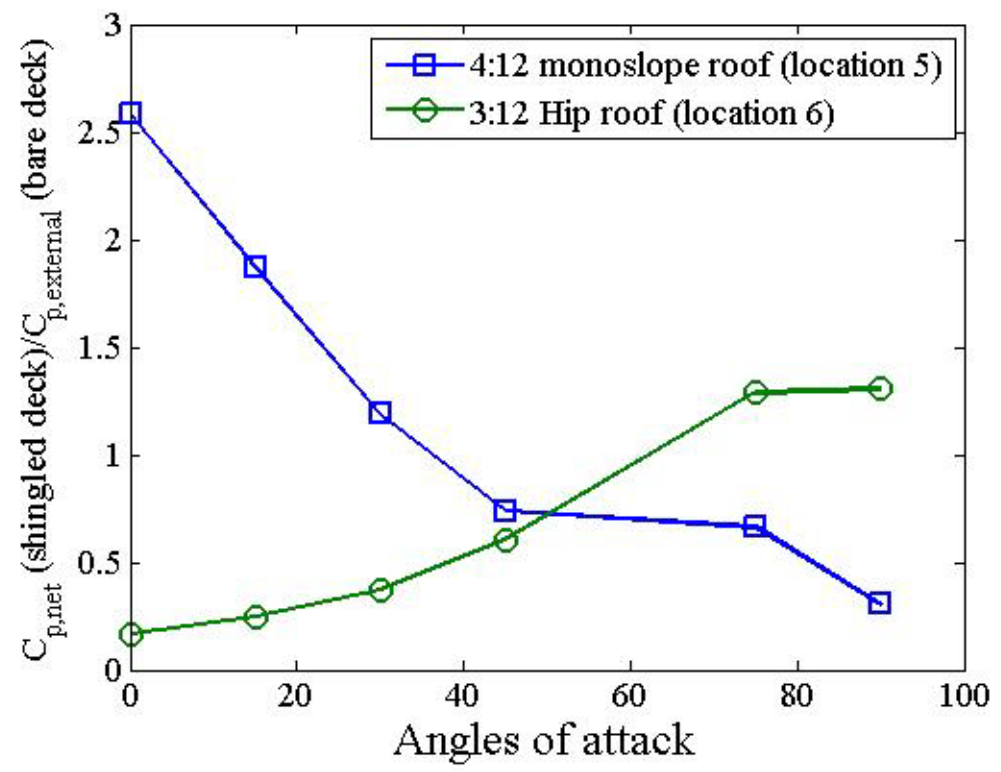

Figure 6.3: Ratio of Area-Averaged Net Peak Pressure Coefficients Obtained from Shingled Versus Bare Roof Decks for 4:12 Monoslope Roof Location 5 and 3:12 Hip Roof for Location 6

\subsection{Conclusions}

Bare deck modeling without considering the tile geometry effects could significatnly underestimate design wind uplift on tiled decks by as much as $45 \%$ for corner and edge tiles. For ridge tiles, the bare deck modeling could underestimate design wind uplift by $55-69 \%$. Bare deck modeling to estimate design wind uplift on shingled decks may be acceptable for corner, edge, and ridge locations but not for field locations it could underestimate the uplift on shingles by $30-60 \%$.

This research is not intended to suggest air-permeable roofing materials' pressure coefficients for wind load provisions but is a preliminary effort to show how considering 
the geometric details of roofing materials could play an important role in wind tunnel or full-scale testing based estimation of wind uplift loading on roofs. The findings demonstrated the importance of modeling geometric details of roofing materials as opposed to modeling only the overall roof geometry. 


\section{Effects of Tile Cavity Internal Pressure on Vulnerability of Roof Tiles}

\subsection{Introduction}

The vulnerability curve and fragility curve are widely used to assess the performance and reliability of the building components at different wind speeds. In order to obtain realistic and reliable vulnerability curve of the building component, the wind load and wind resistance of the building component need to be carefully evaluated. Since there are too many uncertainties that could affect the wind load and wind resistance of the building component, such as the building code, enforcement of the building code, building shape, building ages, structure type and the topographic details, and so on, developing an accurate vulnerability curve is still a significant challenge.

In absent of test-based data, some researchers and loss estimation modelers use roof external pressure coefficients given in the code provisions and assume zero internal pressure while estimating wind loading on roofing materials, such as roof tiles and roof shingles. As an example, the Florida Public Hurricane Loss Model (FPHLM) ignores the cavity internal pressure effects and assumes zero internal pressure in the simulation of vulnerability curves for roofing materials (FPHLM, Volume II, pg.55). However, as the effects of tiles' cavity internal pressure and shingle bottom surface pressure on roof peak pressures were carefully investigated (Chapter 4) and such effects were found to significantly affect the load acting on roofing materials, this chapter is only focused on such effects on the vulnerability of roof tiles since the pressure measurement conducted at full scale is based on the location of the tiles and such measurement was not perform on a entire piece of shingle. Instead of using the external pressure coefficients given in 
the code provisions and to better consider the effect of directionality, the external pressure coefficients were obtained through a series of wind tunnel testing conducted at RWDI boundary layer wind tunnel at Miramar, Florida.

Additionally, to obtain realistic and reliable wind resistance of roof tile, a series of tile uplift load tests was performed at Polyfoam testing lab using pressure data. Such wind resistance was used in the simulation of vulnerability curves of roof tiles.

\subsection{Fundamental Concepts of Vulnerability Curve and Fragility Curve}

Uncertainties affect the wind load acting on and wind resistance of building components. Due to such uncertainties, a building component could either be undamaged ( $0 \%$ damage), partially damage or totally damaged (100\% damage) at a given wind speed. Therefore, there will be a damage distribution to describe the effects of such uncertainties at this given wind speed. When the damage distributions are obtained for a series of wind speeds, the vulnerability curve and fragility curve for that building component can be determined. A fragility curve provides the probability of exceedence of certain damage percentage with different wind speeds. The vulnerability curve shows the mean damage as a function of wind speed. Figures 9.1 and 9.2 show typical vulnerability curve and fragility curve. 


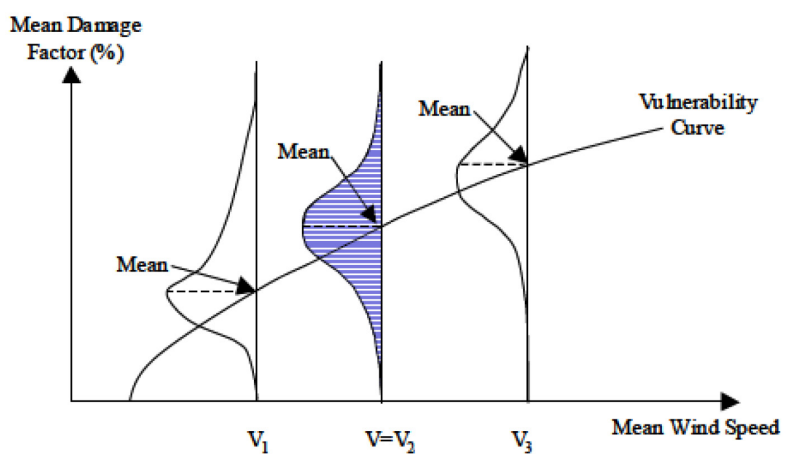

Figure 7.1: Vulnerability Curve Generation (FPHLM, Volume II, 2005)
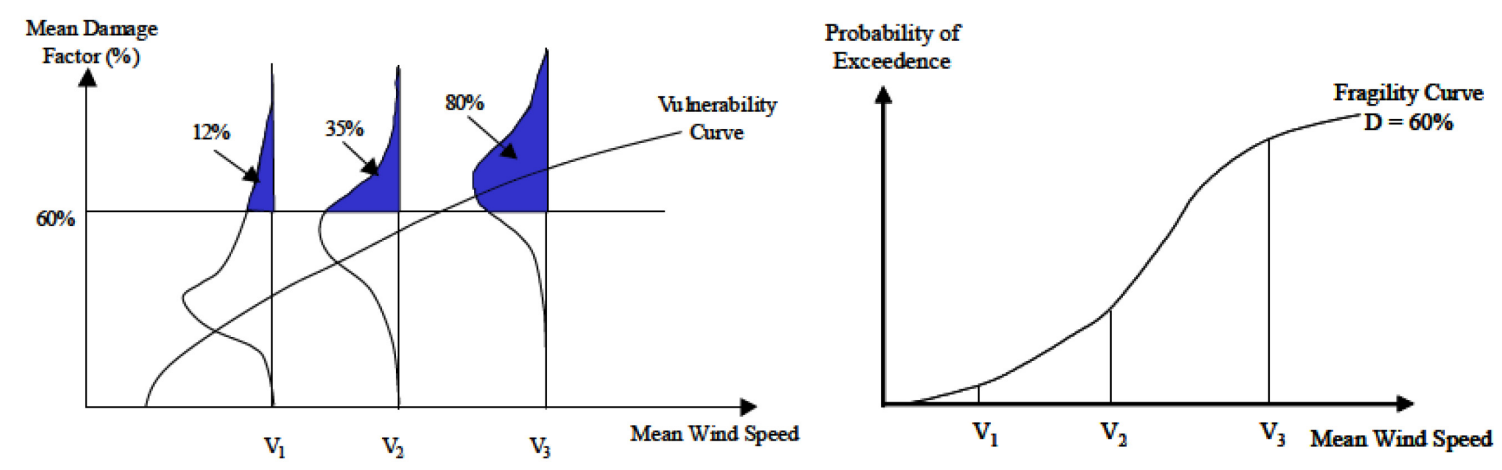

Figure 7.2: Fragility Curve for the Damage State of 60\% Overall Structural Damage

(FPHLM, Volume II, 2005)

\subsection{Wind Load on Roof Tiles}

The wind load for roof tiles can be estimated using external pressures obtained from a series of wind tunnel testing (as a substitute to using ASCE 7 based external pressure, such as done for FPHLM) and cavity internal pressures obtained from 6-fan WoW full scale testing. These pressures were combined to obtain the net load on the roof tiles. 


\subsubsection{Tile External Pressure}

Instead of using the modified pressure coefficients given in code provisions as external load for roof tile and to better consider the effects of directionality, a series of wind tunnel testing was conducted in RWDI's $2.43 \mathrm{~m}$ by $1.98 \mathrm{~m}$ boundary layer wind tunnel facility at Miramar, Florida. 1:20 scale model of the buildings tested at the WoW were built, including a monoslope roof with 4:12 slope, a gable roof with 5:12 slope and two hip roofs with 3:12 and 5:12 slopes. These bare roof deck were tested in the wind tunnel. In wind tunnel, the target mean wind speed profile was a power-law profile with $\alpha=1 / 4$ (typical suburban terrain). The wind tunnel gradient height wind speed at $0.15 \mathrm{~m}$ ( $3 \mathrm{~m}$ at full scale) from the wind tunnel ground was approximately $8.69 \mathrm{~m} / \mathrm{s}$. The longitudinal turbulence intensity at a full scale match height of $3 \mathrm{~m}$ was $22.3 \%$. The longitudinal integral length scale at a full scale match height of $3 \mathrm{~m}$ was estimated to be approximately $0.7 \mathrm{~m}$ in model scale. Figures 9.3 and 9.4 show the mean wind speed and longitudinal turbulence intensity profile simulated in the wind tunnel. The longitudinal turbulence spectrum at roof eave height is shown in Figure 9.5, along with a comparison to the Von Karman spectrum and a typical suburban profile spectrum defined by Engineering Sciences Data Unit (ESDU). Different wind angles of attack were tested. All the pressure measurements were recorded at $512 \mathrm{~Hz}$ for 36 seconds, and low-pass filtered at $135 \mathrm{~Hz}$. Figure 9.6 shows the wind tunnel testing models. 


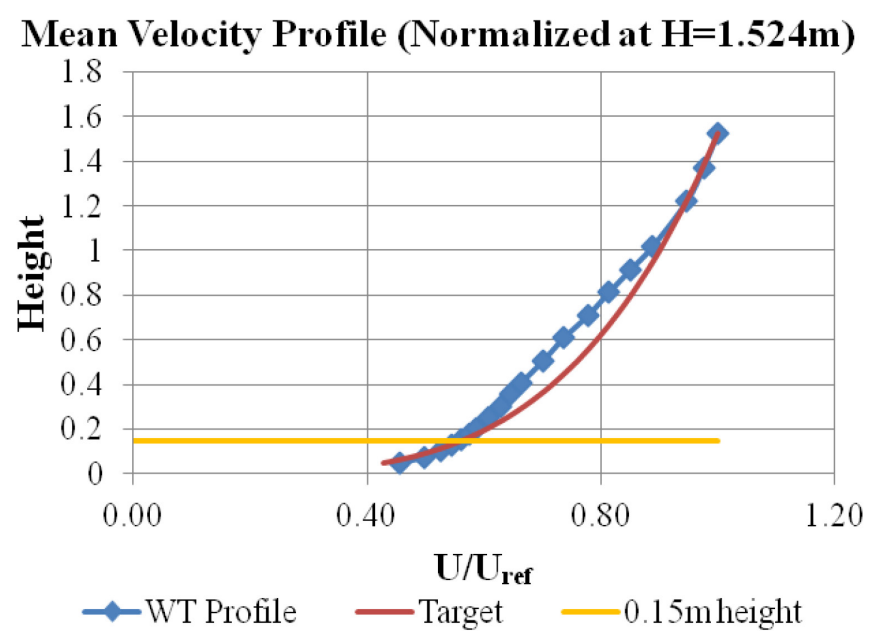

Figure 7.3: Mean Wind Speed Profile Comparison

\section{Longitudinal Turbulence Intensity Profile (Normalized at $\mathrm{H}=\mathbf{1 . 5 2 4 m )}$}

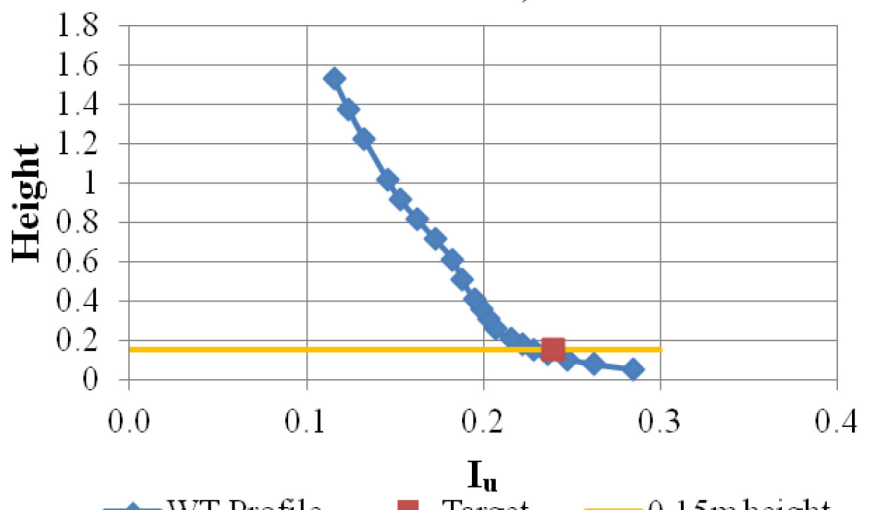

Figure 7.4: Longitudinal Turbulence Intensity Profile Comparison

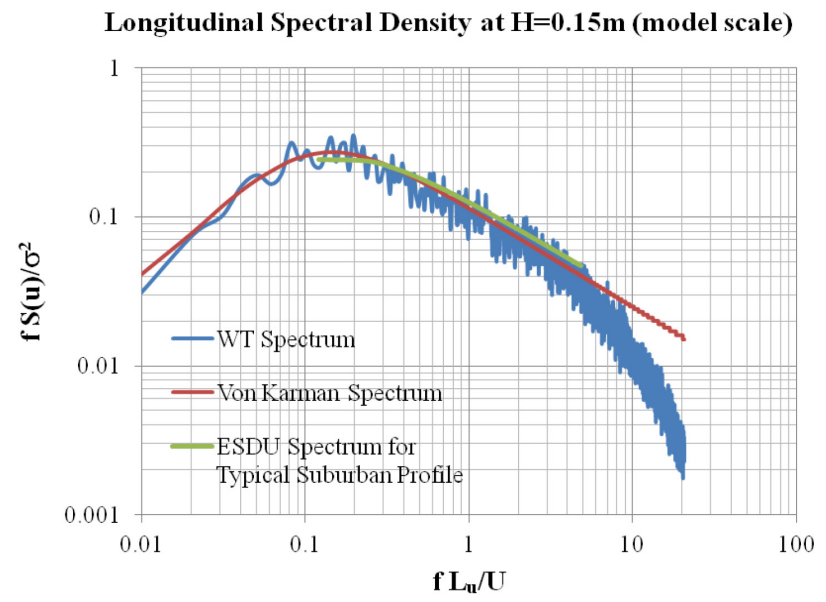

Figure 7.5: Normalized Longitudinal Spectral Density at $\mathrm{H}=0.15 \mathrm{~m}$ 

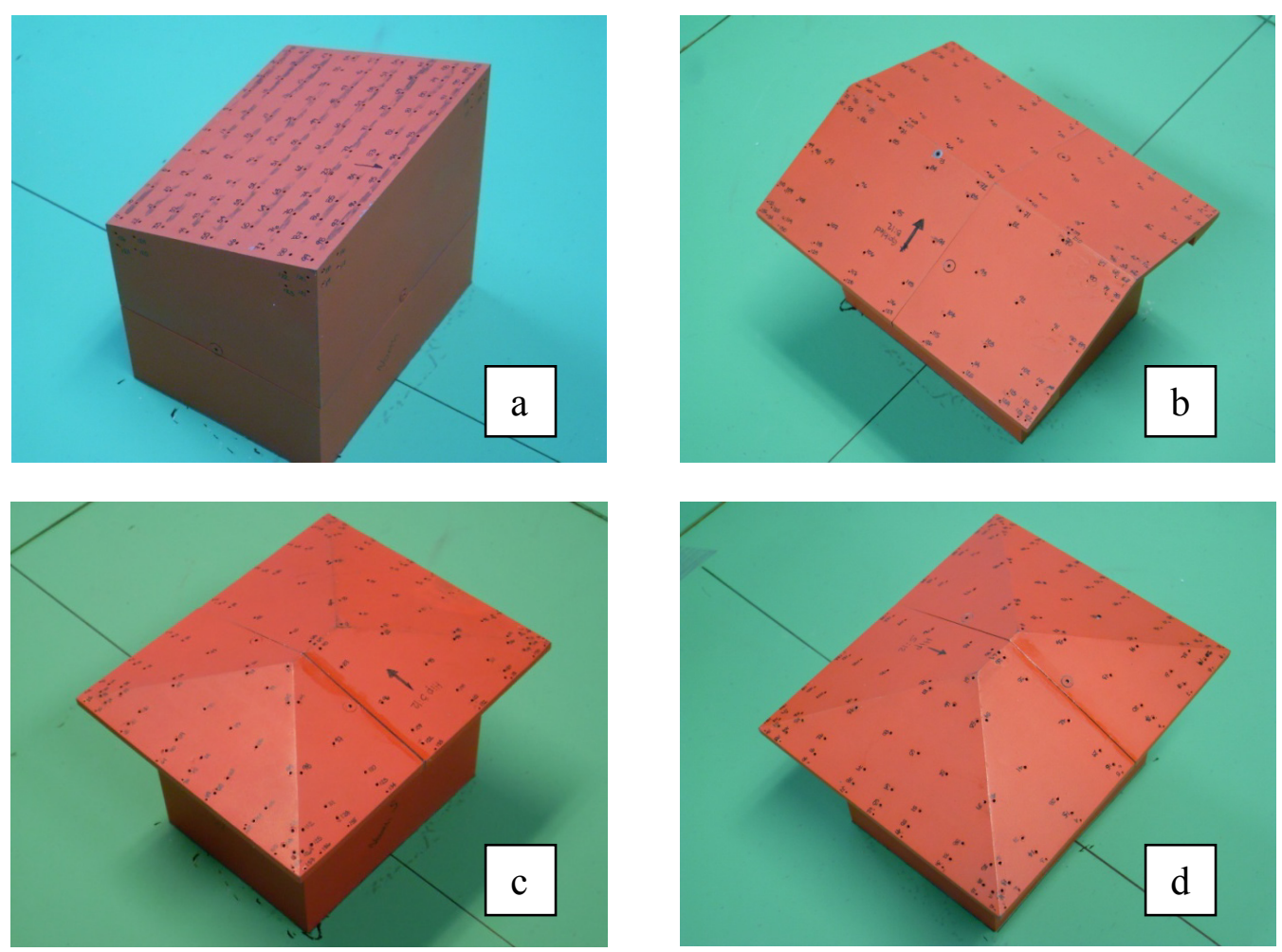

Figure 7.6: Wind Tunnel Testing Model for Each Type of Roof: (a) Monoslope Roof with 4:12 Slope, (b) Gable Roof with 5:12 Slope, (c) Hip Roof with 3:12 Slope, (d) Hip Roof with 5:12 Slope

Figure 9.7 shows the superposition of tiles on the models tested at the wind tunnel. The tiles' locations were exactly the same as for the full-scale models so that the net load for each tile could be obtained by combining the external pressures from the wind tunnel and cavity internal pressures from the WoW test based data. Due to the limitation of number of taps installed on each small-scale roof, the interpolation between taps was applied to estimate the external pressures acting on each tile. 

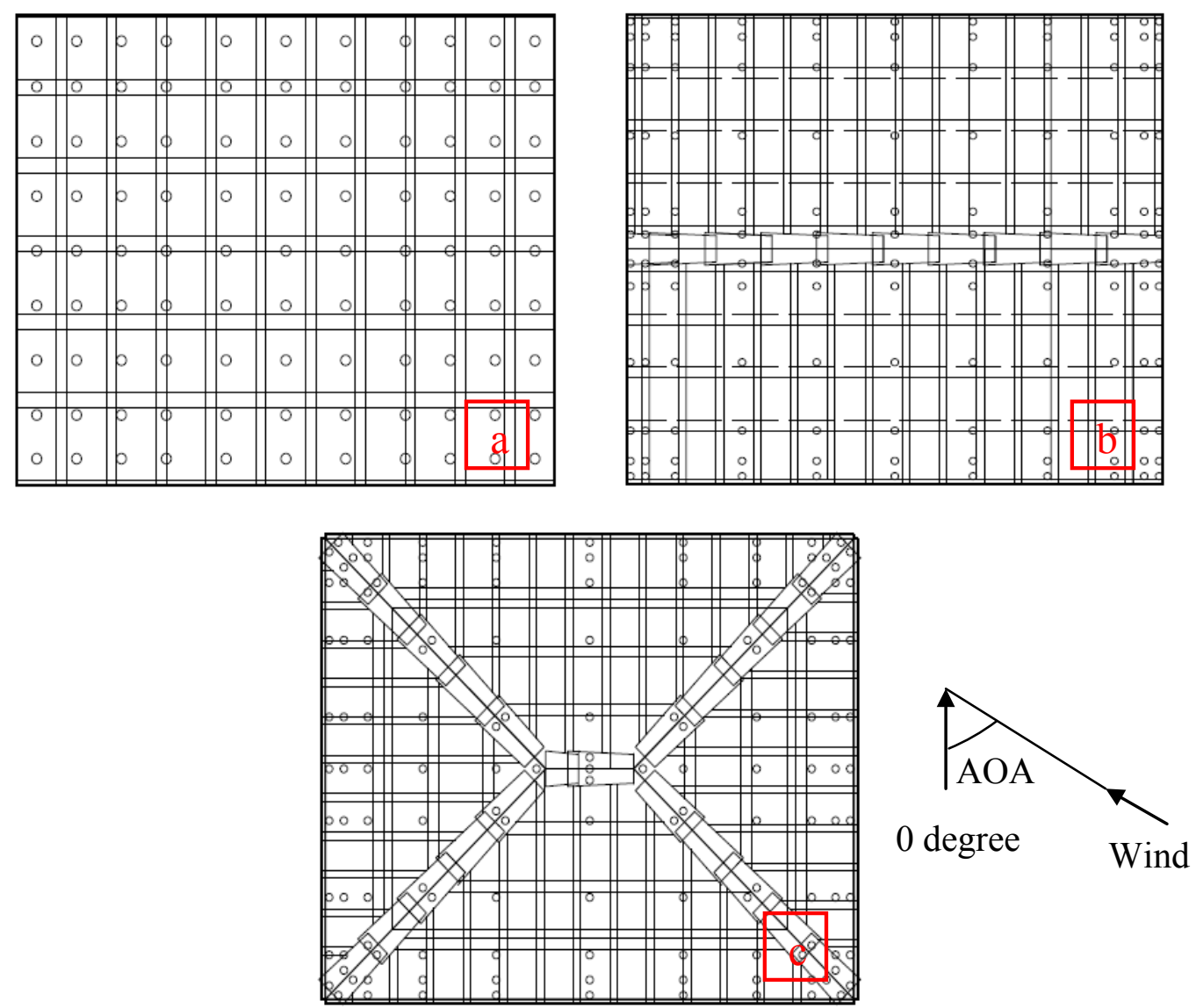

Figure 7.7: Pressure Tap Layouts with Tile Location Superposition Sketch for Each Type of Roof: (a) Monoslope roof, (b) Gable roof, (c) Hip Roof

\subsubsection{Tile Cavity Internal Pressure}

As presented in Chapter 4, the tiles' cavity internal pressure could significantly affect the load acting on roof tiles. Such effects are dependent on the tile join orientation with respect to the wind angle of attack. It was concluded that for wind being oblique, nearly normal, and normal to the windward eave, the cavity internal pressure contributed to (i) an increased net uplift peak pressure when tile joints had windward orientation; (ii) a reduced net uplift peak pressure when the tile joints had leeward orientation. In addition, since only nine tiles were measured for each full-scale roof model, the 
interpolation method was used to apply the cavity internal pressure to each tile based on the conclusions made in Chapter 4.

\subsection{Wind Resistance of Roof Tiles}

The wind resistance of roof tile is the ability of roof tile withstanding the wind force. Wind-induced damage to roof tile allowed wind-driven rain to enter building interiors causing not only loss of function, but substantial damage to building contents due to water and subsequent mold growth. However, only limited information is available about the wind resistance of roof tile. An experimental method is provided by Florida Building Code (FBC, 2007) Testing Application Standard (TAS) Chapter 101-95 “Test Procedure for Static Uplift Resistance of Mortar or Adhesive Set Tile Systems”. Two testing systems, including moment based system and uplift based system, are introduced in this testing protocol. In the current research, the overturning moment based damage was considered to be the most dominant damage pattern for roof tile. Therefore, the moment based system was used in the following tile uplift testing. According to the testing protocol, for the moment based systems, the static uplift load applied at a point along the center of the tile, $0.76 \times l(l=$ tile length $)$ from the head of the tile. However, this incorrectly assumed that same loading point is applicable to all the roof tiles for each type of roof. The location of loading point was studied through the pressure distribution analysis of full scale measurement. The substantial tile resistance capacity testing was

conducted at Polyfoam testing lab, Coral Spring, Florida. It is to be noted that the tile manufacturers are also based on the two testing systems, provide typical wind resistance 
values for each type of tile (Notice of Acceptance), which is obtained by certified test agencies.

\subsubsection{Tile Uplift Testing}

\subsubsection{The Location of Tile Loading Point}

Based on the full scale pressure measurements on four different roofs, including a monoslope roof (4:12 slope), a gable roof (5:12 slope) and two hip roofs (3:12 and 5:12 slopes), with tiled roof decks, the loading centers of instantaneous peak pressure applied on the Spanish ' $\mathrm{S}$ ' tile and Mission Barrel tile were obtained. In order to find some typical loading position, the effects of wind angles of attack were ignored. Based on the equivalent moment arm principle, all the loading points out of the centerline of the tile were converted into the centerline of the tile. Figure 9.8 shows this principle which projects point $\mathrm{B}$ onto point $\mathrm{A}$. In addition, the eccentricity in $\mathrm{y}$-direction is defined to describe the distance of equivalent loading center to the head of roof tile, since the $\mathrm{x}$ coordinate of the centerline is constant.
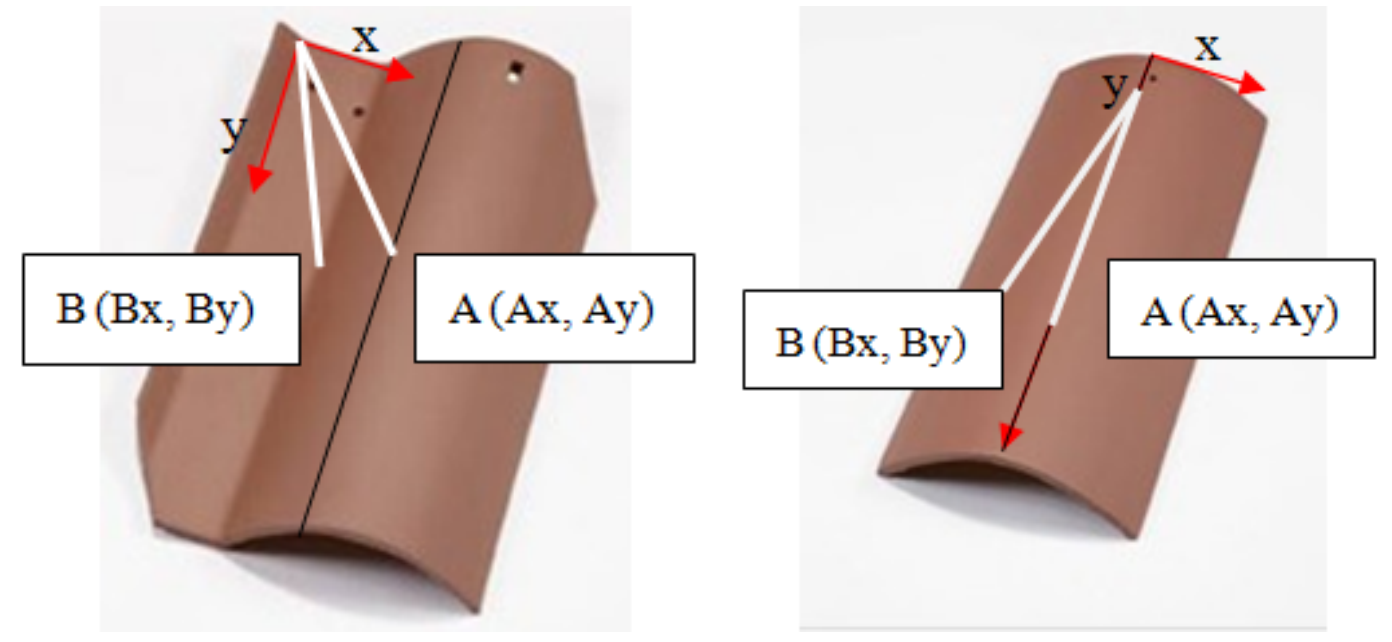

Figure 7.8: Converting Loading Point off the Centerline of Tile into The Centerline 
Figure 9.9 shows the Spanish 'S' tile loading position in y direction distance from the head of tile for four different roofs through the analysis of the pressures measured from WoW. It is noticed that the eccentricity of loading point in y-direction is ranged from 8 inches to 12 inches. Therefore, two different eccentricities of Spanish ' $S$ ' tile, including 9.5 and 10.5 inches from the head of tile are chosen as typical eccentricities in $\mathrm{y}$-direction of loading point for Spanish 'S' tile.
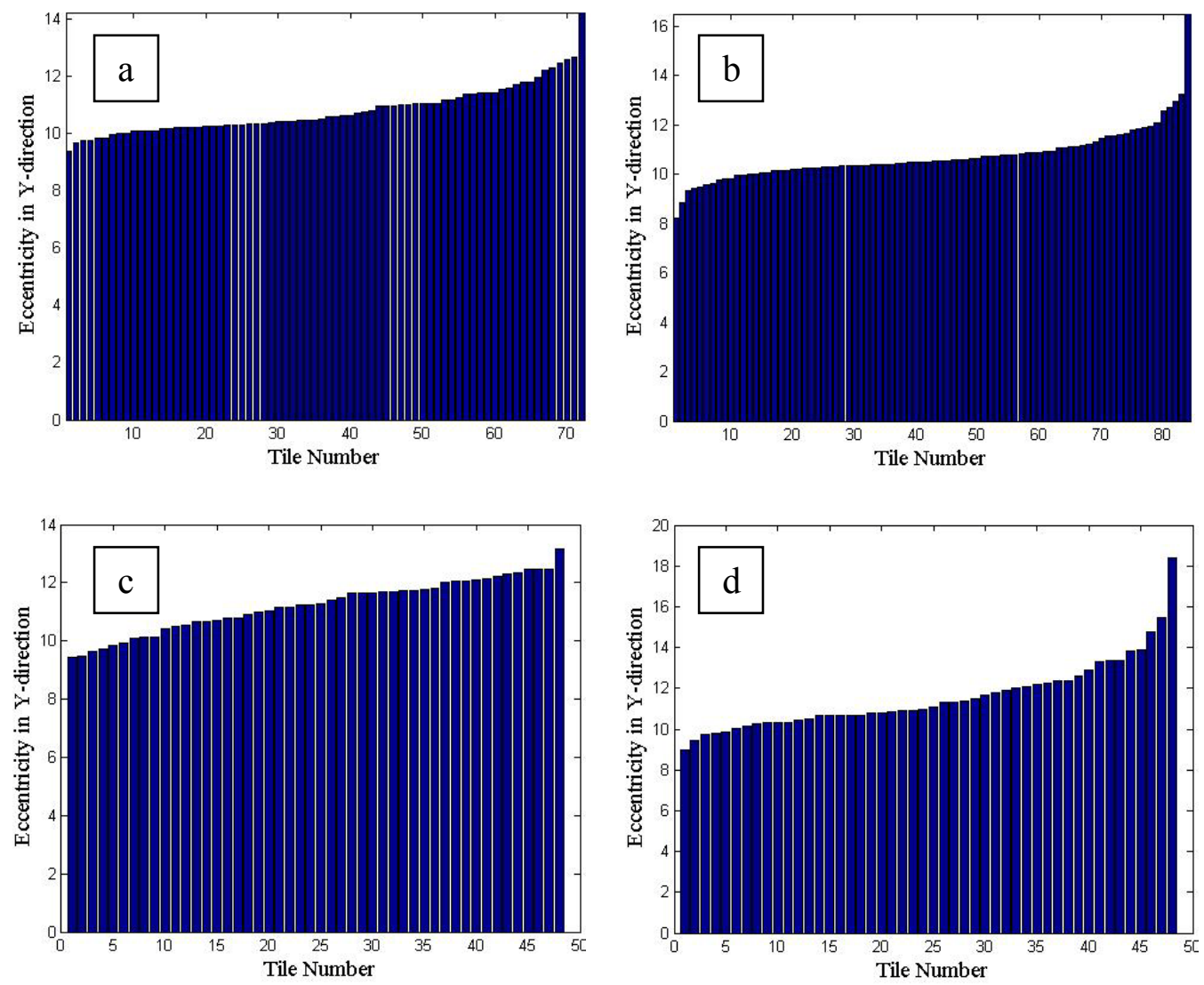

Figure 7.9: Spanish ' $\mathrm{S}$ ' Tile Loading Point in Y-Direction Distance from the Head Of Tile for Each Type of Roof: (a) 4:12 Monoslope Roof; (b) 5:12 Gable Roof; (c) 3:12 Hip Roof; (d) 5:12 Hip Roof

Figure 9.10 shows the eccentricity of barrel tile in y direction for 5:12 gable roof and hip roofs. The eccentricity of barrel tile in y direction ranged from 7 to 14 inches and 
most of them were around 8 inches. Therefore, 8 inches from the head of barrel tile is chosen as a typical eccentricity for barrel tile.
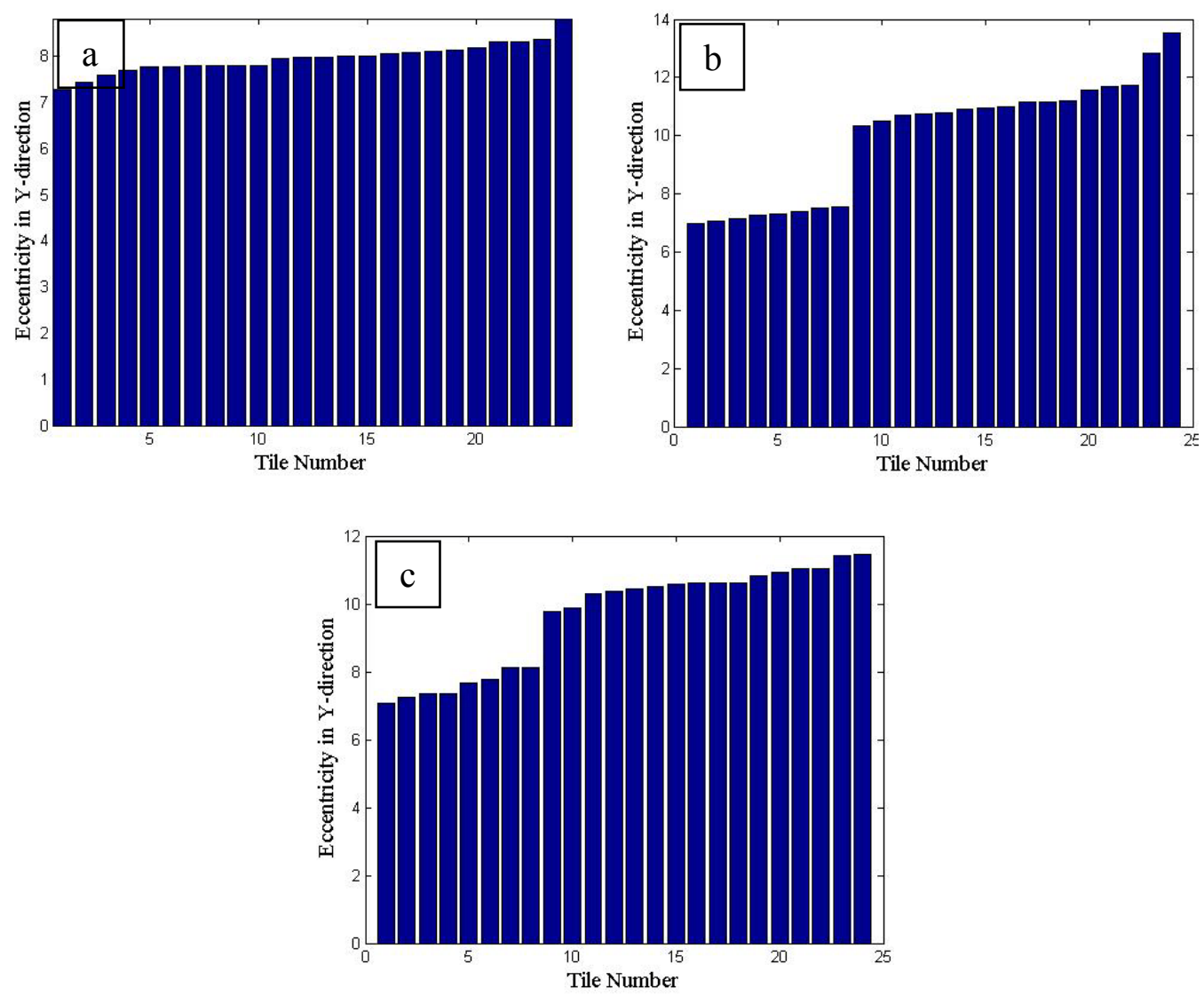

Figure 7.10: Barrel Tile Loading Point in Y-Direction Distance from the Head of Tile For Different Type of Roof: (a) 5:12 Gable Roof; (b) 3:12 Hip Roof; (c) 5:12 Hip Roof.

\subsubsection{Testing Setup}

Based on the tile loading point eccentricity study results, two typical eccentricities (9.5 and 10.5 inches) for Spanish ' $\mathrm{S}$ ' tile and one typical eccentricity ( 8 inches) for Mission Barrel tile were used to conduct the tile uplift testing. Twenty samples for each eccentricity value were tested at Polyfoam testing laboratory, Miramar, Florida. According to the TAS 101-95 specification, five $4 \mathrm{ft}$ by $8 \mathrm{ft}$ wood frames consisting APA $32 / 16$ span rated sheathing of $3 / 4$ in. thickness installed over 2 in. by 6 in. perimeter and 2 
in. by 6 in. intermediate supports spaced 24 in. apart was constructed at Polyfoam testing laboratory. In addition, the underlayment, namely MSA Quik-Stick HT, was installed on the plywood to better simulate the construction procedure in residential buildings. Prior to the testing, each tile was drilled with a hole in excess of $1 / 4$ inch steel bolt fastened to a load transfer device consisting of a $3 / 8$ " washer to avoid premature failure due to stress concentration. The tiles were then attached using Polypro AH 160 roof tile adhesive to the underlayment on the wood frame which was mechanically fastened to the ground. The barrel tiles were attached to 5 inches high metal sheeting which is widely used in residential buildings. The average weight of the foam was approximately 27 grams per tile. Also, the average overlap between tiles was approximately 3 inches to better represent the field conditions. Figure 9.11 shows the testing specimens.
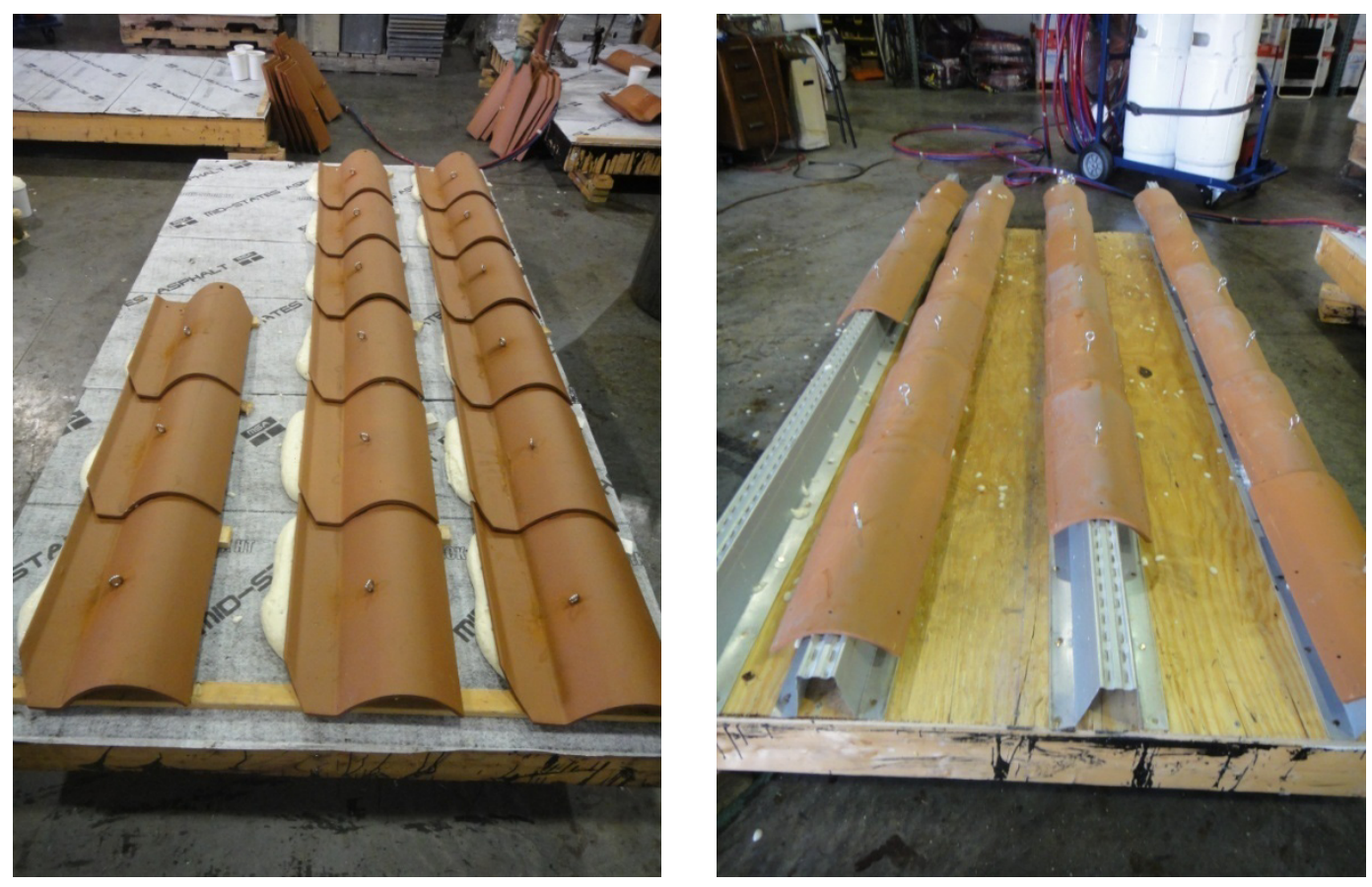

Figure 7.11: Tile Uplift Testing Specimens 
Before testing, all the testing specimens were maintained inside the laboratory at room temperature for five days. A hydraulic jack with a load cell was assembled to functioning as the testing device (see Figure 9.12). Displacement controlled testing (2 in/min) was performed.

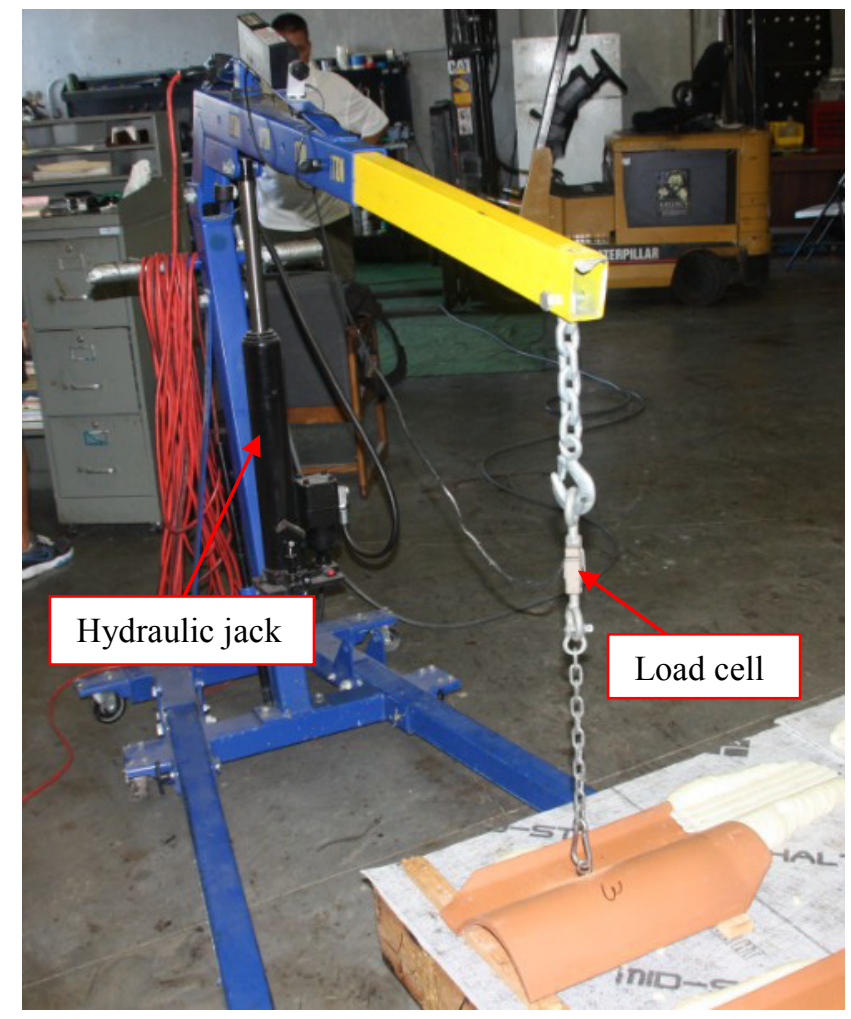

Figure 7.12: Tile Uplift Testing Device

\subsubsection{Testing Results and Discussion}

Sixty tiles, including forty Spanish ' $\mathrm{S}$ ' tiles and twenty Mission Barrel tiles, were tested at Polyfoam testing laboratory. The failure load for each tile was recorded. Two typical failure modes were observed for the Spanish 'S' tiles: (1) bonding failure at the interface between the tile and the foam, (2) failure within the foam paddy itself. Figure 9.13 and Figure 9.14 show these two failure modes. However, there was one Spanish 'S' tile failure with the debonding mode for which the underlayment was also detached from 
the deck. Figure 9.15 shows this underlayment detachment from the deck. For barrel tile tests, the typical failure mode was the bonding failure at the interface between the tile and foam. Figure 9.16 shows this typical failure mode.

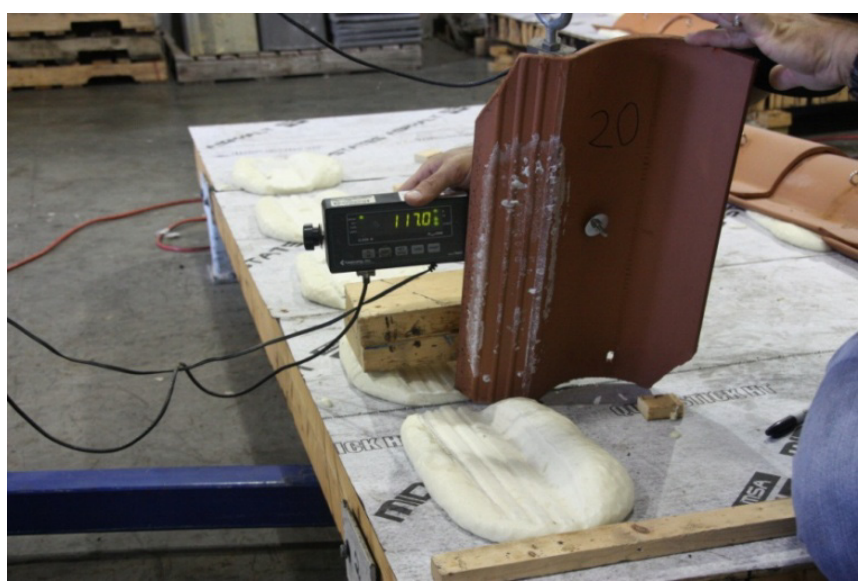

Figure 7.13: Bonding Failure at the Interface between Tile and Foam (Spanish 'S' tile)

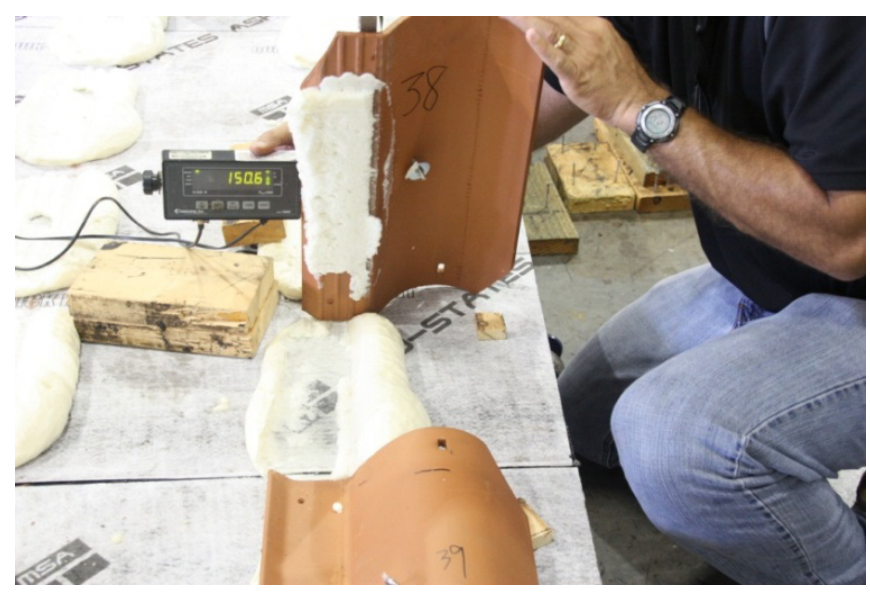

Figure 7.14: Failure within the Foam Paddy (Spanish 'S' tile) 


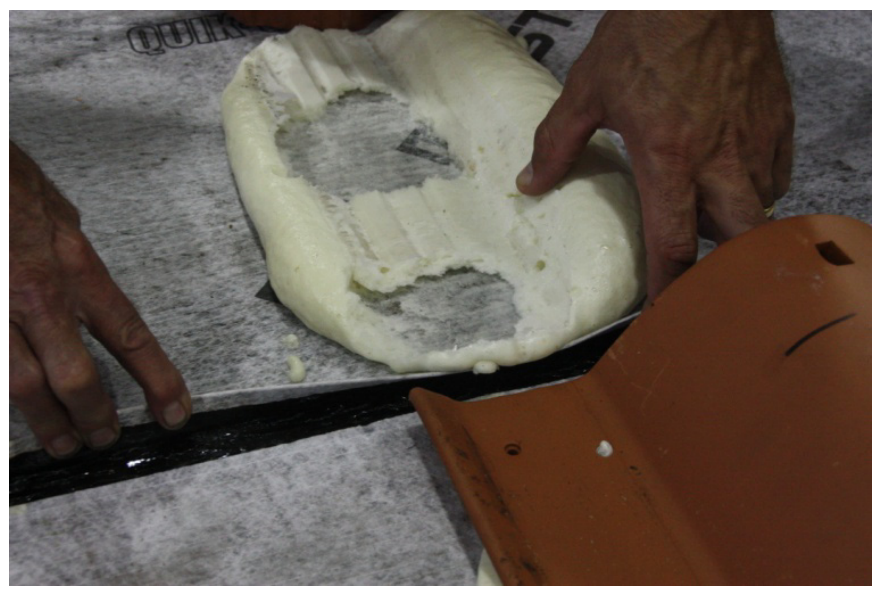

Figure 7.15: Underlayment Detachment from the Deck (Spanish 'S' tile)

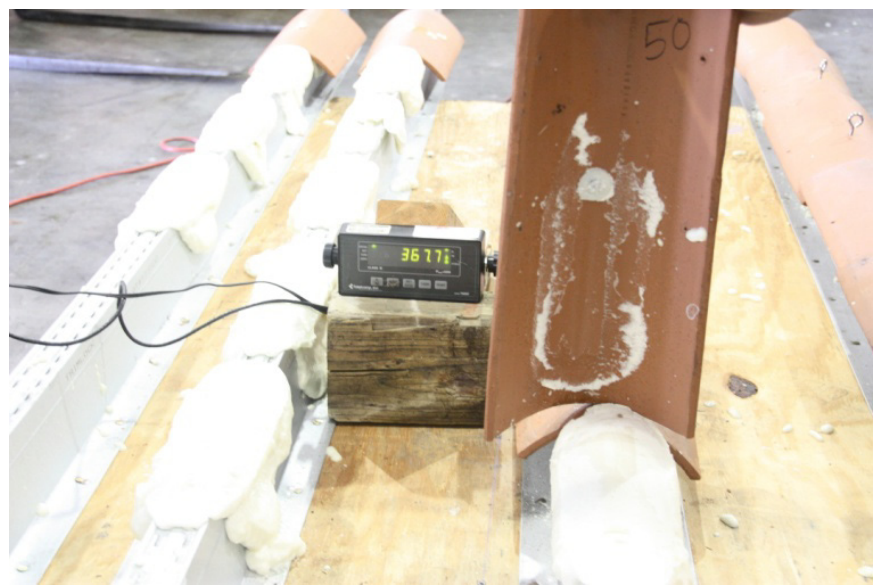

Figure 7.16: Bonding Failure at the Interface between Tile and Foam (Barrel tile)

Table 7.1 shows all the testing results. The mean failure forces for Spanish ' $\mathrm{S}$ ' tiles with 9.5 and 10.5 inches eccentricities were $133.8 \mathrm{lb}$ and $125 \mathrm{lb}$, respectively. It is noticed that the average of failure load for 9.5 inches eccentricity was about $10 \mathrm{lb}$ larger than that for the 10.5 inches eccentricity. In addition, based on TAS Chapter No. 101-95, the attachment resistances $\mathrm{M}_{\mathrm{f}}$ were also calculated and compared to the values provided by the tile manufacturer. The mean attachment resistances of these two eccentricities were $55.9 \mathrm{ft}-1 \mathrm{bf}$ and $56.4 \mathrm{ft}-\mathrm{lbf}$, respectively. For barrel tile test, the mean failure force was $457.8 \mathrm{lb}$ and the mean attachment resistance was $185.4 \mathrm{ft}-1 \mathrm{bf}$. However, from 
structural dynamics point of view, if the amount of foam is the same used for both eccentricities testing, the mean attachment resistance should be the same. It was indicated that the reasonable results were obtained from the tile uplift testing. Also, the results are comparable to the attachment resistance specified in Notice of Acceptance (NOA) obtained from manufacturers' website. Table 7.2 shows the comparison results.

Table 7.1: Failure Loads for All the Tiles

\begin{tabular}{|c|c|c|c|}
\hline \multirow{2}{*}{ Tile No. } & \multicolumn{3}{|c|}{ Failure load (lb) } \\
\hline & $\begin{array}{l}\text { Spanish 'S' tile } \\
\text { (9.5 inches) }\end{array}$ & $\begin{array}{l}\text { Spanish 'S' tile } \\
\text { (10.5 inches) }\end{array}$ & $\begin{array}{l}\text { Barrel tile } \\
\text { (8 inches) }\end{array}$ \\
\hline 1 & 140.2 & 134.1 & 371.2 \\
\hline 2 & 135.6 & 102.6 & 473.6 \\
\hline 3 & 131.4 & 117.1 & 437.6 \\
\hline 4 & 122.1 & 135.5 & 312.4 \\
\hline 5 & 117 & 127.1 & 512.3 \\
\hline 6 & 99.6 & 122.8 & 559 \\
\hline 7 & 153.4 & 148.4 & 438.5 \\
\hline 8 & 136.1 & 126.6 & 575.5 \\
\hline 9 & 109.4 & 122.9 & 571.4 \\
\hline 10 & 152.2 & 116.7 & 367.7 \\
\hline 11 & 147.8 & 99.7 & 402.3 \\
\hline 12 & 121 & 113 & 422.6 \\
\hline 13 & 148.4 & 143.4 & 341.3 \\
\hline 14 & 117.3 & 127.7 & 413.5 \\
\hline 15 & 129.3 & 132.7 & 547.9 \\
\hline 16 & 149.3 & 141.4 & 415.1 \\
\hline 17 & 139.1 & 112.9 & 551.6 \\
\hline 18 & 150.6 & 137.1 & 412.8 \\
\hline 19 & 162.4 & 122 & 571 \\
\hline 20 & 114.7 & 115.3 & * \\
\hline
\end{tabular}

Note: “*” indicates that the tile was not installed correctly. 
Table 7.2: Wind Resistance comparison of Tile Uplift Testing to Notice of Acceptance

\begin{tabular}{|l|c|c|c|}
\hline \multirow{2}{*}{ Source } & \multicolumn{3}{|c|}{ Failure Load (ft-lbf) } \\
\cline { 2 - 4 } & $\begin{array}{c}\text { Spanish 'S' tile } \\
\text { (9.5 inches) }\end{array}$ & $\begin{array}{c}\text { Spanish 'S' tile } \\
(10.5 \text { inches })\end{array}$ & $\begin{array}{c}\text { Barrel tile } \\
\text { (8 inches) }\end{array}$ \\
\hline Tile uplift testing & 55.9 & 56.4 & 185.4 \\
\hline Notice of Acceptance & 61.9 & 61.9 & 141.8 \\
\hline
\end{tabular}

\subsection{Simulation Engine}

The Matlab based Monte-Carlo simulation engine was created to simulate the performance of roof tiles during hurricane winds. In the simulation engine, two parts, including the wind load and resistance of roof tiles, were carefully simulated based on the analysis presented in the above sections.

The current building codes are mainly based on wind tunnel testing. FPHLM used the modified Components and Cladding wind pressure coefficients from ASCE 7 (2006) as the wind load of roof cover but ignored the internal pressure under tile's cavity. The wind pressures obtained from wind tunnel testing described in Section 9.3 were directly used as the external pressures for roof tiles. Also, the internal pressures under tile's cavity obtained from WoW full scale testing were used to the underside pressure for the tiles. Similar to FPHLM, the Gaussian distribution was selected as the probability density functions for wind load of roof tiles. The $3 \mathrm{sec}$ gust wind speed was simulated from 50 $\mathrm{mph}$ to $250 \mathrm{mph}$ with $5 \mathrm{mph}$ increments. Considering the effects of turbulence inherent in the hurricane wind and its effect on aerodynamic pressures, the discrete value of the wind speed, and the discrete value of the pressure coefficients were randomized for each 
simulation. The function randn () was used in the MatLAB based code. The mean value $\mu$ of desired wind load was determined from wind tunnel testing, the coefficient of variance (COV) was selected to be 0.1 ( $10 \%$ of the mean value) for wind speed and pressures.

The Gaussian distribution was also selected as the probability density function of the wind resistance of roof tiles. The mean value of resistance of roof tile was determined from the tile uplift testing results. However, the safety factor in the analysis of the wind resistance of roof tile was removed. The COV was selected to be 0.4 by considering the variety of products, quality of workmanship, the ages and roof shapes of residential building, and so on. The MatLAB function randn() was also used to randomize the wind resistance due to the uncertainties. In addition, to avoid unrealistic wind resistance in the simulation process, each wind resistance was checked to ensure that they are bound within two standard deviations of the mean wind resistance.

The final wind load and wind resistance of roof tiles were calculated by using Equation 9-1, where $z$ is a randomly generated number from standard normal distribution using MatLAB function $\operatorname{randn(),~} \mu$ is the mean value of the wind load or wind resistance, and COV is the coefficient of variation of the wind load or wind resistance. The resulting $x$ value was used in the simulation of vulnerability curve of roof tile through Monte Carlo method.

$$
x=(z \times \operatorname{COV}+1) \mu
$$

In addition, only the wind angles of attack used for the full scale testing were considered in the simulation. A uniform distribution of wind angles was used. Figure 9.17 shows the simulation procedure. Three nested loops were used in the simulation: loops 
for wind angles of attack, 3-second gust wind speed and different roof types (FPHLM, Volume II, 2005).

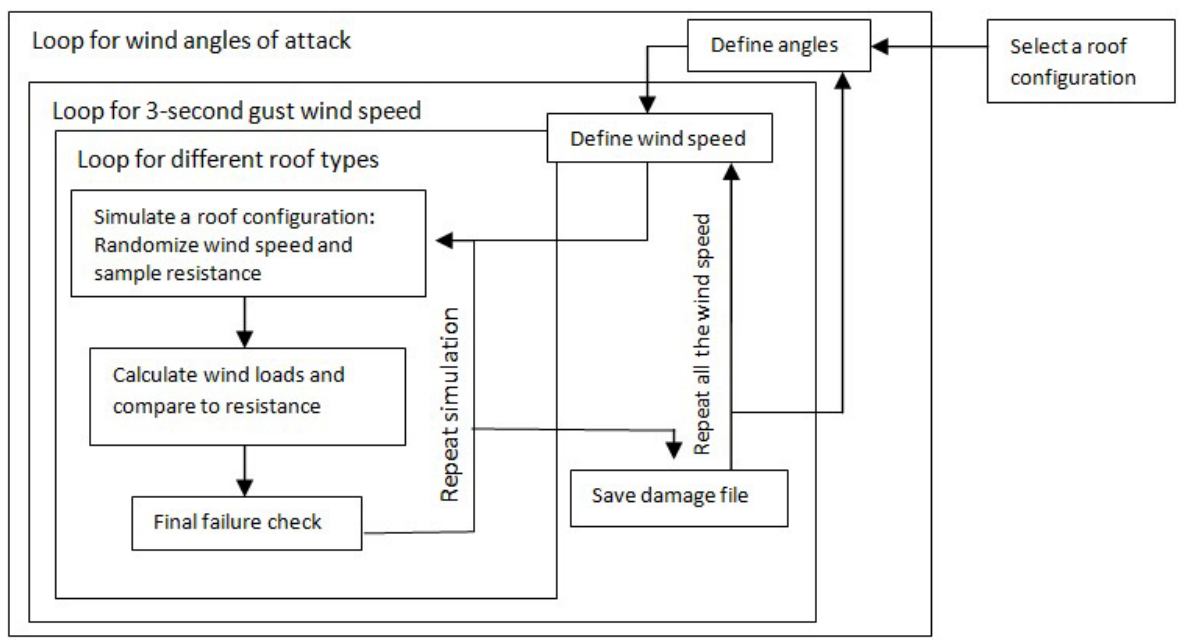

Figure 7.17: Structural Damage Simulation Engine Flowchart

Two different sets of vulnerability curves were developed with different combinations of wind load on and wind resistance of roof tiles. In the first set, the wind load was based on wind tunnel testing results without considering the effects of cavity internal pressure, similar to the simulation process of FPHLM, and wind resistance was from tile uplift testing results. The second set considered the effects of internal pressure under tile's cavity on the net load acting on the roof tiles. Each set was simulated for four different roofs, including a monoslope roof (4:12 slope), a gable roof (5:12 slope) and two hip roofs (3:12 and 5:12 slopes).

\subsection{Results and Discussions}

In the Monte Carlo Simulation engine, two matrices were generated for a specific roof type at a given wind speed, including the wind load matrix and wind resistance matrix. The comparison of each corresponding value of these two matrices was used to 
check the status of each tile. When the wind resistance is larger than the wind load, the tile is secured; when the wind resistance is smaller than the wind load, the tile is considered fail. The damage level was defined as the ratio of the area of damaged tiles to the area of the roof. It is to be noted that in the simulation process the interaction among tiles was not taken into account. Such interaction need to be considered in the future research.

Figures 9.18 shows the comparison of vulnerability curve of roof tile for monoslope roof (4:12 slope) with and without considering the effects of tiles' cavity internal pressure through 5000 simulations. It is noticed that there are significant differences between the vulnerability curves of with and without considering the effects of tiles' cavity internal pressure. If effect of cavity internal pressure is ignored, mean damage of roof tile at a given wind speed could be significantly underestimated. For example, at wind speed $150 \mathrm{mph}$, the mean damage ratios of with and without considering the effects of tiles' cavity pressure are approximately $75 \%$ and $55 \%$.

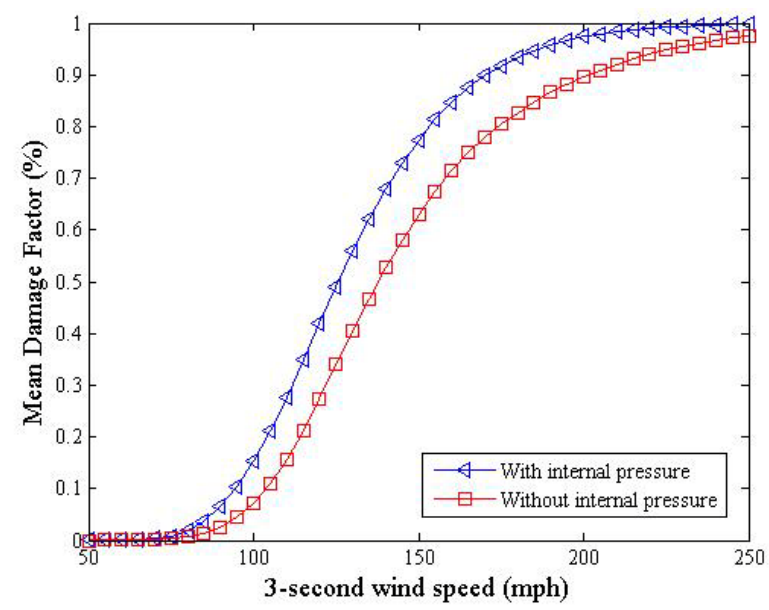

Figure 7.18: Comparison of Vulnerability Curve of Roof Tile with and without Considering the Effects of Tiles' Cavity Internal Pressure for Monoslope Roof with 4:12 Slope 
Figure 9.19 shows the comparison of vulnerability curve obtained from with and without considering the effects of tiles' cavity internal pressure for gable roof (5:12 slope). Such comparison still shows significant effects of tiles' cavity internal pressure on vulnerability curve of roof tiles. The mean damage factor underestimation could reach to approximately $20 \%$.

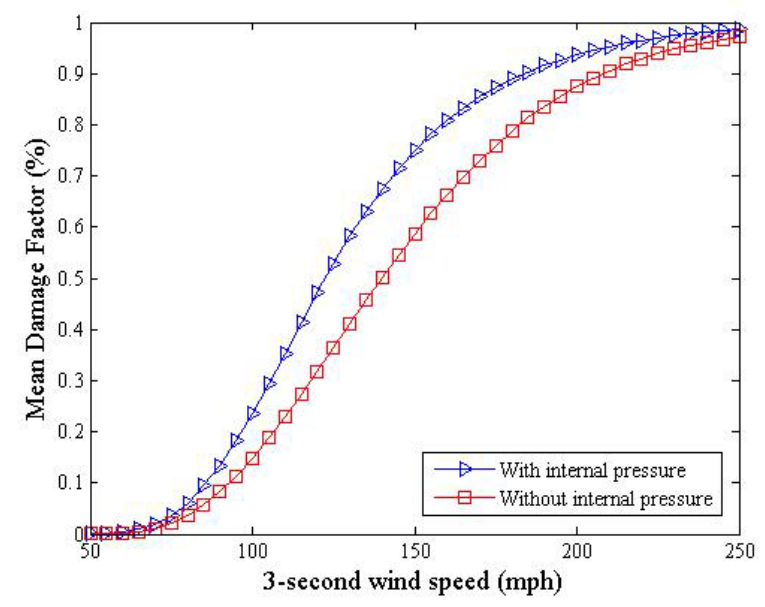

Figure 7.19: Comparison of Vulnerability Curve of Roof Tile with and without Considering the Effects of Tiles' Cavity Internal Pressure for Gable Roof with 5:12 Slope

Figure 9.20 show the comparison of vulnerability curve of roof tile with and without considering the effects of tiles' cavity internal pressure for hip roofs (3:12 and 5:12 slope). The same phenomenon was observed through the comparison. Without considering the effects of tiles' cavity internal pressure, the mean damage of roof tiles could be significantly underestimated. Such underestimation could reach approximately $15 \%$. 

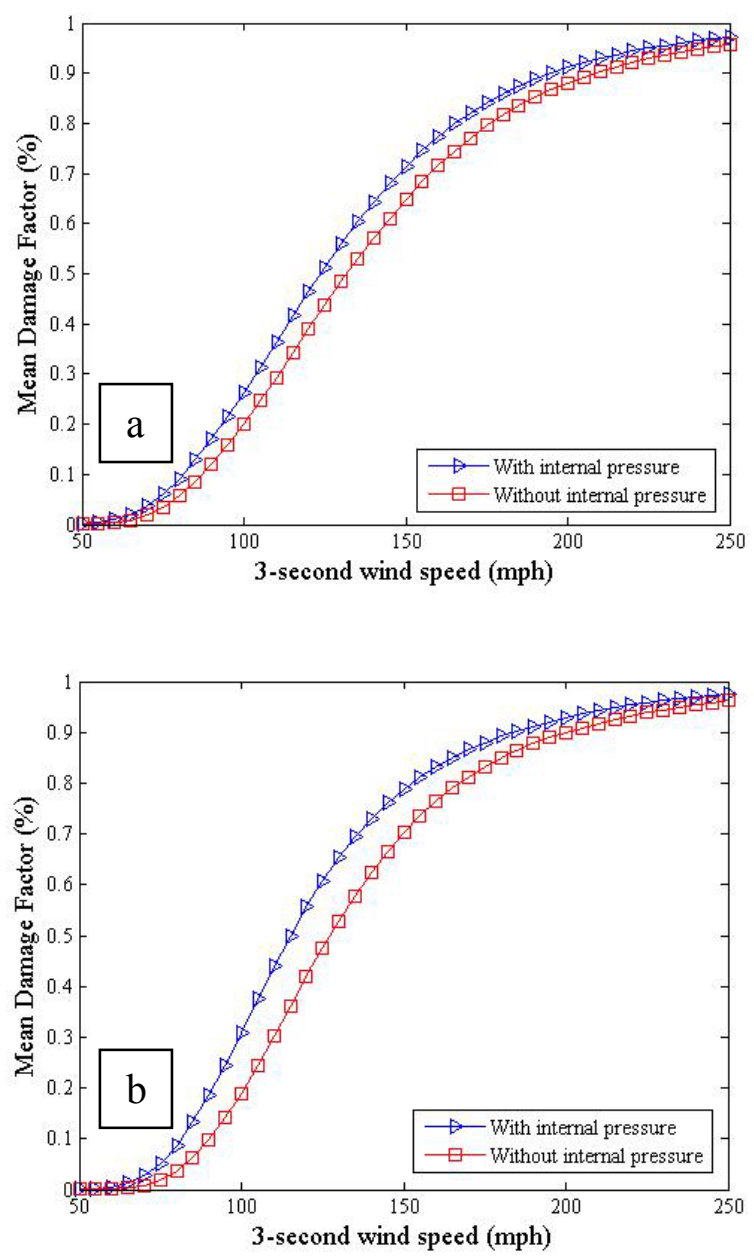

Figure 7.20: Comparison of Vulnerability Curve of Roof Tile with and without Considering the Effects of Tiles' Cavity Internal Pressure for Hip Roofs: (a) 3:12 Slope, (b) 5:12 Slopes

The above vulnerability curves were also compared to the vulnerability curve from FPHLM, as shown in Figure 9.21. It is to be noted that the roof cover vulnerability curve from FPHLM matches well the vulnerability curve from this research without considering the effects of tiles' cavity internal pressure. It is concluded that reasonable agreement was obtained between the vulnerability curves using current procedure using wind tunnel data and FPHLM procedure using ASCE 7 provision. 


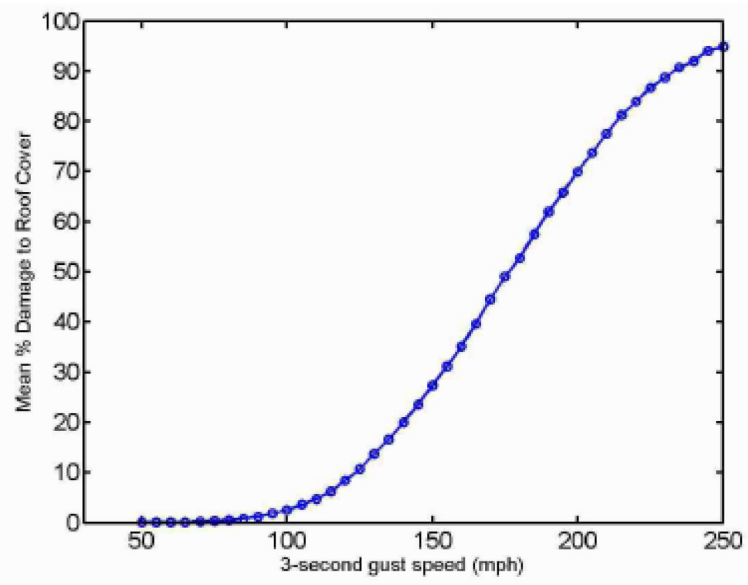

Figure 7.21: Roof Cover Vulnerability of South / Key CGB Homes (FPHLM, Volume II, 2005)

\subsection{Conclusions}

Through the study of simulating the vulnerability curve of roof tiles, it was found that the tiles' cavity internal pressure could significantly affects the mean damage of roof tiles at a given wind speed. Without considering the tiles' cavity internal pressure, the mean damage of roof tile could be underestimated by approximately $20 \%$. In addition, it is concluded that reasonable agreement was obtained between the vulnerability curves using current procedure using wind tunnel data and FPHLM procedure using ASCE 7 provision. Also, through the tile uplift testing, it was found that reasonable wind resistance could be obtained by different loading point eccentricities. Since in process of developing the vulnerability curve of roof tiles, the interaction among adjacent tiles were not taken into account, such interaction needs to be carefully studied in the future. 


\section{Conclusions and Future Work}

\subsection{Conclusions}

Based on the full-scale and wind tunnel studies on the effects of architectural features of roof tile and shingle on wind uplift loading, the following conclusions have been made.

1) In addition to simulating the requisite wind characteristics, pressure measurement was validated for 6-fan WoW by performing the comparison of area-averaged peak pressures obtained from full scale and wind tunnel testing results on bare roof decks.

2) Wind flows with no low-frequency content that simulate correctly the mean wind profile in the atmospheric boundary layer are adequate for the simulation of pressures induced by atmospheric flows on low-rise buildings with dimensions comparable to those of individual homes. The proposed technique allows the use of larger test models allowing the modeling of architectural details, Reynolds number improvements enhancing aerodynamic accuracy, and higher spatial resolution of pressure measurements.

3) The effect of tiles' cavity internal pressure on roof peak pressures was dependent on the tile joint (joint between two overlapping tiles) orientation with respect to the wind angle of attack. For wind being oblique, nearly normal, and normal to the windward eave, the cavity internal pressure contributed to: (i) an increased net uplift peak pressure when the tile joints had windward orientation, (ii) a reduced net uplift peak pressure when the tile joints had leeward orientation. Thus tile 
cavity internal pressure could either aggravate or alleviate wind loading on a tile based on its orientation on the roof with respect to the wind angle of attack.

4) The surface geometry of the high profile tiles could generate higher peak pressures as compared to those for a bare deck owing to the effect of component geometry profile on the local flow pattern. In some cases the peak pressures obtained on bare roof deck models could underestimate the peak pressures acting on roof tiles by as much as $50 \%$.

5) The internal pressure coefficients specified in the code provisions are not applicable for estimating net wind uplift on roof tiles.

6) For shingled deck, top and bottom surface pressures can act in the same direction and aggravate the wind uplift loading for windward shingles located near the center of the roof deck. For windward shingles located away from the center region (field zone) and for all leeward shingles, partial air-pressure equalization alleviates the wind uplift loading.

7) The effect of overhang dimensions on roof shingle area-averaged peak is minimal and further research on such effects still need to be carefully studied.

8) The research work also suggested that for different air-permeable roof materials, it is better to differentiate the design wind uplift load based on the type of materials being used (high profile tiles versus asphalt shingles).

9) Bare deck modeling without considering the tile geometry effects could significantly underestimate design wind uplift on tiled decks by as much as $45 \%$ for corner and edge tiles. For ridge tiles, the bare deck modeling could underestimate design wind uplift by $55-69 \%$. Bare deck modeling to estimate 
design wind uplift on shingled decks may be acceptable for corner, edge, and ridge locations but not for field locations it could underestimate the uplift on shingles by $30-60 \%$.

10) Reasonable agreement was obtained between the vulnerability curves using current procedure using wind tunnel data and FPHLM procedure using ASCE 7 provision.

11) Tiles' cavity internal pressure could significantly affect the vulnerability curve of roof tiles. The mean damage ratio for roof tile could be underestimated as high as approximately $20 \%$.

\subsection{Future Work}

Based on the current research works, the following future works were suggested by the author:

1) Future tests are planned to further refine the technique and validate it for a wide range of model-to-full-scale ratios. Additional research will also concentrate on the appropriate ratios between mean speeds in the flows with and without low frequency content.

2) Detailed local flow field measurements are needed to determine whether the differences between pressure coefficients on tiled versus bare roof decks and shingled versus bare roof deck apply to both separated flow near the roof edge or in the field of the roof where there is attached flow. This important aspect will be studied in the future when hot-film anemometry and requisite flow visualization capability will become 
available at the WoW facility. Such study will help show how the local flow field around a tile induces the uplift.

3) More detailed research is needed in the future to develop an extensive database on the effects of various roofing components (e.g., tiles and shingles) on roof peak pressures. Such estimation can improve the aerodynamic load provisions for low-rise building roofs by considering the effects of the roofing components which are often damaged during extreme wind events.

4) More detailed pressure measurement on full-scale low-rise building is needed in the future to develop more accurate vulnerability curve for roof covering.

5) More detailed pressure measurement is needed by using 12-fan Wall of Wind, which is the facility capable of simulating the wind characteristics of different terrain (e.g., open terrain, suburban terrain), generating different hurricane level wind speed and testing the large- and full-scale building under controllable and repeatable wind environment. 


\section{REFERENCES}

American Association for Wind Engineering, Wind Engineering Research and Outreach Plan to Reduce Losses due to Wind Hazards, 2004.

American Society of Civil Engineering (ASCE). (2006). "Minimum Design Loads for Buildings and Other Structures.” ASCE/SEI 7-05, Reston, VA.

ASTM E 779 - 03. (2007). "Standard Test Method for Determining Air Leakage Rate by Fan Pressurization", American Society for Testing and Materials. 247-257.

Amano, T., Fujii, K., \& S.Tazaki. (1988). "Wind Loads on Permeable Roof-Blocks in Roof Insulation Systems." J. Wind Engineering and Industrial Aerodynamics, 29, 39-48.

Aly, A.M., Gan Chowdhury, A., \& Bitsuamlak, G.T. (2011). "Wind Profile Management and Blockage Assessment for a New 12-Fan Wall of Wind Facility at FIU." Wind and Structures, 14 (4), 285-300

Bienkiewicz,B., Y.Sun. (1997). "Wind Loading and Resistance of Loose-laid Systems.” J. Wind. Eng. Ind. Aerodyn., 72(1), 401-410.

Bitsuamlak, G.T., Gan Chowdhury, A., and D. Sambare. (2009). "Application of a FullScale Testing Facility for Assessing Wind-Driven-Rain Intrusion." Building and Environment, 44(12), pp. 2430-2441.

Bitsuamlak, G.T., Dagnew, A., Gan Chowdhury, A., Computational Blockage and Wind Sources Proximity Assessment for a New Full-scale Testing Facility, Wind and Structures,13(1), 21-36, (2010)

Blessing, C.M. (2007). "Mitigation of Roof Uplift through Vortex Suppression Techniques.” M.S.Thesis, Florida International University, Miami, FL.

Cheung, J.C.K., Holmes, J.D., Melbourne, W.H., Lakshmanan, N. and P. Bowditch. (1997).Pressures on a 1/10 Scale Model of the Texas Tech Building, Journal of Wind Engineering and Industrial Aerodynamics, Volume 69-71, pages 529-538.

Corbin, R. L. (2000). "New Method for Measuring the Wind Resistance of Asphalt Roofing Shingles.” RCI Interface Magazine.

Dao, T.N. and J.W. van de Lindt. (2010). "Methodology for Probabilistic Modeling and Quantification of Wind-Driven Rain Water Intrusion to Roof Systems during Hurricanes." ASCE Journal of Structural Engineering, 136(6), 700-706.

Eaton, K.J. and J.R. Mayne. (1975). "The Measurement of Wind Pressures on Two Storey Houses at Aylesbury." Journal of Wind Engineering and Industrial Aerodynamics 1, 67-109. 
Ellingwood, B., and Rosowsky, V.D. (2004). Fragility Assessment of Light-Frame Wood Construction Subjected to Wind and Earthquake Hazards. Journal of Structural Engineering 130(12), 1921-1930.

Florida Public Hurricane Loss Projection Model (FPHLPM). (2005). Volume II, Predicting the Vulnerability of Typical Residential Buildings to Hurricane Damage.

Federal Emergency Management Agency. (2005). "Summary Report on Building Performance: 2004 Hurricane Season,” FEMA 490.

Federal Emergency Management Agency. (2006). "Hurricane Katrina in the Gulf Mexico: Mitigation Assessment Team Report, Building Performance Observations, Recommendation, and Technical Guidance" FEMA 549.

FBC. (2007). Florida Building Code. Florida Building Commission, Tallahassee, FL.

FRSA. (2005). Concrete and Clay Roof Tile Installation Guide. 4th Edition, Florida Roofing, Sheet Metal and Air Conditioning Association, Winter Park, FL.

Fu, T.C., Aly, A.M., Chowdhury, A.G., Bitsuamlak, G., Yeo D.H. and E. Simiu. A Proposed Technique for Determining Aerodynamic Pressures on Residential Homes, Wind and Structures, 15(1), 000-000.

Gan Chowdhury, A., Huang, P., J. Erwin. (2009). "Aerodynamic Testing Application of a Full-Scale Facility for Mitigating Hurricane-Induced Coastal Disasters.” Far East Journal of Ocean Research, 2 (1), pp. 1-27.

Gerhardt, H.J., Kramer, C., and K.K. Bofah. (1990). "Wind Loading on Loosely Laid Pavers and Instruction Boards for Flat Roofs." J. Wind Engineering and Industrial Aerodynamics, 36, 309-318.

Gregory, A.K., Christian, M., and S. David. (2005). Wind Effects of Parapets on Low Buildings: Part4. Mitigation of Corner Loads with Alternative Geometries, J. Wind Eng. Ind. Aerodyn., 93, 873-888.

Holmes, J.D. (2001). “Wind Loading on Structures.” SponPress, London, U.K.

Hunt, J.C.R., Abell, C.J., Peterka, J.A. and H.G.C. Woo. (1978). "Kinematical Studies of the Flow around Free or Surface-mounted Obstacles: Applying Topology to Flow Visualization.” Journal of Fluid Mechanics, Vol. 86, 179-200.

Hazelwood, R.A. (1980). "Principles of Wind Loading on Tiled Roofs and Their Application in the British Standard BS5534.” J. Wind. Eng. Ind. Aerodyn., 6(1-2), 113124.

Hazelwood, R.A. (1981). "The Interaction of the Two Principal Wind Forces on Roof Tiles.” J. Wind. Eng. Ind. Aerodyn., 8(1-2), 39-48. 
Holmes, J.D. (1982). "Techniques and Modeling Criteria for the Measurement of External and Internal Pressures", Proceedings of the International Workshop on Wind Tunnel Modeling Criteria and Techniques in Civil Engineering Applications, edited by Reinhold, T.A, pages 245-256, Maryland, USA.

Huang, P., Mirmiran, A., Chowdhury, A.G., Abishdid, C., and T. L. Wang. (2009a). "Performance of Roof Tiles under Simulated Hurricane Impact." ASCE Journal of Architectural Engineering, 15(1), 26-34.

Huang, P., Gu, M., Mirmiran, A., A.G. Chowdhury. (2009b). "FEM Analysis of Tile Roofs under Simulated Typhoon Impact." The Seventh Asia-Pacific Conference on Wind Engineering, Taipei.

Huang, P., Chowdhury, A.G., Bitsuamlak, G. T., and R. Liu. (2009c). "Development of Devices and Methods for Simulation of Hurricane Winds in a Full-scale Testing Facility." Wind and Structures, 12(2), 151-177.

Henderson, D. J., and J. D. Ginger. (2007). "Vulnerability Model of an Australian Highset House Hubjected to Cyclonic Wind Loading.” Wind Struct., 10(3), 269-285.

Kramer, C., and H.J. Gerhardt. (1983). "Wind Loads on Permeable Roofing Systems." J. Wind Engineering and Industrial Aerodynamics, 13, 347-358.

Kawair, H., and H. Nishimura. (2003). "Field Measurement on Wind Force on Roof Tiles" Proc., 11th Int'l Conf. Wind Engineering, International Association for Wind Engineering and American Association for Wind Engineering, Texas Tech University, Lubbock, Tex., 599-606.

Kopp, G. A., Morrison, M. J., Gavanski, E., Henderson, D. J., and H.P. Hong. (2010). "Three little pigs project: Hurricane Risk Mitigation by Integrated Wind Tunnel and Fullscale Laboratory Tests.” Natural Hazards Review, ASCE, 11, 151-161.

Long, F., Smith, D.A., Zhu, H., and K. Gilliam. (2006). "Uncertainties Associated with the Full-Scale to Wind Tunnel Pressure Coefficient Extrapolation," Draft Paper submitted to National Institute of Standards and Technology (NIST), Work performed under NIST/TTU Coop. Agreement Award 70NANB3H5003.

Levitan, M. L., and K. C. Mehta. (1992). "Texas Tech field experiments for wind loads part 1. Building and pressure measuring system." J. Wind Eng. Ind. Aerodyn., 43(pt3), $1565-1576$.

Li, Y., and B.R. Ellingwood. (2006). Hurricane Damage to Residential Construction in the US: Importance of Uncertainty Modeling in Risk Assessment, Eng. Struct., 28, 100918 
Liu, Z., Brown, T. M., Cope, A. D., and T. A. Reinhold. (2011). "Simulation Wind Conditions/Events in the IBHS Research Center Full-scale Test Facility." 13 Int'l Congress on Wind Engineering (13ICWE), Amsterdam, Netherlands.

MDC-BCCO. (2006). Post Hurricane Wilma Progress Assessment. Miami-Dade County Building Code Compliance Office, 1-22, Miami, FL.

Mensaha, A.F., Datin, P.L., Prevatt D.O., Gupta, R., and van de Lindt J.W. (2011). "Database-assisted Design Methodology to Predict Wind-induced Structural Behavior of a Light-framed Wood Building." Eng. Struct., 33, 674-684.

Marshall, R.D. (1977). "The measurement of Wind Loads on Full-Scale Mobile Homes," NBSIR 77-1289, national Bureau of Standards, Washington, D.C.

Marshall, T. P., Morrison, S. J., Herzog, R. F., and J. R. Green. (2010). "Wind effects on asphalt shingles." Proc., 29th Conference on Hurricanes and Tropical Meteorology.

Milford, R.V., Waldeck, J.L., and A.M. Goliger. (1992a). Jan Smuts Experiment: Details of Full-scale Experiment, J. Wind Eng. Ind. Aerodyn, 41-44 ,1693-1704.

Milford, R.V., Waldeck, J.L., and A.M. Goliger. (1992b). Jan Smuts Experiment: Comparison of Full-scale and Wind-tunnel Results, J. Wind Eng. Ind. Aerodyn, 41-44, $1705-1716$.

Morisaki, Y., Saito, T., Honda, A., and K.Saito. (1994). "Study on Aerostatic Force Acting on Roof Tiles." Journal of Wind Engineering JAWE, No.58, 19-31.

Marc L.L., M.C. Kishor. (1992). Texas Tech Field Experiments for Wind Loads Part1: Building and Pressure Measuring System, J. Wind Eng. Ind. Aerodyn., 41-44,1565-1576.

National Institute of Standards and Technology (2006), "Performance of Physical Structures in Hurricane Katrina and Hurricane Rita: A Reconnaissance Report," NIST Technical Note 1476.

National Science Board (2007), Hurricane Warning: The Critical Need for a National Hurricane Research Initiative, NSB-06-115, p. 1-36.

NAHB Research Center, Assessment of Damage to Single-Family Homes Caused by Hurricanes Andrew and Iniki, Prepared for U.S. Department of Housing and Urban Development, Office of Policy Development and Research, 1993.

Natarajan, D., and H. Hangan. (2010). "Preliminary Numerical Simulation of Axisymmetric Flows in WindEEE Dome Facility." The Fifth International Symposium on Computational Wind Engineering (CWE2010), Chapel Hill, North Carolina, USA. 
Okada H., Ohkuma T., Katagiri J., and H. Marukawa (2009). "Study on Method for Evaluating Wind Performance of Tiled Roof." The Seventh Asia-Pacific Conference on Wind Engineering, Taipei, Taiwan.

Peterka, J.A., Hosoya, N., Dodge, S., Cochran, L., and J.E., Cermak. (1998). Areaaverage Peak Pressures in a Gable Roof Vortex Region, J. Wind Eng. Ind. Aerodyn., $77 \& 78,205-215$.

Peterka, J.A., Hosoya, N., Cermak, J. E., Cochran, L. S., Cochran, B. C., Derickson, R. G., Harper, C., Jones, J., and B., Metz. (1997). "Wind Uplift Model for Asphalt Shingles." Journal of Architectural Engineering, 3(4), Pgs. 147-155.

Pita, G.L., Pinelli, J.-P., Subramanian, C., Gurley, K., and S. Hamid.(2008).Hurricane Vulnerability of Multi-Story Residential Buildings in Florida, Proceedings, ESREL 08, Valencia, Spain, September 22-25.

Pita, G.L., Pinelli, J.P., Subramanian, C., Gurley, K., Weekes, J., and S.Hamid. (2009).Vulnerability of Mid-high Rise Commercial-Residential Buildings in the Florida Public Hurricane Loss Model Proceedings, ESREL 09, Prague, Czech Republic , September 7-10.

Pita, G.L., Pinelli, J.-P., Subramanian, C., Gurley, K., and S. Hamid. (2010). "Commercial-Residential Buildings' Vulnerability Component of the Florida Public Hurricane Loss Model.” SC-NASCC Conference.

Richards, P.J., Hoxey, R.P. and L.J. Short. (2001). "Wind Pressures on a 6 m Cube", J. Wind Eng. Ind. Aerodyn., 89, 1553-1564.

Richards, P.J., Hoxey, R.P, Connell B.D., D.P., Lander. (2007). Wind Tunnel Modeling of the Silsoe Cube, J. Wind Eng. Ind. Aerodyn., 95 1384-1399.

Richardson, G.M., and D., Surry. (1992). "The Silsoe Building: A Comparison of Pressure Coefficients and Spectra at Model and Full-scale.” J. Wind. Eng. Ind. Aerodyn., 43(1-3), 1653-1664.

Richardson, G.M., Hoxey, R.P., Robertson, A.P., and J.L., Short. (1997). "The Silsoe Structures Building: Comparisons of Pressures Measured at Full Scale and in Two Wind Tunnels.” J. Wind. Eng. Ind. Aerodyn., 72, 187-197.

Rosowsky, D.V. and B.R. Ellingwood. (2002). Performance-Based Engineering of Wood Frame Housing: Fragility Analysis Methodology. Journal of Structural Engineering 128(1), 32-38.

Robertson, A.P., Hoxey, R.P., Rideout., N.M. and P., Freathy. (2007). "Full-scale Study of Wind Loads on Roof Tiles and Felt Underlay and Comparisons with Design Data." Wind and Structures, 10(6), 495-510. 
Roger, P.A., Joel, G., Christopher, L.W., Douglas, C., Mark, S.A., and M., Rade. (2008). Normalized Hurricane Damage in the United States: 1900-2005, Natural Hazards Review, 9, 29-42.

Swami, M.V., Cummings, J., Sharma, S.R., Withers, C., and M., Basarkar. (2006). "Florida Building Code - Enhance Florida's Building To Next-Generation Energy \& Mechanical Codes and Enrich Compliance." Report of Florida Solar Energy Center (FSEC)-CR-1678-06, DEP Agreement No: G0165, FSEC/UCF Contract Numbers: $20127037 \& 20124129$.

Sill, B.L., Cook, N.J., and P.A., Blackmore. (1989). "IAWE Aylesbury Comparative Experiment-Preliminary Results of Wind Tunnel Comparisons." J. Wind. Eng. Ind. Aerodyn., 32(3), 285-302.

Sill, B.L., Cook, N.J., and Fang, C. (1992). "The Aylesbury Comparative Experiment: A final report.” J. Wind. Eng. Ind. Aerodyn., 43(1-3), 1553-1564.

Simiu, E., and F. Sadek. (2002)."Peak Non-Gaussian Wind Effects for Database-Assisted Low-Rise Building Design." Journal of Engineering Mechanics, ASCE, 128(5), 530-539.

Simiu, E., Pinelli, J., Gurley K, Subramanian C, Zhang, L., Cope, A., Filliben, J.J. and S. Hamid. (2004). Hurricane Damage Prediction Model for Residential Structures, J. Struct. Eng., 130, 1685-91.

Simiu, E., Vickery, P., Kareem, A., (2007). "Relation between Saffir-Simpson Hurricane Scale Wind Speeds and Peak 3-s Gust Speeds Over Open Terrain.” Journal of Structural Engineering, 133 (7), 1043-1045.

Surry, D., Kopp, G.A., and Bartlett, F.M. (2005). "Wind Load Testing of Low Buildings to Failure at Model and Full Scale." Nat. Hazards Rev., 6(3), 121-128.

Shinozuka, M., Feng, M.Q., Lee, J., and T., Naganuma. "Statistical Analysis of Fragility Curves," J. Eng. Mech. 126(12),1224-1231.

Tecle, A.S. (2012). Evaluation of Wind-Induced Internal Pressure in Low-Rise Buildings: a Multi Scale Experimental and Numerical Approach. Doctoral dissertation, Florida International University.

Vickery, P.J. (2008). "Component and Cladding Wind Loads for Soffits," Journal of Structural Engineering, no. 5, pp. 846-853.

Woo, H.G.G., Peterka, J.A., and Cermak, J.E. (1997). "Wind-tunnel Measurements in the Wakes of Structures." NASA Contractor Report NASA CR-2806, National Aeronautics and Space Administration.

Wu, F., Sarkar, P.P., and Mehta, K.C., (2001). Full-scale Study of Conical Vortices and Roof Corner Pressures, Wind and Structures, Vol. 4, No. 2, 131-146. 
Yasushi, U., and Nicholas, I., (1999). Review Wind Pressures acting on Low-rise Buildings, J. Wind Eng. Ind. Aerodyn., 82, 1-25.

Yu, B., Gan Chowdhury, A., Masters, F.J., (2008). "Hurricane Power Spectra, CoSpectra, and Integral Length Scales.” Boundary Layer Meteorology, 129, pp. 411-430.

Zhu, H.C. (2006). C-130 Testings on Low-rising Buildings. Doctoral dissertation, Texas Tech University. 
VITA

\section{RUILONG LI}

2000-2004

2004-2007

2004

2004-2007

2007-2008

2010-2012

2008-2012
B.A., Civil Engineering Harbin Institute of Technology Harbin, China

M.S., Engineering Mechanics Harbin Institute of Technology Harbin, China

Outstanding Graduate Harbin Institute of Technology Harbin, China

Research Assistant Harbin Institute of Technology Harbin, China

Dean's Special Assistantship Florida International University Miami, Florida

Doctoral Candidate Florida International University Miami, Florida

Research Assistantship Florida International University Miami, Florida 


\section{PUBLICATIONS AND PRESENTATIONS}

Ruilong Li, Arindam Chowdhury, Amir Mirmiran, Girma Bitsuamlak. (2012). "An Experimental Study on Wind Effects on Tiled Roofs." Journal of Engineering Mechanics, under review

Emil Simiu, Girma Bitsuamlak, Arindam Chowdhury, Ruilong Li, Amanuel Tecle, Donghun Yeo. (2011). “Testing of Residential Homes under Wind Loads", Natural Hazard Review-ASCE, April 7, 2011

Ruilong Li, Arindam Chowdhury, Amir Mirmiran. (2011). "Effects of Roofing Materials on Low-Rise Building Roof Peak Pressures." 2011 EMI Annual Conference, Boston, MA, June 2-4, 2011

Tuan Chun Fu, Arindam Gan Chowdhury, Girma Bitsuamlak, Ruilong Li, Aly Mousaad Aly. (2011). "Estimation of Wind Loads on Low-Rise Buildings using an Open Jet Wind Simulator." 2011 EMI Annual Conference, Boston, MA, June 2-4, 2011

Ruilong Li, (2008). "RenaissanceRe Wall of Wind Research - Vortex Suppression Research." Presented to US-Japan Panel on Wind and Seismic Effects, May 24, 2008

Ruilong Li, (2007). “Atmospheric Turbulence: Turbulence Intensity, Integral Length Scale, Spectra and Cross-spectra." Class project presentation (Topics in Wind Engineering), 2007 